$\mathrm{X}$.

Aus der inneren Abtheilung des städt. Krankenhauses am Urban in Berlin.

\title{
Die primären combinirten Strangerkrankungen des Rückenmarks (combinirte Systemerkrankungen).
}

\author{
Yon \\ Dr. Max Rothmann, \\ ehemaligem Assistenzarzt des Krankenhauses.
}

(Hierzu Tafel I-IV.)

Die Entwicklung der Rückenmarkspathologie in den letzten Jahrzehnten ist eine ungewöhnlich rasche gewesen. Den bahnbrechenden Arbeiten Leyden's und Charcot's auf klinischem und pathologischanatomischem Gebiet folgten die grandlegenden entwickltingsgeschichtlichen Untersuchungen Fle chsig's, die Vervollkommnung der klinischen und mikroskopischen Untersuchungstechnik; in rascher Folge wurden neue Krankheitsbilder aus der schnell anwachsenden Menge der Einzelbeobachtungen herausgehoben, die Tabes, die acute und chronische Myelitis, die amyotrophische Lateralsklerose, die spastische Spinalparalyse, die multiple Sklerose, die Syringomyelie, die Frie d re i ch'sche Ataxie n. a. m. Hatte man sich zunächst bemiuht, nach anatomischen Gesichtspunkten Scheidungen herbeizuführen, so war man später dazu gelangt, das Verhältniss der Erkrankung zu den einzelnen entwicklungsgeschichtlich begrïndeten Systemen festzustellen. Endlich ging man dazu über, die combinirte Erkrankung mehrerer Systeme in den Kreis der Betrachtung zu ziehen. Die combinirten Systemerkrankangen, denen die Friedreich'sche Ataxie nahe verwandt ist, haben in den letzten Jahren eine immer steigende Beachtung gefunden, und die Zahl der klinisch und anatomisch genau untersuchten Fälle hat sich rasch vermebrt. Trotzdem ist es dieser Ritckenmarkskrankheit bisher nicht gelungen, eine ähnlich gesicherte Position za erringen, wie z. B. der Tabes und einer Reihe anderer Erkrankungen. Gestützt auf das Sehwankende in dem Krankheitsbild, auf wesentliche Differenzen des anatomischen Befundes, haben einige Beobachter, allen voran Leyden, die Berechtigung der Abgrenzung einer beson- 
deren Krankheit bestritten and die Fälle einfach dem grossen Gebiet der chronischen Myelitis eingereiht.

Bei dieser bis in die neueste Zeit anhaltenden Unsicherheit ist gewiss jede einschlägige, genau untersuchte Beobachtung von Bedeutung. Ich will deshalb zunächst über drei, auf der inneren $A b-$ theilung des Krankenhauses am Urban klinisch und pathologisch-anatomisch untersuchte, hierher gehörige Fälle berichten.

I. Fall. August Plotzki, 36 Jahre alt, Arbeiter. Aufgenommen 16. October 1890, gestorben 27. December 1890.

Keine Syphilis, kein Potus. Kein Trauma. Seit Sommer 1890 rasch zunehmende Kachexie. Anfang September Bewegungsstörungen und Parästhesien in den Beinen. Bei der Aufnahme kachektische Gesichtsfarbe, starke Hautpigmentirung, Schwellung der Lymphdrüsen. Empfindlichkeit des 7. Brustwirbels. In den Armen leichte Abnahme der motorischen Kraft. Spastisch paretischer Gang. Herabsetzung der groben motorischen Kraft und leichte Rigidität der Beinmusculatur. Patellarreflexe gesteigert, Plantarreflexe schwach. Sensibilität an den Füssen herabgesetzt. Schwache Reaction der Pupillen. Kernbaltige rothe Blutkörperchen, Herabsetzung des Hämoglobingehalts des Bluts. - Im weiteren Verlauf Anfälle von grosser Unruhe mit unwillkürlichen Zuckungen in den Beinen. Verschlechterung des Ganges, Zunahme der Rigidităt. Entschiedene Ataxie, Abnahme des Muskelsinns in den Beinen. Rasche Abnahme der activen und passiven Beweglichkeit zuerst des rechten, dann des linken Beins, mit vorübergehender Besserung im November. Zuuahme der Drüsenschwellung. Blasen- und Mastdarmlähmung. Abnahme des Gedächtnisses. Zunahme der Macies. Starke Herabsetzung der Sensiliitităt an den Unterschenkeln. Abschwächung der Patellarreflexe. Das linke Bein im Knie flectirt; deutliche Spasmen. Patellarreflex zuletzt nur angedeutet. Rechtsseitige Lungenentzündung. 27. December Exitus. Untersuchung des Rückenmarks ergiebt symmetrische Degeneration der KI.S., Py.S. und Py.V., und der H.Str. ${ }^{1}$ ) Nur vereinzelte Fasern der hinteren Wurzeln degenerirt. In der granen Substanz multiple Blutungen in Hals- und Brustmark. Rareficirung der Vorderhörner im oberen Brustmark. Ganglienzellen erhalten. Vordere Wurzeln normal.

A namnes e. Eltern gesund, desgleichen 5 Geschwister. Patient, der stets gesund war, arbeitete auf dem Lande. Vor 9 Jahren verheirathete er sich, hat 2 gesunde Kinder von 8 und 4 Jahren. Specifische Infection leugnet er. Die Frau hat keinen Abort gehabt. Kein Potus. Ein Trauma oder einen Stoss gegen die Wirbelsäule hat Patient nicht erlitten.

Im Laufe des Jahres 1890 begann Patient ïber Appetitmangel zu klagen, litt viel an Aufstossen, ohne Erbrechen. Anfang September nabmen die Magenbeschwerden zu. Zugleich empfand Patient eine leichte Spannung in den Fussgelenken, als wenn die Füsse fest gebunden wären; dazu trat Kribbeln und Prickeln in den Fusssohlen, wenn Patient ausser Bett war, bis zu den Oberschenkeln berauf. Das Gehen wurde Patient schwer, er hatte des Spannungsgefühls in den einzelnen Muskelgruppen wegen die Empfindung, als wenn er mit den Füssen ein Brett fortschie-

1) Kl.S. = Kleinhirnseitenstrangbahn, Py.S. = Pyramidenseitenstrangbahn, Py.V. = Pyramidenvorderstrangbahn, H.Str. = Hinterstrang. 
ben müsste. Dazu kamen leichte Schwindelanfälle, die normale Gesichtsfarbe machte allmählich einer fahlen Blässe Platz, die sich über den ganzen Körper erstreckt. Seit dem 20. September vermag Patient nur noch kurze Schritte mit grösster Anstrengung und starker Unsicherheit zu machen. Keine Urin- und Stublbeschwerden. Auch in den Armen seit Mitte September Mattigkeitsgefühl. Heiserkeit der Stimme.

Status am 18. October 1890. Mittelgrosser Mann mit kachektischer Gesichtsfarbe. Gesichtsausdruck normal. Die Haut des gesammten Körpers zeigt eine äusserst dunkle, schmutziggelbe Pigmentirung, welche am Abdomen und der Innenfläche der Oberschenkel eine hellbraune Färbung annimmt, an den Geschlechtstheilen sogar schwarzbraun wird. Schleimhäute etwas blass, nicht abnorm pigmentirt. Conjunctiva sclerae von schmutzig grünlichergelber, nicht ikterischer Farbe. An den Wangen und auf der Brust einzelne, stecknadelkopfgrosse Leukodermaflecke.

Cervical-, Axillar- und Inguinaldriisen dentlich geschwollen.

Eigenthümlich heisere Stimme.

Herz normal.

Lungengrenzen normal. Athemgeräusch über der Fossa supraclavicularis dextra etwas rauh.

Leber und Mil z nicht vergrössert. Indican.

Urin hellgelb, klar, ohne Albumen, Saccharum, Diazoreaction und

Keine Kopfschmerzen, kein Schwíndelgefühl. Deutliches Gürtelgefühl. Kribbeln in den Beinen. Gefühl von Schwäche in den Armen und besonders den Beinen. Anfallsweise Zittern und Fliegen der Beine.

An der nicht difformen Wirbelsänle eine circumscripte, mässig empfindliche Stelle am 7. Brustwirbel.

Sensorium frei.

Pupill en ziemlich eng, reagiren träge auf Licht, prompt auf Accommodation.

Die Zunge, auffällig glatt, wird gerade herausgestreckt, ist leicht atrophisch, zeigt lebhafte, fibrilläre Zuckungen. Keine Lähmungen der Hirnnerven.

Keine Sprachstörungen.

Die Musculatur der oberen Extremitäten ist mässig entwickelt. Leichte Herabsetzung der groben motorischen Kraft, im Uebrigen active und passive Bewegungen völlig frei.

Tricepsreflex rechts zu erzielen, links normal. Sensibilität erhalten, desgleichen Schmerzgefühl und Temperatursinn.

Keine Ataxie der oberen Extremitäten, Herabsetzung des Lagegefühls an den Fingern der rechten Hand.

Auch am Rumpf normale Sensibilität.

Der Gang des Patienten ist sehr unsicher, etwas breitbeinig, steif, stelzenartig stampfend, leicht ataktisch. Der rechte Fuss wird dabei stets seitwärts vor den linken gesetzt. Patient bekommt die Beine schwer vom Boden los, tritt mehr mit den Hacken als mit der Spitze auf. Nach wenigen Scbritten starke Ermiidung mit lebhaften fibrillären Muskelzuckungen im Gebiet des Quadriceps und der Adductoren. Die Musculatur der unteren Extremitäten ist mässig entwickelt, nicht besonders schlaff. 
Die grobe Muskelkraft, besonders reclits, gemindert.

Patellarreflex beiderseits lebhaft gesteigert.

Deutlicher Fussclonus.

Links leichte Rigidität der Musculatur.

Patient führt complicirte Bewegungen ziemlich gut aus, mit Andeutung von Ataxie.

Die Sensibilität ist an beiden Füssen deutlich herabgesetzt. Im Uebrigen Sensibilität und Schmerzempfindung normal.

La ge gef ühl an den Zehen herabgesetzt.

Am Fussrücken Herabsetzung des Temperatursinns.

Cremasterreflex rechts deutlich, links fehlend.

Bauchdeckenreflex beiderseits erhalten.

Plantarreflex beiderseits sehr schwach.

19. October. Patient hat in vergangener Nacht starke Schmerzen in beiden unteren Extremitäten gehabt, denen ein tiber eine Stunde anhaltender Frost und Zittern des ganzen Körpers vorangegangen war. Die Schmerzen sind krampfartig und so heftio, dass Patient laut aufschreien muss. Auf 0,006 Morphium Schlaf.

22. October. In allen Nächten Wiederholung der Anfälle. Zuerst Schwindelgefühl in Kopf und Unruhe im ganzen Körper. Beide Beine werden steif und "flattern" heftig. Nach längerem Bestehen des Anfalls heftiges Schmerzgefühl über dem Abdomen. Patient hat das Gefühl, als ob die Beine in der Kniehöhe durch ein Band zusammengeschnürt seien. Dabei leichte Temperatursteigerung.

25. October. Verhältnissmässig subjectives Wohlbefinden. Die Drüsensehwellung am Halse hat zugenommen. Dentliche Druckempfindlichkeit des Processus spinosus des 7 . Brustwirbels.

Die unterej Extremitäten heute vollkommen schlaff. Patellarreflex beiderseits dentlich, hat aber an Intensität wesentlich abgenommen.

Fussclonus rechts nicht zu erzielen, links sehr gering.

Patient setzt beim Gehen die Beine kreuzweis voreinander. Der Gang ist sehr unsicher geworden. Milz nicht vergrössert.

Stuhl und Urin normal.

27. October. Wiederholte Anfälle von Schmerzen nnd Zucken in beiden Beinen. Dieselben sind dabei krampfhaft gestreckt.

Das Blnt des Patienten ist von ziemlich blasser Färbung. Hämoglobingehalt (nach Fleischl) 50 Proc. In Deckglastrockenpräparaten spärliche kernhaltige rothe Blutkörperchen, sehr zahlreiche Mikro- und Poikilocyten. Unter den anscheinend nicht vermehrten weissen Blutkörperchen fallen sehrzahlreiche, die normalen an Grösse übertreffende polynucleäre Zellen auf.

Eine Blutzählung wurde leider verabsäumt.

Abends $10 \mathrm{Uhr}$ ein ungemein heftiger Anfall. Die Oberschenkel sind stark adducirt.

Patient hat derartige Schmerzen im Rumpf und den Beinen, dass er lant aufschreien muss. Der ganze Körper ist dabei mit Schweiss bedeckt. Auf 0,01 Morphium tritt Beruhigung ein. 
28. October. Es fällt hente zum ersten Mal die ausserordentliche Schlaffheit der Beinmusculatur, vor Allem der Waden auf. Der Gang des Patienten hat sich erheblich verschlechtert. Er kann nur noch mit kräftiger Unterstiitzung gehen und setzt hierbei die am Boden schleifenden Füsse in ganz uncoordinirten Bewegungen voreinander. Die elektrische Prüfung ergiebt keine Herabsetzung der Erregbarkeit, keine Umkehr des Zuckungsgesetzes.

Während der Untersuchung treten wiederholt unwillkürliche Zuckungen in einzelnen Muskeln oder Muskelgebieten der Beine anf. Versucht Patient dieselben zu unterdricken, so werden sie noch gesteigert.

30. October. Händedruck normal. Die Vola manus stark ausgehöhlt, sonst keine Atrophie an den Armen nachweisbar. Motilität und Sensibilität der Arme normal.

Bei passiven Bewegungen der unteren Extremitäten ist heute eine entschiedene Rigidität der Musculatur nachweisbar, die rechts sogar ziemlich stark ausgeprägt ist. Sucht Patient activ die Beine im Kniegelenk zu beugen und strecken, so geschieht dies mit grosser Anstrengung. Die Bewegungen der unteren Extremitäten bei geschlossenen Augen sind entschieden ataktisch. Lageveränderungen der unteren Extremitäten werden nur in höchst unvollkommener Weise percipirt; Lageveränderungen der Zehen werden ïberhaupt nicht wahrgenommen. Der Muskelsinn ist gegen die ersten Untersuchungen wesentlich herabgesetzt. Die Sensibilität unverändert, nur an den Zehen leicht herabgesetzt.

Das Aufsetzen geschieht mit einiger Mühe. Empfindlichkeit der Wirbelsäule unverändert.

Patellarreflex beiderseits deutlich, jedoch nicht erhöht. Deutlicher Plantarreflex. Lebhafter Fussclonus beiderseits.

3. November. In den letzten Tagen wiederholte Schmerzattaquen in den Beinen, begleitet von Spasmen der Musculatur.

Die Pigmentirung der Haut unverändert. Der Ernährungszustand entschieden in Abnahme. Heute Morgen ist Patient zum ersten Mal nicht im Stande, die rechte untere Extremität nennenswerth zu bewegen. Nur bei durchgedriickten Knieen gelingt es ihm, den rechten Fuss 20-30 Cm. emporzuheben. Weitere Bewegung wird nach Aussage des Patienten durch die Steifigkeit der Oberschenkelmuskulatur verhindert.

Auch der passiven Bewegung setzen sich ziemlich starke Widerstände entgegen, als ob der Oberschenkel im Hüftgelenk ankylosirt wäre. Das Becken und das linke Bein machen die Bewegung mit. Im Kniegelenk ist das rechte Bein activ nur bis zum Winkel von $120^{\circ} \mathrm{zu}$ flectiren, passiv, nach Ueberwindung starken Widerstandes vollkommen.

Das linke Bein nicht verändert.

Patellarreflex links ziemlich stark, rechts in Form mehrerer klonischer Contractionen.

Fussclonus beiderseits stark. Deutlicher Plantarreflex. Keine wesentlichen Störungen der Sensibilität. Der grobe Ortssinn an beiden Beinen stark herabgesetzt.

4. Norember. Die Bewegungsbeschränkung des rechten Beines un- 
verändert. Patient empfindet heftige Schmerzen im rechten Hacken und Knie.

Auch in der linken unteren Extremität werden heute beim Versuch der Abduction deutliche Spasmen im Abductorengebiet constatirt. Auch bei der Beugung im Hiiftgelenk starke Spannung der Beugemuskeln.

Die grobe Muskelkraft rechts wesentlich stärker als links herabgesetzt.

5. November. Patient erhält Acidum arsenicosum.

Da derselbe Festes nicht mehr zn geniessen vermag, erhält er ausschliesslich flüssige Diät.

9. November. In der rechten unteren Extremität heute etwas ausgiebigere active Bewegungen. Die Spasmen haben sehr nachgelassen. Doch bestebt grosse motorische Schwäche. Die passiven Bewegungen nur wenig behindert.

Bei Bewegungen mit geschlossenen Augen an beiden Beinen ausgesprochene Ataxie.

Sensibilität frei.

Ortssinn und Lage gefühl stark herabgesetzt.

11. November. Heute Morgen heftiger Anfall, in dem beide Beine krampfartig adducirt werden. Dabei ungemein starke, nur durch Mor. phium zu beseitigende Schmerzen.

Die activen Bewegungen des rechten Beines werden immer ausgiebiger. Contractur im Hiiftgelenk fast ganz verschwunden.

Das linke Bein für active und passive Bewegungen frei.

Ein Gehversuch ergiebt, dass Patient ohne Unterstiutzung auf beiden Seiten sich nicht fortbewegen kann; er muss fast getragen werden.

12. November. In der Nacht ein heftiger Anfall. Die Beine stehen dabei in Adductionsstellung, an den Leib gezogen, werden ruckweise gestreckt, um sofort wieder in die Contractionsstellung zurickzuschnellen. Patient hat dabei das Gefühl, dass ihm die Beine gebrochen werden. Auf 0,01 Morphium Beruhigung.

Heute das rechte Bein zum ersten Mal ödematös. Inguinaldrüsen rechts stärker geschwollen, als feste Knollen bis zu Kirschgrösse zu fühlen, nicht schmerzhaft.

15. November. Inguinaldrtisen rechts unverändert geschwollen; die Schwellung setzt sich in Form rosenkranzartiger Stränge bis in die Fossa cruralis fort. Links ist die Vergrösserung der Lymphdrüsen nur wenig geringer.

Die ganze rechte untere Extremität leicht geschwollen; stärkeres Oedem nur in der Knöchelgegend. Von einer Venenthrombose nichts zu fühlen.

Fussclonus und Patellarreflex heute beiderseits lebhaft. Die Musculatur beider Beine sehr schlaff und atrophisch.

Das linke Bein kann jedoch bei ziemlich guter Muskelkraft emporgehoben werden, während rechts die Muskelkraft stark herabgesetzt ist.

Druck auf die Nervenstämme und die Musculatur nirgends schmerzhaft.

Galvanische und faradische Prüfung ergiebt an Nerven und Muskeln der Beine normale Verhältnisse.

19. November. In den letzten Tagen Wiederholnngen des am 12. beschriebenen Anfalls mit starkem Oppressionsgefihl auf der Brust. 
Seit einigen Tagen bemerkt Patient selbst starke Abnahme des Gedächtnisses.

Gesichtsfarbe schmutzig gelb. Ausdruck verfallen und leidend. Urinträufeln.

21. November. Das rechte Bein wesentlich abgeschwollen. Die active Bewegungsfähigkeit desselben stark beschränkt, desgleichen die passive, namentlich infolge von Widerstand im Adductorengebiet.

Patient will seit einigen Tagen im linken Handgelenk, mitunter anch im Ellenbogengelenk das Gefuhl der Span$\mathrm{nung}$ haben. Doch ist objectiv nichts nachzuweisen. Patient hustet ziemlich viel. Ueber den Lungen katarrhalische Geräusche mit leichter Schallabschwächung links hinten über den 3 untersten Rippen.

1. December. Die active Beweglichkeit des rechten Beines ist wieder ausgiebiger geworden. An beiden Beinen deutliche Ataxie, starke Abnahme des Ortssinnes. Sensibilität normal.

12. December. Progrediente Kachexie und Macies.

Sputum ca. 11/2 Esslöffel von homogen eitriger Beschaffenheit, exquisit grasgrün, zähe, leicht übelriechend.

Ueber der Fossa supra clavicularis dextra Schallabschwächung. Hinten beiderseits ïber den 3 untersten Rippen leichte Dämpfung. Daselbst zahlreiche klanglose Rasselgeräusche.

14. December. Urinverhaltung mit starken Schmerzen in Blase und Harniöhre.

Urin leicht getrübt, schwach sauer, ohne Albumen.

Allgemeinbefinden sehr schwach.

Schwellung des rechten Beines geschwunden. Beide Beine zeigen starke Herabsetzung der activen Beweglichkeit mit deutlicher Ataxie; passive Bewegungen vollkommen frei, Adductorencontraction geschwunden.

18. December. Sehr lebhafte, schmerzhafte Zuckungen des linken Beines.

Andauernde Urinverhaltung; Patient lässt zum ersten Malden Stuhl unter sich.

26. December. Entschiedene Abnahme der activen Beweglichkeit der Beine, namentlich rechts.

Die Sensibilität rom Knie abwärts beiderseits stark herabgesetzt.

Patient lässt Urin und Stuhl unter sich. Decubitus am Steissbein. verfallen.

27. December. Patient ist in den letzten Tagen ausserordentlich

Athmung sehr vertieft, etwas beschleunigt.

Puls fadenförmig, kaum fühlbar.

Das linke Bein im Knie leicht flectirt, kehrt, passiv gestreckt, sofort in diese Stellung zurück. Die Arme kann Patient activ frei bewegen mit leichter Herabsetzung der motorischen Kraft.

Das linke Bein ist gleichfalls ziemlich frei beweglich. Das rechte kann nur wenig angezogen werden.

Bei passiven Bewegungen werden in der rechten oberen Extremität leichte Spasmen beobachtet, während die übrigen Extremitäten frei beweglich sind.

Sensibilität in den Beinen dentlich herabgesetzt. 
Patellarreflex beiderseits vorbanden, aber sehr schwach.

Plantarreflex beiderseits lebhaft.

Fusselonus links sehr dentlich, rechts nicht zu erzielen.

Die Wirbelsäule nicht druckempfindlich.

Ueber den Lungen hinten vom Angulus abwärts beiderseits Dämpfung.

Im Gebiet der Dämpfung Bronchialathmen ohne wesentliche Neben. geräusche.

Leber, Milz nicht vergrössert.

Patient lässt Stuhl und Urin unter sich.

In der Nacht Exitus letalis.

Section 28. December 1890 (Prof. A. Fränkel).

Ziemlich kleine männliche Leiche mit schwacher Musculatur und Schwund des Fettpolsters. Decubitus am Steissbein und beiden ScapularWinkeln.

Herz auffallend schlaffe, bräunliche Musculatur, sonst normal.

Linke Lunge mit der Pleura rings verwachsen. Der Unterlappen im oberen Theil infiltrirt, stark ödematös.

Rechte Lunge starkes Oedem des Oberlappens; schlaffe Pneumonie des Unterlappens.

Milz von normaler Beschaffenheit.

In der linken Niere zahlreiche Hämorrhagien, die rechte normal. Le ber normal.

Blasenschleimhaut stark verdickt, von schiefriger Farbe, auf der Höhe der Falten ausgedehnte hämorrhagische Flecke.

Die Mesenterialdruisen, Axillar- und Inguinaldrỉsen stark vergrössert.

Vena femoralis dextra in ihrer ganzen Ausdehnung von der Vena iliaca bis zur Kniekehle völlig thrombosirt. In der Höhe des Lig. Pupartii wandständige weisse Thromben, im übrigen rothe.

Gehirn normal.

Rückenmark von sehr weicher Consistenz. In unteren Brustmark fällt besonders röthliche Färbung der Vorderhörner auf. Hinterstränge zum Theil grau verfärbt. Das Rïekenmark wird zur genaueren Prüfung in Müller'sche Flüssigkeit eingelegt, nach 3 Monaten in Alkohol gehärtet und, in Celloidin eingebettet, geschnitten.

Makroskopische Beschreibung der Rückenmarksstúcke:

Pons normal.

Medulla oblongata in den oberen Partien desgleichen. An der oberen Grenze der Pyramidenkreuzung sieht man an der Fissura posterior in der Peripherie des rechten Hinterstranges eine degenerirte Stelle, die links nur eben angedeutet ist. Ferner erkennt man beiderseits lateral von den Hinterhörnern degenerirte Partien.

Untere Grenze der Pyramidenkreuzung. Symmetrische Degeneration im Gebiet der KI.S., sowie in den Hintersträngen dicht an der Fissura posterior, nach der Peripherie zu sich verbreiternd und fast die Hinterhörner erreichend. In den Py.V. tritt dicht am Suleus anterior beiderseits eine weissliche Verfärbung auf, rechts schwächer wie links.

Oberstes Halsmark. Die Degeneration in den KI.S. hat an Ausdehnung zugenommen. Die Hinterstränge zeigen im Gebiet der Goll'schen Stränge starke Degeneration in dem dorsal gelegenen Theil. Dabei ge- 
ringere Degeneration in den Burdach'schen Strängen. Py.V. etwas stärker degenerirt, Py.S. frei (Taf. I-IV, Fig. 11).

Halsanschwellung. Die Peripherie des Rückenmarks zeigt verschiedene narbenartige Einziehungen. In den Hintersträngen die Gollschen Stränge in ganzer Ausdehnung degenerirt, die Burdach'schen nur in der Peripherie. Kl.S. etwas geringer afficirt; dagegen treten einzelne weisse Flecke in den Py.S. auf; die Py.V. fleckweise degenerirt, vollkommen symmetrisch (Taf. I-IV, Fig. 12).

Unteres Halsmark. Die Degeneration in den Py.S. und Py.V. hat an Intensität zugenommen, sonst die alten Verhältnisse (Taf. I-IV, Fig. $1_{3}$ ).

Oberes Brustmark. Goll'sche Stränge in ihrer Totalität, Burdach'sche nur in der Peripherie befallen. Die Kl.S. rechts etwas stärker' afficirt, Py.S. beiderseits in mässigen Grenzen degenerirt, Py.V. sehr intensiv, links stärker wie rechts. Die übrige weisse und die graue Substanz normal (Taf. I-IV, Fig. $1_{4}$ ).

In der Hölhe des 3.-4. Dorsalnerven treten die Vorderbörner beiderseits durch eine bellere Färbang deutlich aus der grauen Substanz hervor. Die. Degeneration der H.Str., Kl.S., Py:S. und V. unverändert, vollkommen symmetrisch.

Mittleres Brustmark. Die Veränderung der Vorderhörner nicht mehr zu constatiren; Degeneration der weissen Substanz unverändert.

Unteres Brustmark. Vom 9. Brustnerven abwärts weicht die Degeneration der Goll'schen Stränge von der Fissura posterior nach aussen zuritck, an derselben einen Streifen normalen Gewebes freilassend. Die degenerirte Zone läuft, an der Commissura posterior beginnend, bogenförmig nach aussen bis zur Peripherie, wo sie sich verbreitert. Die Burdach'schen Stränge ziemlich frei. Kl.S. zeigen keine Degeneration. Py.S. und $V$. stark degenerirt.

Oberes Lendenmark. Die Degeneration in Py.S. und V. in Abnahme begriffen, namentlich im linken Py.V. und rechten Py.S. und V. Ueber den Hintersträngen fällt Verdickung der Pia mater auf. In den Hintersträngen zeigen die Goll'schen Stränge starke, die Burdach'schen schwache Degeneration (Taf. I-IV, Fig. $1_{5}$ ).

Lendenanschwellung. Starke Degeneration der Hinterstränge, mit Freilassung des äusseren Theils der Burdach'schen Stränge. In den Seitensträngen Degeneration noch angedeutet. Py.V. frei.

Unteres Lendenmark. Die Peripherie der Hinterstränge an der Fissura posterior degenerirt. Sonst normale Verhältnisse (Taf. I-IV, Fig. 16).

Sacralmark, Conus terminalis normal.

\section{Miliroskopische Untersuchung.}

Die Schnitte werden theils mit der van Guison'schen Methode (Vorfärbung mit Hämatoxilin, Nachfärbung mit Säurefuchsin-PikrinsäureLösung), theils mit Hämatoxylin-Eosin, theils mit der alten und netien Weigert'schen Markscheidenfürbung behandelt. 


\section{Hinterstränge.}

Sakralmark. Einzelne gequollene Fasern an der Fissura posterior.

Unteres Lendenmark. An der dorsalen Hälfte der Fissura posterior beiderseits starke Degeneration, die rechts lateralwärts bis fast zum Hinterhorn reicht. Pia nicht wesentlich verdickt. Die hinteren Wurzeln vollkommen frei (Taf. I-IV, Fig. 16.)

Lendenanschwellung. Zu beiden Seiten der Fissura posterior von der Peripherie bis zur Mitte totaler Untergang der Fasern. Lateralwärts reicht die Degeneration bis zur Grenze von Goll'schen und Burdach'schen Strängen. In letzteren nur vereinzelte Herdchen degenerirten Gewebes. Die Gegend an der Commissura posterior vollkommen normal. Von hier aus erstreckt sich ein Theil gesunden Gewebes mit der Spitze dorsalwärts in das erkrankte Gewebe längs der Fissura posterior. Pia mater über den Hintersträngen leicht verdickt. In den hinteren Wurzeln vereinzelte degenerirte Fasern.

Oberes Lendenmark. Starke Verdickung der Pia mater über den Hintersträngen; an der Fissura posterior eine narbenförmige Einziehung mit starker Verdickung der Gefässwände (Taf. I-IV, Fig. 2). Die Degeneration nimmt einen mehr fleckenförmigen Charakter an. Sie ist noch immer am stärksten in den Goll'schen Strängen, in denen sie sich in einzelnen Flecken bis zur hinteren Commissur erstreckt. In den äusseren Partien nur kleine Degenerationsherde, welche die hinteren Wurzelzonen so gut wie frei lassen. Leichte Degeneration der hinteren Wurzeln (Taf. I-IV, Fig. $1_{5}$ ).

Unteres Brustmark. Die Degeneration der Hinterstränge greift immer weiter nach aussen um sich, erreicht jedoch kaum die hintere Wurzelzone. Nach vorn reicht dieselbe, wenn auch in geringer Intensität, bis zur Commissur. Es besteht fast völlige Symmetrie. Die Pia mater ist noch immer verdickt, doch in geringerem Grade. Hintere Wurzeln zeigen nur vereinzelte degenerirte Fasern.

Mittleres Brustmark. Starke Degeneration in den Goll'schen Strängen beiderseits in schmalen Streifen an der Fissura posterior entlang von der Peripherie bis zur Commissur. Dorsalwärts verbreitert sich der Streifen und reicht bis in die hintere Wurzelzone. In dem äusseren Theile der Hinterstränge geringe, fleckweise, beiderseits symmetrisch gelegene Degenerationsherde. Pia normal, hintere Wurzeln frei (Taf. I-IV, Fig. $1_{4}$ ).

Oberes Brustmark. Die Degeneration der Hinterstränge an Intensität und Extensität vermehrt. Nur eine schmale Zone in dem ventralen Theil der Burdach'schen Stränge am Rande des Hinterhorns beider. seits frei. Die hintere Wurzelzone total degenerirt. Pia leicht verdickt. Hintere Wurzeln frei (Taf. I-IV, Fig. $1_{3}$ ).

Unteres Halsmark. Derselbe Befund.

Halsanschwellung. Die Degeneration nimmt die ganze Breite der Hinterstränge, mit Ausnahme eines schmalen Randes der Burdachschen Stränge, ein. Doch sind auch in den degenerirten Partien, namentlich in den Burdach'schen Strängen, einzelne Fasern erhalten. In den hinteren Wurzeln schwache Degeneration (Taf. I-IV, Fig. $1_{2}$ ).

Oberes Halsmark. Die Degeneration entschieden in Abnahme 
begriffen. Dieselbe zieht sich von der Peripherie aus an der Fissura posterior in schmalen Streifen ventralwärts, lässt jedoch das vordere Drittel des Goll'schen Stranges frei. Auf eine Zone normalen Gewebes folgt dann lateralwärts an der Grenze der Goll'schen und Burdach'schen Stränge ein etwas schwächerer Degenerationsstreifen, der die Commissura posterior nicht ganz erreicht, sich nach hinten aussen verbreitert, ohne jeđoch die Hinterhörner zu erreichen. Pia ist verdickt. Hintere Wurzeln normal (Taf. I-IV, Fig. $1_{1}$ ).

Untere Grenze der Pyramidenkreuzung. Schwache Degeneration in Burdach'schen und Goll'schen Strängen noch immer zu constatiren.

Obere Grenze der Pyramidenkreuzung. An der Fissura posterior unmittelbar an der Peripherie rechts eine schmale Zone schwacher Degeneration; links an der entsprechenden Stelle nur vereinzelte degenerirte Fasern. Weiter aufwärts normale Verhältnisse.

\section{Vorder- und Seitenstränge.}

Sacralmark normale Verhältnisse.

Lendenmark. Erst in der Lendenanschwellung vereinzelte degenerirte Fasern beiderseits in den Py.S. Im obersten Lendenmark starke Degeneration im rechten, schwächere im linken Py.S. und rechten Py.V. Im linken Py.V. nur einzelne Fasern gequollen (Taf. I-IV, Fig. 15).

Unteres Brustmark. In beiden Py.S. und Py.V. ausgesprochene Degeneration; doch sind in diesen Strängen mehrere Nervenfasern erhalten, und auch in den gequollenen die Axencylinder zum Theil unversehrt. Körnchenzellen in mässiger Zahl. Die Randzone der Seitenstränge fast ganz intact. Die Pia nicht verdickt.

Mittleres Brustmark. Py.S. und Py.V. stark degenerirt, beiderseits annähernd symmetrisch. Auch die Kl.S. beginnen hier an der Degeneration theilzunehmen. Die Degeneration nimmt nach oben schnell an Ausdehnung za, erreicht jedoch nicht die der Py.S. an Intensität; auch die Hinterseitenstrangreste in nächster Nähe der granen Substanz zeigen einzelne degenerirte Fasern. Vorderseitenstränge normal. In den Vordersträngen auch ausserhalb der Py.V. einzelne Fasern gequollen (Taf. I-IV, Fig. 14).

Oberes Brustmark. Die Degeneration ist in den Py.S. nnd Py.V. noch immer sehr intensiv; etwas schwächer in den Kl.S. Die tibrigen Partien der Vorderseitenstränge fast völlig frei. Auf der rechten Seite ist die Degeneration intensiver als auf der linken.

Unteres Halsmark. Starke Degeneration der Py.S. und der Kl.S., bis an die Spitze des Hinterhorns heranreichend. Auch in den Hinterseitenstrangresten etwas ausgesprochenere, auf beiden Seiten symmetrische Degeneration. Die Py.V. stark entwickelt und intensiv degenerirt. Auch in ihrer nächsten Umgebung einzelne gequollene Fasern, im übrigen die Vorderstränge normal (Taf. I-IV, Fig. $1_{3}$ ).

Halsanschwellung. Die Kl.S. sehr weit nach vorn reichend, intensiv in ganzer Ausdehnung degenerirt. In den Py.S. rasche Abnahme der Degeneration, während dieselbe in den Py.V. noch unverändert fort- 
besteht. Im Gebiet der letzteren ist die Pia mater deutlich verdickt und dringt an einzelnen Stellen in Form von Einkerbungen des Randes in die Riückenmarksubstanz ein. Um diese Einkerbungen herum die Degeneration besonders intensiv, zum Theil anch ausserhalb des Gebietes der Py.V. Doch finden sich auch im Gebiet der Seitenstränge derartige Einkerbungen ohne Degeneration (Taf. I-IV, Fig. 12).

$\mathrm{Oberes} \mathrm{Halsmark}$. Die Degeneration der Py.S. auf einzelne Fasern beschränkt. Auch in den Py.V. nimmt die Intensität der Degeneration $a b$, rechts früher als links. Die Degeneration der Kl.S. sehr ausgesprochen, doch etwas schwächer als in der Halsanschwellung (Taf. I bis IV, Fig. 11).

Untere Grenze der Pyramidenkreuzung. Starke Degeneration der Kl.S. Von den Pyramidensträngen zeigt nur noch der linke Py.V. schwache Degeneration.

Obere Grenze der Pyramidenkreuzung. Die Degeneration der Kl.S. beiderseits sehr gering. Sonst normale Verhältnisse.

Weiter anfwärts in Mednlla oblongata und Pons keine Degeneration nachweisbar.

Graue Substanz.

Sacralmark. Starke Füllung der Blutgefässe mit Lücken um dieselben (Härtung?), sonst normale Verhältnisse.

Unteres Lendenmark normal.

Lendenanschwell ung. In der Mitte der grauen Substanz Lïckenbildungen, von denen es nicht mit Sicherheit festzustellen ist, ob es sich um Kunstproducte handelt. In der Umgebung derselben das feine Fasernetz zerstört, Markschollen und Blutkörperchen sichtbar. Die Ganglienzellen der Vorderhörner normal. Gefässe prall gefüllt, zum Theil perivasculäre Blutungen geringen Grades.

Oberes Lendenmark. Im Allgemeinen normale Verhältnisse. Auch die hier zuerst auftretenden Clarke'schen Säulen in Bezug auf Ganglienzellen und Markfaserung normal. Gefässe zeigen verdickte Wandungen, sind prall geftillt. Vereinzelte Blutungen.

Unteres Brustmark normal.

Mittleres Brustmark. Das Markfasernetz in den Vorderhörnern und in der Mitte der grauen Substanz entschieden vermindert; die Substanz macht daselbst einen leicht rareficirten Eindruck. Dabei zeigen die Ganglienzellen der Vorderhörner normale Verhältnisse, die der Clarkeschen Säulen sind spärlich, doch got erhalten; das Markfasernetz der Clarke'schen Säulen normal.

Die Blutgefässe zeigen verdickte Wandungen, sind über die Norm vermehrt, prall gefüllt und dilatirt. Zahlreiche perivasculäre Blntungen theils in den Vorderhörnern, theils in grösserer Ausdehnung an der Basis derselben mit beträehtlicher Lückenbildung des Gewebes, in dem Markschollen erkennbar sind. Man erkennt schon mit blossem Auge sowohl '́n den mit Säurefuchsin-Pikrinsäure behandelten Schnitten, als auch an Weigert-Präparaten eine hellere Färbung der vorderen Abschnitte der grauen Substanz.

Oberstes Brustmark. Die Rareficirung der vorderen Partien der 
grauen Substanz noch stärker ausgeprägt. Die Vorderhörner treten schon makroskopisch in den Schnitten durch hellere Färbung hervor. Daselbst fast völliger Schwund der markhaltigen Fasern, die Ganglienzellen sind erhalten. Zablreiche Lückenbildungen, deren Entstehung von Blutungen aus sich nur zum Theil nachweisen lässt. Die Clarke'schen Säulen völlig intact. Gefässe sehr zahlreich, prall gefüllt, mit verdickten Wandungen; in der Umgebung zum Theil sehr beträchtliche Blutungen, vor allen zwischen Vorder- und Hinterhörnern.

Gegen das Halsmark zu nimmt die Veränderung an Intensität ab, die Blutungen nur noch perivasculär in geringem Umfange. Ganglienzellen der Vorderhörner völlig intact, doch sind die markhaltigen Fasern daselbst ziemlich beträchtlich vermindert.

Unteres Halsmark. Spärliche, perivasculäre Blutungen, sonst normale Verhältnisse.

Halsanschwellung. Durch einen bei der Section gemachten Schnitt, der auf der rechten Seite von der hinteren Wurzel bis ins Vorderhorn reicht, wird die Beurtheilung etwas erschwert. Links sehr beträchtliche Blutungen an der Basis des Vorderhorns, zum Theil zwischen erhaltenen Ganglienzellen der mittleren Gruppe gelegen (Taf. I-IV, Fig. 3). Zwischen den Ganglienzellen des Seitenhorns spärliche perivasculäre Blutungen; an einzelnen Stellen offenbar von Blutungen herriihrende Liickenbildungen. Das Markfasernetz in der grauen Substanz etwas spärlicher als normal.

Oberes Halsmark. Bis auf spärliche Blutungen normale Verbältnisse.

Pyramidenkrenzung. Normale Verhältnisse. Auch im Nuclets funiculi gracilis und Nucleus funiculi cuneati keine Degeneration oder Atrophie der Ganglienzellen nachweisbar.

Vordere Wurzeln in ganzer Ausdehnung des Rückenmarks intact.

In diesem Falle wurde die Diagnose intra vitam auf chronische Myelitis gestellt. Als Patient in das Krankenhaus aufgenommen wurde, sprach der spastisch-paretische Gang, die Steigerung der Patellarreflexe, der vorbandene Fussclonus, die Rigidität der Musculatur, die anfallsweise auftretenden Zuckungen und Contractionen der Beine für eine spastische Spinalparalyse. Doch war schon damals gegen diese Annahme anzuführen die leichte Ataxie der Beine, die Sensibilitätsherabsetzung und der Mangel des Lagegefühls an den Zehen. Da nun eine deutliche Druckempfindlichkeit des Processus spinosus des 7 . Brustwirbels zu constatiren war, so musste man daran denken, dass es sich um eine Wirbelerkrankung handeln könne. Aber erstens war der Schmerz an der Wirbelsäule durchaus nicht constant, ferner liess sich nicht die geringste Andeutung einer Difformität nachweisen, und endlich sprach auch der weitere Verlauf der Erkrankung gegen eine solche Annahme. Während nämlich in der ersten Zeit die Parese der Beine und die Spasmen andauernd in Zu- 
nahme begriffen waren, trat von Anfang December an eine Abnahme der Spasmen ein, so dass die active Beweglichkeit der Beine sich sogar vorübergehend besserte. Zugleich nahm der Patellarreflex entschieden an Intensität $a b$ und war am Tage des Todes nur noch sehr schwach auszulösen, die Sensibilitätsstörung an den Beinen nahm $z u$, der Ortssinn schwand immer mehr, und die Ataxie wurde deutlicher. Es musste daher, neben der Erkrankung der Seitenstränge eine solche der Hinterstränge bestehen. Da die Arme erst in den letzten Tagen Andeutung von Rigidität zeigten, im Uebrigen nur eine Herabsetzung der motorischen Kraft ohne Steigerung der Reflexe und ohne Ataxie zu constatiren war, so musste die stärkste Entwieklung des Processes unterhalb des Halsmarks zu erwarten sein.

Die genaue Untersuchung des Rückenmarks ergab nun die oben geschilderte systematische Erkrankung der H.Str., Py.S. und V., und Kl.S. In den Hintersträngen reichte die Erkrankung vom obersten Sacralmark bis zur Pyramidenkreuzung, mit stärkster Ausdehnung vom unterem Brustmark bis zur Halsanschwellung. Die Degeneration nimmt vorwiegend die Goll'schen Stränge ein, greift jedoch auf die Burdach'schen uber und hat nirgends den Charakter der secundären aufsteigenden Degeneration. Im Lendenmark ist die Wurzelzone so gut wie frei, wird dagegen im Brust- und unteren Halsmark, wenn auch in geringem Grade, von der Degeneration betroffen. Die hinteren Wurzeln zeigen, im scharfen Gegensatz zur Tabes, kaum eine Andeutung von Degeneration. Die Pyramidenbahnen sind von der Lendenanschwellung bis zum obersten Halsmark afficirt. Dabei sind Seiten- und Vorderstränge ziemlich gleichmässig befallen. Während jedoch die Degeneration der Seitenstränge bereits in der Halsanschwellung abnimmt und im obersten Halsmark nur noch angedeutet ist, sind die Pyramidenvorderstränge noch im obersten Halsmark deutlich afficirt, der rechte zeigt sogar noch im Beginn der Pyramidenkreuzung einzelne gequollene Fasern. Die Degeneration der Kleinhirnseitenstrangbahnen erstreckt sich vom mittleren Brustmark bis zur Pyramidenkreuzung und ist im Halsmark am stärksten ausgesprochen. Die tibrigen Partien der Vorderseitenstränge zeigen, besonders im oberen Brust- und unteren Halsmark einzelne degenerirte Fasern, welche jedoch gegen die vollständig degenerirten Fasersysteme ganz zurücktreten.

Bemerkenswerth sind nun die nicht unbeträchtlichen Veränderangen der grauen Substanz, vor allem die Rarefication der Vorderhörner im mittleren und oberen Brustmark, und die Blutungen im Brust- und Halsmark. Man könnte daran denken, hierauf das 
Bild einer Querschnittsmyelitis im oberen Brustmark mit anf- und absteigender Degeneration aufubauen. Doch ist weder die Veränderung des Rückenmarks an irgend einer Stelle derart ausgedehnt, dass sie den ganzen Querschnitt umfasst, noch entsprechen die Veränderungen der weissen Substanz den Formen der secundären Degenerationen, indem sowobl die Pyramidenbahnen oberhalb, als auch die Kleinhirnseiten- und Hinterstränge unterhalb der oberen Partien des Brustmarks erkrankt sind, und zwar die letzteren nicht nur in der Schultze'schen Commaform.

Indem ich auf die principielle Frage, inwieweit die combinirten Systemerkrankungen als selbstständige Krankheitsform zu Recht be. stehen, erst im Zusammenhang mit den beiden anderen Fällen eingehen will, soll hier nur auf einen Punkt in der Krankengeschichte dieses Falles hingewiesen werden, auf den Blatbefund. Schon bei der Aufnahme des Patienten fiel die ungemein fahle Gesichtsfarbe desselben auf; leider ist die, nicht von mir selbst ausgeführte Untersuchung des Blutes nur eine sehr unvollkommene gewesen. Vor allem fehlen Zählungen der Blutkörperchen vollständig. Immerhin lässt der Blutbefund, Verminderung des Hämoglobingehalts auf 50 Proc., das Vorkommen von zahlreichen Poikilo- und Mikrocyten und von einigen kernhaltigen rothen Blutkörperchen nicht daran zweifeln, dass es sich um eine perniciöse Anämie handelte.

Lichtbeim ') bat zuerst auf die nicht seltene Combination von perniciöser Anämie mit Rückenmarksaffectionen aufmerksam gemacht und betont, dass beide Erkrankungen als von einer gemeinschaftlichen, nicht bekannten Ursache ausgegangen anzusehen sind. v. Noorden hat dann im Verlauf von Untersuchungen über sehwere Anämien ${ }^{2}$ ) bei einer 59jährigen Frau in Verbindung mit dem Blutbefund der perniciösen Anämie Parese beider unteren Extremitäten mit erloschenen Patellarreflexen und leichten Sensibilitätsstörungen beobachtet. Die Autopsie ergab Degeneration der Kl.S., Py.S. und V. und der Hinterstränge von der Pyramidenkreuzung bis zum Lendenmark, da neben leichte Degeneration im N. tibialis und peroneus. Bald darauf veröffentlichte dann $\mathrm{Minnich}{ }^{3}$ ) eine umfassende Arbeit, in welcher er zum Theil die von Lich theim bereits kurz mitgetbeilten Fälle, zum Theil neue Beobachtungen ausführlich beschrieb. Während einige Male nur eine Hinterstrangserkrankung vorhanden war, berichtet Verf. über

1) Verhandlungen des Congresses für innere Medicin. 1887. S. 84.

2) Untersuchungen über schwere Anämien. Charité-Annalen. 1891/92.

3) Zur Kenutniss der im Verlauf der perniciösen Anämie beobachteten Spinalerkrankungen. Zeitschr. f. klin. Medicin. Bd. XXI n. XXII. 1892. 
vier Fälle von combinirter Erkrankung der Hinter- und Seitenstränge. Doch sind dies, nach seiner Ansicht, keine Systemerkrankungen. Eisen $\operatorname{lohr}^{1}$ ) publicirt gleichfalls einen einschlägigen Fall, in dem bei einem 59 jährigen Manne in Anschluss an Magen- und Darmatrophie schwere Anämie und Parese der Arme und Beine mit spastisch paretischem Gang und erloschenen Patellarreflexen auftrat. Im Rückenmark waren die Hinterstränge wie bei der Tabes, ferner die Py.S. und Kl.S. symmetrisch, aber nicht in typischer Weise, degenerirt. Verf. nimmt die Abhängigkeit der Rückenmarkssymptome von der Anämie an. Nonne ${ }^{2}$ ) berichtet über zwei einschlägige Fälle; in dem ersten bekam ein 48 jähriger Mann im Anschluss an eine Taenia mediocanellata perniciöse Anämie, der bald Schwäche und Ataxie der unteren Extremitäten mit Herabsetzung des Patellarreflexes folgte. Trotz Abtreibung der Taenia Fortscbritte der Rückenmarkserkrankung, Versehwinden der Patellarreflexe, die kurz vor dem Tode wieder auftreten. Im Rückenmark ausgedehnte Degeneration der Hinterstränge, irreguläre Degenerationsherde in den Seitensträngen. Bemerkenswerther ist der zweite Fall, in dem bei einem 57 jährigen Mann Ataxie, Sensibilitätsstörungen in den unteren Extremitäten, Herabsetzung des Patellarreflexes auftraten und sich von selbst wieder zurïckbildeten, während der Mann an schwerer progressiver Anämie zu Grunde ging. Trotzdem fanden sich fleckweise Degenerationen in den Hintersträngen und isolirte kleine Herde in den Seitensträngen. Verf. konnte überall das Confluiren kleinster Degenerationsherde im Anschluss an hyalin degenerirte Capillaren beobachten. Auch diese Fälle können nicht als ausgeprägte Systemerkrankungen aufgefasst werden; doch hat man es hier wahrscheinlich mit den zu Erkrankungen ganzer Systeme führenden Anfangsstadien zu thun. Die Fälle wiurden unter diesen Gesichtspunkten sogar eine besondere Bedeutung für die Entstebungsweise der combinirten Systemerkrankungen gewinnen. Da die Riickenmarksaffection in dem einen dieser Fälle der Bluterkrankung lange voraufging, so kann man die Beziehung: beider Processe nur so auffassen, dass eine gemeinschaftliche Ursache beide bedingt. Dasselbe beweist ein von Leyden ${ }^{3}$ ) beobachteter

1) Ueber primäre Atrophie der Magen- und Darmschleimhaut und deren Beziehung zu schwerer Anämie und Rückenmarkserkrankung. Deutsche med. Wochenschrift. 1892. S. 1105.

2) Beiträge zur Kenntniss der im Verlaufe der perniciösen Anämie beobachteten Spinalerkrankungen. Archiv für Psych. Bd. XXV. 1893.

3) Ueber chronische Myelitis und die Systemerkrankungen im Rückenmark. Zeitschr. für klin. Medicin. Bd. XX. 1892. 
Fall. Nach Ritickenmarkserschütterung durch Eisenbahnunfall Entwicklung spastischer Spinalparalyse. Mehrere Monate später perniciöse Anämie. Im Rückenmark sklerotische Degeneration der Hinter-und Seitenstränge, ungefähr dem Bilde der combinirten Systemerkrankung entsprechend; im Brustmark auch die Pyramidenvorderstränge afficirt. Endlich hat $\mathrm{B}$ ow $\operatorname{man}^{1}{ }^{1)}$ neuerdings einen in Anschluss an perniciöse Anämie entstandenen Fall von typischer combinirter Systemerkrankung berichtet. Eine 53jährige Frau leidet seit 2 Jahren an zunehmender Anämie; vor 9 Monaten Schwäche, bald darauf Parästhesien in den Beinen. Bei der Aufnahme wird eine hocbgradige perniciöse Anämie constatirt, mit starker Verminderung der rothen Blutkörperchen und des Hämoglobingehalts (bis 20 Proc. des Normalen). Schwäche der sämmtlichen Extremitäten obne Ataxie. Sensibilität an den Untersehenkeln herabgesetzt, etwas auch an den Fingerspitzen. Lebhafte Patellarreflexe, Pupillarreaction normal. A uf Arsenbehandlung Besserung der Anämieundagleichdes Rücken. marksleidens. Pat. kann nach einem Vierteljahr ohne Unterstützung gehen; die rothen Blutkörperchen betragen 87 Proc. des Normalen. Nachdem die Patientin aus der Behandlung entlassen ist, rasche Verschlechterung der Blutmischung und des Rückenmarkleidens. Parese der Beine mit deutlicher Ataxie und unwillkürlichen, sehmerzhaften Spasmen. Herabsetzung der Sensibilität und des Lagegefühls an den Beinen. Patellarreflexe lebhaft. Allmählich werden auch die Arme ergriffen; die Beinmusculatur ist deutlich rigide. Auftreten von Fussclonus. Die Zahl der rothen Blutkörperchen sinkt endlich auf 12 Proc. des Normalen. $3 / 4$ Jahr nach dem Rückfall Exitus letalis.

Die Untersuchung des Rückenmarks ergiebt eine combinirte Systemerkrankung mit Affection der Py.S. und Py.V., der ersteren vom oberen Sacralmark bis mittleren Halsmark, der letzteren rom oberen Lumbarmark bis mittleren Halsmark, der Kl.S. vom unteren Brustmark bis zur Pyramidenkreuzung, der Hinterstränge vom mittleren Lumbarmark bis zur Pyramidenkreuzung mit Freilassung der hinteren äusseren Felder und der hinteren Wurzeln. Graue Substanz normal.

Da die Rückenmarkssymptome zugleich mit dem Blutbefund sich besserten und verschlechterten, nimmt Verf. die Abhängigkeit der spinalen Symptome von dem Blutbefund an. Jedoch ist hier entschieden Vorsicht geboten; denn in dem oben erwähnten zweiten

1) On the association of disease of the spinal cord with pernicious anaemie. Brain 1894. p. 198.

Deutsche Zeitschr. f. Nervenheilkunde. VII. Bd. 
Nonne'schen Fall trat gerade umgekehrt mit der Besserung der spinalen Symptome die perniciöse Anämie überhaupt erst hervor. Da die Ursache der perniciösen Anämie in den meisten Fällen ebenso dunkel ist wie die der combinirten Systemerkrankungen, so wird man hier kaum mit Sicherheit ein Abhängigkeitsverhältniss feststellen können, ehe nicht unsere Kenntnisse über die Aetiologie dieser Krankheiten weitere Forschritte gemacht haben.

Für die Frage der combinirten Systemerkrankungen ist es jedenfalls von Wichtigkeit, dass namentlich durch den Bowman'schen und unseren eigenen Fall nachgewiesen ist, dass in Verbindung mit schweren Erkrankungen des Blutes spinale Erkrankungen vorkommen können, die den als combinirte Systemerkrankungen beschriebenen Krankheitsformen klinisch und pathologisch-anatomiseh voll und ganz entsprechen. Da ferner die perniciöse Anämie selbst eine zum Tode führende Erkrankung ist, so können wir hoffen, bei sorgfältiger Beobachtung der spinalen Symptome intra vitam und genauer Untersuchung des Rückenmarks in allen einschlägigen Fällen die Entwicklung der combinirten Systemerkrankungen von den ersten Anfängen bis zu den ausgebildeten Formen festzustellen.

II. Fall. Ernst A $1 \mathrm{~g} \mathrm{n}$ e r, 38 Jahre alt, Arbeiter. Aufgenommen 13. Februar 1893, gestorben 30. März 1893.

Im 23. Jahre Lues, seitdem gesund. Verheirathet, 2 gesunde Kinder. Sommer 1892 Magendarmkatarrh mit Schmerzen im Leib und den Beinen. Seit November 1892 entschiedene Schwäche der Beine und deutliche Parästhesien in denselben. Nach einer Schmiercur in December Zunahme der Schwäche. Urinverhaltung. Februar 1893 starke Parese der Beine. Sensibilitätsherabsetzung der Unterschenkel. Oedem der Beine, Schmerzhaftigkeit der Wirbelsäule vom 6. Brustwirbel abwärts. Die Patellarreflexe in den ersten Tagen schwach auszulösen, dann ganz erloschen. Pupillarreaction erhalten. Im weiteren Verlauf Zunahme der motorischen und sensorischen Störungen der unteren Extremitäten. Mitte Februar Blasen- und Mastdarmlähmung. Starke Temperaturerhöhungen infolge eitrigen Blasenkatarrhs. Schnell zunehmende Macies. Sensorium zeitweise benommen. Mitte März totale Paralyse der unteren Extremitäten mit Aufhebung der Sensibilität und Schmerzempfindung. Auch an Bauch und Rücken bis zum unteren Rippenbogen Abschwächung derselben. Zunehmende Schwäche der oberen Extremitäten, schliesslich Parese derselben mit deutlicher Ataxie, heftige Dyspnoe. 30. März Exitus letalis unter den Zeichen der $Z_{\text {werchfellslähmung. }}$

Untersuchung des Rückenmarks: Degeneration der Hinterstränge, der Py.S. und Py.V., der Kl.S. Hintere Wurzeln frei. In der grauen Substanz überall reichliche Gefässbildung mit perivasculären Blutungen. Im Sulcus anterior des Halsmarks reichliches Exsudat und Blutungen. Im unteren Lendenmark etwas ausgedehntere Blutungen und Exsudate, im oberen Lendenmark vereinzelte vacuolisirte Ganglienzellen der Vorderhörner, im Halsmark partielle Atrophie der medialen und mittleren Gruppe der Vorderhornganglienzellen. 
Anamnese. Eltern an Altersschwäche gestorben, 2 Geschwister, Frau und 2 Kinder gesund. 1872 Wechselfieber. 1876 aquirirte Patient als Soldat harten Schanker. Hautausschlag will er nicht gehabt haben, doch machte er $1 / 4$ Jahr darauf eine Schmiercur durch. Juni 1892 erkrankte Patient an einem fieberbaften Magen- und Darmkatarrh, der bis in den Herbst angehalten haben soll. Er will zu dieser Zeit auch nierenund leberkrank gewesen sein und gelb ausgesehen haben. Doch war er ausser Bett und ging aus, wobei er einmal zusammengebrochen ist. Vorübergehend klagte er damals über ziehende Schmerzen im Leibe und den Beinen. Im Herbst 1892 stellte sich dann allmählich eine langsam zunehmende Schwäche der Beine ein. In den Beinen und im linken Arm traten unangenehme Kältegefühle auf, in den Beinen zuweilen Schmerzen. Ausgesprochenes Gürtelgefühl. Im Herbst zeigten sich auch die ersten Blasenstörungen, erst Retentio, dann Incontinentia urinae. Stuhlgang immer angehalten. Von Mitte December bis Mitte Januar 1893 machte Patient in der Charité eine Schmiercur durch, verliess das Krankenhaus jedoch im schlechteren Zustande als vorher. Seitdem Schwäche der Beine, so dass Patient nicht gehen kann, dazu völlige Gefühlslosigkeit. Allmähliche Anschwellung der Füsse und des Leibes.

Patient führt seine Erkrankung auf eine im Mai erlittene starke Durchnässung zurück. Potus wird in mässigem Grad zugestanden.

Am 13. Februar 1893 sucht Patient das Krankenhaus am Urban auf.

Seine augenblicklichen Klagen beziehen sich auf Lähmung und Anschwellung der Beine mit Schmerzen in denselben and in der Wirbelsäule.

Status praesens am 14. Februar. Mittelgrosser, mässig kräftig gebauter Mann von auffallend geringem Ernährungszustande.

Starkes Oedem der Beine bis zur Mitte der Oberschenkel, links stärker als rechts.

Keine Exantheme, keine Drüsenschwellungen. Gesicht, sichtbare Schleimhäute blass.

Beide untere Extremitäten liegen in schlaffer Extensionsstellung auf der Unterlage, fallen erhoben schlaff hernieder. Die active Beweglichkeit sehr gering; Patient vermag beide Beine, das rechte besser wie das linke, im Knie ein wenig zu beugen. Auch in den Zehen- und Fussgelenken geringe active Beweglichkeit. Dagegen vermag Patient nicht die Hacken von der Unterlage zu erheben.

Unterhalb des Lig. Ponpartii links an der Innenseite des Oberschenkels ein harter Strang zu fühlen.

Patellarreflex rechts sehr schwach, nur mit Hülfe des Jendrassik'schen Handgriffs auszulösen, links nicht deutlich zu erzielen.

Plantarreflex beiderseits erhalten.

Kein Fuss-, kein Patellarclonus.

Sensibilität und Schmerzempfindung an den Unterschenkeln herabgesetzt, an den Oberschenkeln und dem übrigen Körper normal.

Muskel- und Lagegef ühl an beiden Beinen stark herabgesetzt.

Arme vollkommen frei activ und passiv beweglich.

Im Gesicht keine Lähmungen. modation.

Pupillen mittelweit, reagiren prompt auf Lichteinfall und Accom- 
Puls 84, regelmässig, klein, wenig gespannt.

Athmung 24 , regelmässig.

Lungen: hinten rechts über den vier, hinten links über den beiden untersten Rippen Abschwächung des Percussionsschalls und der Athmung. Kein Auswurf.

Herz normal.

Le ib leicht aufgetrieben, in den abhängigen Partien Oedem der Haut.

Leber und Milz nicht vergrössert.

Es besteht Urinverhaltung. Der katheterisirte Harn klar, röthlichgelb, enthält eine Spur Albumen, deutlich Indican.

Stublgang angehalten.

Am Rücken in den abhängigen Partien starkes Oedem.

Wirbelsäule ohne Difformität. Am Proc. spinosus des 2. und 3. Lendenwirbels Schmerzempfindlichkeit auf Druck.

Leichte Schmerzhaftigkeit der N. peronei auf Druck; die anderen Nervenstämme schmerzfrei.

Patient klagt andauernd über stechende Schmerzen in den Beinen.

Ordination: Sol. Kal. jodati $(6,0: 200,0)$.

17. Februar. Der Urin geht jetzt von selbst $a b$, doch hat Patient ein Gefiuhl dabei. Die Oedeme an den Beinen nehmen rasch zu.

Faradische und galvanische Prüfung der Nervenstämme der unteren Extremitäten ergiebt Herabsetzung der Erregbarkeit (Oedem?) ohne Umkehr des Zuckungsgesetzes.

Leichte Temperaturerhöhung.

19. Februar. Lendenwirbelsäule leicht lordotisch. Vom Proc. spinosus des 7. Brustwirbels nach abwärts Schmerzhaftigkeit der Wirbelsäule beim Beklopfen.

Urin und Stuhl gehen jetzt von selbst ab.

Das Oedem an beiden Beinen sehr stark.

In der linken Inguinalgegend ein harter, nicht schmerzhafter Strang auch heute deutlich zu fühlen. In der rechten Inguinalgegend starke Schmerzhaftigkeit, ohne dass ein Strang za fiuhlen wäre.

Die active Beweglichkeit beider Beine bis auf minimale Bewegungen in Zehen- und Fussgelenken erloschen.

Patellarreflex beiderseits nicht zu erzielen.

Feine Berührungen werden an den Unterschenkeln nicht wahrgenommen, im übrigen Sensibilität und Schmerzempfindung erhalten.

21. Februar. In der Nacht heftiger Frostanfall. Temperatur am Morgen iiber $39^{\circ}$, Haut brennend heiss. Leichte Zunahme der Oedeme; doch ist die active Beweglichkeit der Beine etwas ausgiebiger geworden.

Leib aufgetrieben, gespannt, auf Druck in der Blasengegend schmerzhaft.

Urin und Stuhl gehen von selbst ab.

U rin rothgelb, getrübt, enthält reichlich Albumen (nach $\mathrm{Esbach}$ 2,5 pro Mille). Starke Indikanreaction. Im Sediment neben spärlichen Blasenepithelien ungemein reichliche Eiterkörperchen (Blasencatarrh).

Patient erhält Blasenausspülungen.

Wegen starker Schlaflosigkeit tägliche Gaben von Chloralhydrat. 
23. Februar. Temperatur noch immer stark erhöht mit beträchtlichen Remissionen.

Patient klagt über zuckende Schmerzen, die von der Rickengegend in die Beine ausstrahlen. Auch treten zeitweise unwillkürliche, krampfhafte Beugungen und Streckungen der Beine ein.

Die active Beweglichkeit der Beine hat etwas zugenommen. Starker Blasencatarrh.

Blutuntersuchung ergiebt normale Verhältnisse.

25. Februar. Patient seit 2 Tagen leicht benommen, weiss jedoch, wo er sich befindet.

Schwellung der Beine unverändert, active Beweglichkeit derselben sehr gering. Sensibilität und Schmerzempfindung nur schwer zu prüfen, scheint jedoch an den Unterschenkeln herabgesetzt zu sein.

A rme völlig frei.

Schmerzhaftigkeit der Wirbelsäule unverändert.

Urin geht zum Theil von selbst ab. Trotz täglicher Blasenausspülung mit 2 proc. Bor-Salicyllösung starker Blasencatarrh.

Stuhlgang angehalten. Nach Ricinusöl lïsst Patient unter sich.

28. Februar. Temperatur zeigt noch immer Anstieg über $39^{\circ}$.

Sensorium frei. Patient macht einen sehr schwachen Eindruck, rasche Zunahme der Macies.

Active Beweglichkeit der Beine nur noch in Spuren nachweisbar; passiv sind dieselben, soweit es die Oedeme gestatten, frei beweglich.

Sensibilität an den Beinen und am Leib bis zum unteren Rippenbogen entschieden herabgesetzt, an den Unterschenkeln fast ganz aufgehoben.

Die Arme activ frei beweglich; doch nimmt die grobe motorische Kraft entschieden ab. Sensibilität normal. Keine Ataxie.

Gesichtsmusenlatur normal.

Am Kreuzbein deutlicher Decubitus.

Patient lässt Stuhl und Urin unter sich.

1. Närz. Beide unteren Extremitäten bis zur Lendenbeuge herauf hochgradig geschwollen, liegen schlaff und regungslos da, der rechte Unterschenkel nach einwärts rotirt. Das linke Bein kann nicht von der Unterlage erhoben werden, das rechte wird etwas im Knie gebeugt. Keine Rigidität der Musculatur.

Patient klagt über zeitweise auftretende reissende Schmerzen in den Beinen vom Knie bis zum Hacken. Bei den Blasenausspülungen werden mitunter spontane Zuckungen in der Oberschenkelmusculatur bemerkt; dieselben treten auch einige Zeit nach dem Beklopfen des Lig. patellae auf.

Patellarreflex erloschen. Kein Fussclonus.

Bewegung der Zehen unmöglich.

Sensibilität an den Beinen bedeutend herabgesetzt; weder Pinselstriche, noch Nadelstiche werden empfunden.

Plantarreflex total erloschen.

Am Abdomen fühlt Patient Pinselstriche und Nadelstiche rechts undeutlich, links deutlich. Ascites.

$A b$ domen aufgetrieben. Banchhaut ödematös und glänzend. Kein 
Die ganze Brustwirbelsäule ist empfindlich, besonders in der Höhe des 6. Dorsalwirbels. Hals- und Lendenwirbelsäule nicht schmerzhaft. Hant auf beiden Seiten des Gesässes zeigt Herabsetzung der Sensibilität; auch weiter herauf bis in die Gegend der Schulterblätter sind die Angaben unsicher.

Gesicht blass, kachectiseh.

Keine wesentlichen Lymphdrüsenschwellungen.

2. März. Temperatur etwas gefallen $\left(38,2^{\circ}\right)$.

Patient klagt ïber gürtelförmige Schmerzen im Leib und Zucken in den Beinen.

An beiden Hacken beginnender Jecubitus.

Die active Beweglichkeit der Beine besteht heute nur in schwachen Rotationsbewegungen der Füsse, links ausgiebiger als rechts, und minimalen Bewegungen der Zehen.

Decubitus am Kreuzbein hat an Ausdehnnng zugenommen.

Der katheterisirte Urin ist klarer geworden. Wenig Albumen, kein Saccharum, keine Diazoreaction, schwacher Indicangehait.

6. März. Temperatur noch immer erhöht. Sensorium ziemlich frei. Gesicht, Arme vollkommen frei.

In den Beinen nur noch Spuren activer Beweglichkeit. Vollkommen schlaffe Lähmung.

Oedem der Beine unverändert.

Decubitus am Krenzbein und Hacken gereinigt, doch ziemlich umfangreich.

Die Herabsetzung der Sensibilitat in Zunahme begriffen.

Die Wirbelsäule heute nirgends auf Druck schmerzhaft.

8. März. Rasche Zunahme der Macies.

Noch immer Spuren activer Beweglichkeit in den Beinen.

Sensibilität und Schmerzempfindung an beiden Untersehenkeln erloschen, desgleichen am rechten Oberschenkel, am linken nur stark herabgesetzt.

In den unteren Partien des Bauches leichte Herabsetzung der Sensibilität, rechts stärker als links.

Bauchdeckenreflex erloschen.

Rückenödem in Zunahme begriffen.

Wirbelsäule auch heute nirgends schmerzhaft.

14. März. Patient klagt über Frostgefühl und Schmerzen im Leib.

Active Beweglichkeit der Beine heute zum ersten Mal völlig erloschen.

Beide Beine stark ödematös.

Sehnen- und Hautreflexe nicht zu erzielen.

Passive Bewegung der Beine völlig frei.

Muskel- und Lagegefiuhl aufgehoben.

Sensibilität und Sehmerzempindung an den Beinen erloschen, desgleichen am Abdomen bis zur Nabelhöhe. Weiter aufwärts bis an den unteren Rippenbogen Sensibilitätsherabsetzung ohne scharfe Grenzen nach oben. Schmerzempfindung daselbst normal. Auch am Rücken von der 10. Rippe abwärts Sensibilität herabgesetzt. 
Dagegen ist an den Armen Sensibilität und Schmerzempfindung normal.

Die motorische Kraft der Arme nimmt deutlich ab; doch sind dieselben activ und passiv frei beweglich. Leichte Schmerzhaftigkeit der unteren Hälfte der Brustwirbelsäule.

Lähmung des Sphincter und Detrusor urinae.

Patient lässt den Stuhl unter sich.

Inguinal- und Cubitaldrïsen leicht geschwollen.

15. März. Patient ausserordentlich matt; er vermag seine Anfmerksamkeit nur schwer zu concentriren.

Die Arme werden entschieden schwächer; bei intendirten Bewegungen wird hente leichte Ataxie constatirt.

Beine unverändert.

Temperatursinn am Unterschenkel erloschen, am Oberschenkel und Bauch stark herabgesetzt.

Am 14. März Nachmittags dyspnoischer Anfall.

Puls heute klein, beschleunigt. Respiration milhsam. Augenbewegungen frei, Pupillen gleich weit, reagiren prompt bei Lichteinfall and Accomodation. Augenhintergrund normal.

17. März. Sensorium benommen, Patient unruhig, leichte Phantasmen.

Patient hat Parästhesien in der linken Hand (Gefühl eines Fremdkörpers).

23. März. Athmung rein costal. Bei tiefer Respiration kein wesentliches Einsinken der Intercostalräume.

27. März. Patient klagt über Athemnoth, Sehmerzen in der Magenund Nabelgegend.

Leichte Benommenheit.

Patient liegt in passiver Rïckenlage, mit äusserster Dyspnoe.

Respiration ca. 14 in der Minute, rein costal, ohne Betheiligung des Zwerchfells und der Bauchmusculatur und unter starker Contraction des Mm. sternocleidomastoidei und sternothyreoidei, so dass bei jeder Inspiration der Keblkopf tief herabsteigt und der Kopf nach hinten iber gebeugt wird. Präinspiratorische Erweiterung der Nasenflügel. Puls 96 regelmässig von mittlerer Spannung.

29. März. Patient liegt in passiver Rückenlage, ist äusserst anämisch und kachectisch, vermag vor Schwäche kaum zu sprechen.

Leichte Benommenheit, doch giebt Patient auf Befragen richtige Antworten. Er klagt iber Schmerzen in der Nabelgegend.

Temperatur nur wenig erhöht. Patient klagt über Dyspnoe.

Respiration 14 in der Minute, angestrengt. Der Kopf hebt sich bei der Inspiration stark; die Halsmuskeln, vor allem der Sternocleidomastoideus, contrahiren sich bei der Athmung. Der Thorax wird als Ganzes nur durch die Contraction der Halsmuskeln gehoben, erweitert sich in seinen unteren Partien nur wenig im Breiten- und Tiefendurchmesser. Das Epigastrium wird nicht vorgewölbt, die Bauchdecken bleiben schlaff. Die Arme können hente activ kaum noch erhoben werden; den passir gebeugten Arm vermag Patient nicht zu extendiren. Händedruck, besonders rechts, sehr schwach.

Eine Sensibilitätsprüfung lässt sich der ungenauen Angaben des $\mathrm{Pa}$ tienten wegen nicht ausführen. 
Die Musculatur der Arme entschieden atrophisch, vor allem die Interossei. Es besteht deutliche Ataxie.

Eine elektrische Prüfung der Nervenstämme und Muskeln der Arme ergiebt normale Verhältnisse. loschen.

Totale Paralyse der stark ödematösen Beine. Patellarreflexe er-

30. März. 4 Uhr Morgens Exitus letalis.

Section (30. März 11 Uhr Vormittags):

Ueber Fersen und Krenzbein ausgedehnter Decubitus. Im Wirbelcanal an den Knochen der Bögen und Wirbelkörper nichts Abnormes. Dura mater im Halsmark leicht verdickt. Pia und Dura mater an einzelnen Stellen verwachsen. Auf Querschnitten ist die Substanz im Hals. mark auffallend weich, über die Ränder überquellend, im Lendenmark etwas fester, aber auch weicher als normal. Die Hinterstränge und im geringeren Grade die Seitenstränge zeigen leichte Verfärbung.

Gehirn. Dura gespannt. Sonst normale Verhältnisse.

Linke untere Extremität. Stark ödematös. A. und V. cruralis unter dem Lig. Poupartii thrombosirt durch ältere, theils rothe, theils gelbe, stellenweise der Gefässwand adhärirende Thromben, die jedoch leicht ablösbar sind.

Rechte untere Extremität. Weniger ödematös; die Vena cruralis thrombosirt.

Herz gross, mit leichter Hypertrophie des linken Ventrikels. Am Schliessungsrande der Mitralis einzelne wärzchenförmige Auflagerungen.

Aorta zart. Intima zeigt einzelne kleine punktförmige Verfettungen.

Linke Lunge. Unterlappen stellenweise atelectatisch, Emphysem des Oberlappens.

Rechte Lunge. Stark ödematös. Im Unterlappen lobuläre pneumonische Stellen.

Milz gross, mit leichter Schwellung der Follikel.

Beide $\mathrm{N}$ i ere n vergrössert, mit nekrotischen Keilen und punkt- und streifenförmigen Eiterherden, stark marmorirt.

Magen und Darm normal.

Bl as enschleimhaut grau verfärbt, stellenweise stark injicirt, mit trüber Flüssigkeit bedeckt.

Leber gross, zeigt im rechten Lappen eine narbige Einziehung, von der Bindegewebszüge strahlenförmig in die Leber hineinziehen.

Beckengefässe rechts frei, links Vena iliaca bis zur Vereinigung mit der Cava von einem gemischten Thrombus erfüllt.

Diagnose. Combinirte Systemerkrankung. Endocarditis chron.der Mitralis. Nephritis parenchymatosachron., Pyelitis, Cystitis.

\section{Untersuchung des Rückenmarks.}

Das Rückenmark, sowie Stiicke von beiden Nn. crurales und phrenici werden in Müller'scher Flüssigkeit gehärtet und nach Behandlung mit Alcohol in einzelnen Stiucken in Celloidin eingebettet. 


\section{Makroskopische Beschreibung der Stücke.}

$\mathrm{O}$ beres $\mathrm{Halsmark.} \mathrm{Hinterstränge:} \mathrm{Intensive} \mathrm{Erkrankung} \mathrm{eines}$ von der Peripherie bis zur Mitte der Fissura posterior reichenden, keilförmigen, ventralwärts sich zuspitzenden, beiderseits symmetrischen Streifens. Nach aussen folgt eine schmale Zone wenig veränderten Gewebes, dann eine schmale, stark degenerirte, den inneren Degenerationsstreifen leicht bogenförmig umgreifende Zone, die sich von der Peripherie bis fast zur Commissura posterior erstreckt und gleichfalls symmetrisch angeordnet ist. Die äusseren Partien der Burdach'schen Stränge, besonders die Wurzelzonen, normal.

Seitenstränge. Kl.S. beiderseits symmetrisch stark degenerirt. Py.S. zeigen eine nur angedeutete Degeneration, die erst in der Höhe der 4. Cervicalwurzel deutlich ausgeprägt wird. Etwas stärker ist die Degeneration in den Py.V., streng symmetrisch (Taf. I-IV, Fig. 4 1 ).

Halsanschwellung. Die Degeneration der Hinterstränge intensiver geworden. Der Streifen an der Fissura posterior reicht jetzt bis zur hinteren Commissur. Der äussere Streifen ist etwas breiter geworden, biegt in den unteren Partien der Anschwellung dicht oberhalb der Wurzelzone nach aussen um, so dass er nicht zur Peripherie, sondern zum Hinterhorn heranreicht. Dafür befindet sich am lateralen Theil der inneren Degenerationsstreifen ein kleiner, fleckenförmiger Degenerationsherd an der Peripherie, der die hintere Wurzelzone jedoch freilässt. Degeneration der Kl.S. noch immer sehr intensiv, jedoch nach abwärts schwächer werdend.

Py.S. schwach degenerirt, etwas stärker die Py.V. Vereinzelte Degenerationsherde in Vorderseitenstrangresten (Taf. I-IV, Fig. 42).

Unteres Halsmark. Die Hinterstränge zeigen einen intensiven Degenerationsstreifen an der Fissura posterior von der Peripherie bis dicht an die Commissura posterior. Der laterale Degenerationsstreifen sehr schmal.

Kl.S. mässig intensiv degenerirt.

Py.S. etwas stärker degenerirt, wie in den oberen Partien.

Py.V. sehr intensive Degeneration (Taf. I-IV, Fig. 43 ).

Oberes Brustmark. Intensive Degeneration an der Fissura posterior, doch beginnen die Degenerationsstreifen lateral wärts auseinanderzurücken und in der Mitte eine Zone normalen Gewebes frei zu lassen. An der Peripherie biegen sie hakenförmig nach aussen um und reichen in besonders starker Degeneration fast bis zum Hinterhorn. Ein lateraler Degenerationsstreifen nicht mehr sichtbar.

Kl.S. und Py.Str. (Seiten- und Vorderstränge) in typischer Weise beiderseits degenerirt. Daneben, ganz vereinzelte Degenerationsflecke in den Vorderstrangresten (Taf. I--IV, Fig. 44.)

Mittleres Brustmark. Die beiden Degenerationsstreifen der Hinterstränge vollständig auseinander gerückt, peripher stärker als central; peripher erreicht die sehr intensiv gewordene Degeneration fast das Hinterhorn. Kl.S. sehr schwach degenerirt. Starke Degeneration der Py.S. und Py.V. Geringe Flecken in Vorder- und Seitenstrangresten. 
Unteres Brustmark. Sehr intensive Degeneration der Hinterstränge, an einzelnen Stellen nicht ganz symmetrisch. Zwischen den auseinandergewichenen Degenerationsstreifen an der Fissura posterior ein feiner degenerirter Streifen erkennbar.

KI.S. frei.

Py.S. und Py.V. entschieden schwächer degenerirt wie oben, jedoch ist die Degeneration noch immer deutlich ausgesprochen (Taf. I-IV, Fig. 45 ).

Oberes Lendenmark. Hinterstränge: Zwei breite intensive Degenerationsstreifen längs der Fissura posterior, nach der hinteren Commissur zu leicht nach aussen anseinanderweichend. Wurzelzone frei.

Py.S. and Py.V. nur noch schwach degenerirt (Taf. I-IV, Fig. $4_{6}$ ).

Lendenanschwellung. In der hinteren Hälfte der Hinterstränge beiderseits ein Degenerationsstreifen längs der Fissura posterior. Wurzelzone frei.

Py.S. schwach degenerirt.

Py.V. frei (Taf. I-IV, Fig. $4_{7}$ ).

Sacralmark. Schwache Degeneration in der Peripherie der Hinterstränge an der Fissura posterior, sonst normaler Befund.

\section{Mikroskopische Untersuchung.}

Die angewandten Färbemethoden sind dieselben, wie im ersten Falle.

1. Hinterstränge.

Sacralmark. Vereinzelte gequollene Fasern in der Peripherie, sowie an der Fissura posterior. Pia mater verdickt, mit leichter Kernwucherung, sendet verdickte Fortsätze in die Hinterstränge hinein. Hintere Wurzeln frei.

Am Uebergang zum Lendenmark tritt im rechten Hinterstrang dicht an der Fissura posterior eine stärkere Degeneration anf, während links an derselben Stelle nur wenige Fasern gequollen sind. Beiderseits in der Wurzelzone spärliche degenerirte Fasern.

Unteres Lendenmark. Starke Degeneration, rechts etwas ausgesprochener wie links, von der die Wurzelzone fast ganz frei bleibt. Auch an der Fissura posterior ein schmaler Längsstreifen nicht degenerirt. Im Uebrigen lässt die Degeneration das vordere Drittel des Hinterstrangs frei und verbreitert sich nach der Peripherie zu. Leichte Verdickung der Pja mater. Hintere Wurzeln normal (Taf. I-IV, Fig. 4 7).

Lendenanschwellung. Starke, annähernd symmetrische Degeneration, am stärksten in geringer Entfernung von der Fissura posterior. In den lateralen Partien die hintere Wurzelzone nur schwach degenerirt, ventralwärts degenerirte Fasern am Rande der grauen Substanz. An einzelnen Stellen nimmt die Degeneration in der Umgebung grösserer Gefässe mit verdickten Wandungen einen fleckenförmigen Charakter an. An einer solchen Stelle, dicht unterhalb der Commissura posterior, eine perivasculäre Blutung. Pia leicht verdickt; von derselben aus ziehen breite Bindegewebszigge tief in die Substanz der Hinterstränge hinein. Hintere Wurzeln frei.

Oberes Lendenmark. Die Degeneration der Hinterstränge hat 
an Intensität und Extensität entschieden zugenommen, ist am stärksten in der Mitte zwischen Fissura posterior und Hinterhorn, am schwächsten in der Wurzelzone, deren lateraler Theil frei ist. Der oben erwähnte fleckenförmige Charakter der Degeneration tritt hinter dem strangförmigen vollkommen zuritck. Pia wenig verdickt. Hintere Wurzeln frei (Taf. I-IV, Fig. 46.)

Unteres Brustmark. Die Degeneration breitet sich allmählich weiter nach aussen aus, lässt nur noch einen schmalen Streifen der hinteren Wurzelzone frei; dagegen ist die Lissauer'sche Randzone degenerirt. Im Gebiet der Goll'schen Stränge fleckförmige, jedoch beiderseits symmetrische Degeneration mit ungemein reichlicher Bindegewebsentwickelung: In diesen Flecken ist kaum noch eine erhaltene Nervenfaser nachzuweisen; dagegen sind sie vollgestopft mit Fettkörnchenzellen mit stark tingirtem Kern. Nach vorn reicht die Degeneration bis nahe an die Commissura posterior.

Pia deutlich verdickt; die Gefässe derselben zeigen verdickte Wandungen mit einzelnen Blutextravasaten. Hintere Wurzeln nicht degenerirt (Taf. I-IV, Fig. 45.)

Mittleres Brustmark. Die Degeneration hat jetzt die ganze hintere Wurzelzone ergriffen, ohne dass die hinteren Wurzeln Degeneration zeigten. Frei von Degeneration ist nur ein schmaler Streifen an dem peripheren Abschnitt der Fissura posterior. Die degenerirten Partien, besonders in den Goll'schen Strängen, zeigen auch hier starke Bindegewebsentwickelung und reichliche Fettkörnchenzellen. Pia mässig verdickt. Gefässe prall gefüllt, mit verdickten Wandungen. Lissaner'sche Randzone degenerirt.

Oberes Brustmark. Ziemlich diffuse Erkrankung der Hinterstränge einschliesslich der Wurzelzone. Hintere Wurzeln nicht degenerirt, nur an einer Stelle (in der Höhe des 5. und 6. Brustnerven) vereinzelte degenerirte Fasern in der rechten hinteren Wurzel. Pia mater zeigt normales Verhalten (Taf. I-IV, Fig. 44).

Unteres Halsmark. Ziemlich intensive, sich ïber das ganze Gebiet der Hinterstränge erstreckende Degeneration, am intensivsten an der Fissura posterior und am Uebergang von Goll'schen und Burdach'schen Strängen. Auch die Wurzelzone ergriffen, jedoch weniger intensiv wie im oberen Brustmark. Die Gefässe prall gefüllt, mit verdickten Wandungen; um dieselben herum zum Theil frische Blatungen, zum Theil eine mit Säurefuchsin sich diffus roth färbende, hyalinartige Masse, welche die Nervensubstanz an dieser Stelle total zerstört hat und in der noch entfärbte rothe Blatkörperchen erkennbar sind.

Pia mater nicht verdickt. Hintere Wurzeln frei. (Taf. I-IV, Fig. 43.)

Halsanschwellung. Es machen sich deutlich 2 Degenerationsstreifen auf jeder Seite bemerkbar, der eine an der Fissura posterior, von der Peripherie nach dem Centrum sich verschmälernd und das vorderste Drittel der Fissura posterior freilassend, der andere an der Grenze von Goll'schen und Burdach'schen Strängen. Die ïbrige Substanz der Hinterstränge zeigt jedoch auch zahlreiche degenerirte Fasern; nur die hintere Wurzelzone ist fast ganz frei. Auch in dieser Höhe Blutungen 
und amorphe Massen um die Gefässe herum, jedoch nicht so reichlich, wie im unteren Halstheil. Pia nicht verdickt. Hintere Wurzeln frei (Taf. I-IV, Fig. 4.2.)

$\mathrm{Oberes} \mathrm{Halsmark.} \mathrm{Die} \mathrm{Degeneration} \mathrm{ungefähr} \mathrm{in} \mathrm{derselben} \mathrm{Aus-}$ dehnung und Anordnung, wie in der Halsanschwellung. Es besteht utberall vollkommene Symmetrie der Degenerationszone beider Hälften. Hintere Wurzelzone fast ganz frei. Hintere Wurzeln normal. Pia mater leicht verdickt (Taf. I-IV, Fig. 4ı). worden.

Höhere Abschnitte des Centralnervensystems sind nicht aufbewahrt

\section{Seiten- und Vorderstränge.}

Sacralmark. Vereinzelte gequollene Fasern in den Py.S. Pia mater leicht verdickt. Im Gebiet der Vorderstränge an einzelnen Stellen Randdegeneration.

Unteres Lendenmark. Vereinzelte degenerirte Fasern in Py.S. und Py.V. Pia stark verdickt. Vordere Wurzeln frei (Taf. I-IV, Fig. $4 r)$.

Lendenanschwellung desgleichen.

Oberes Lendenmark. Die Degeneration der Py.V. sehr intensiv geworden, Py.S. wesentlich schwächer degenerirt. Auch in den Vorderseitenstrangresten einzelne gequollene Fasern. Pia beträchtlich verdickt mit leichter Randdegeneration. Vordere Wurzeln frei (Taf. I-IV, Fig. $4_{6}$ ).

Die einzelnen Nervenfasern in den degenerirten Partien zeigen deutliche Vergrösserung der Myelin-Scheide, in welcher zahlreiche Fettkörnchenzellen mit intensiv gefärbtem Kern liegen. Der oft noch erhaltene, bei der Ira van Guison'schen Färbung roth gefärbte Axencylinder hebt sich scharf gegen die blau tingirten Kerne ab.

Unteres Brustmark. Typische Degeneration der Py.S. und Py.V. Vereinzelte gequollene Fasern in Vorderseitenstrangresten. Die Gegend der KI.S. normal. Pia verdickt mit geringer Randdegeneration. Vordere Wurzeln frei (Taf. I-IV, Fig. 45 ).

Mittleres Brustmark. Py.S. und Py.V. stark degenerirt. In den Kl.S. an der Grenze der Py.S. degenerirte Fasern. Doch bleibt zwischen Pia mater und Degeneration eine schmale Zone vollkommen erhaltener Fasern, die zu den KI.S. gehören. Etwas reichlichere degenerirte Fasern in dem übrigen Theil der Vorder- und Seitenstränge. Pia nicht verdickt, vordere Wurzeln frei.

Oberes Brustmark. Py.S. und Py.V. total degenerirt. Auch die KI.S. degenerirt, zeigen jedoch an der Peripherie eine Reihe erhaltener Fasern. Nur vereinzelte gequollene Fasern in dem Rest der Vorder- und Seitenstränge. Pia nicht verdickt, vordere Wurzeln frei (Taf. I-IV, Fig. $4_{4}$ ).

Unteres Halsmark. KI.S. und Py.S. und Py.V. intensiv in typischer Weise degenerirt. Vereinzelte gequollene Fasern in den übrigen Partien, fast sämmatlich mit erhaltenem Axencylinder. Pia nicht verdickt, vordere Wurzeln frei. Neben den hinteren Wurzeln befindet sich eine kleine Zone normaler Fasern (Taf. I-IV, Fig. 43 ). 
Mittleres Halsmark. Die Degeneration der KI.S. sehr intensiv, doch bleibt ein kleines Feld neben dem Hinterhorn frei. Leichte Abnahme der Degeneration, zuerst in Py.S., dann in Py.V. Sonst nur sehr vereinzelt degenerirte Fasern. Pia leicht verdickt, vordere Wurzeln frei (Taf. I-IV, Fig. $4_{2}$ ).

Oberes Halsmark. Kl.S. sehr intensiv degenerirt, doch lässt sich auch die Degeneration der Py.S. and Py.V., wenn auch mit abnehmender Intensität, bis zu den obersten Abschnitten verfolgen.

Mässige Degeneration anderer Fasern. Pia leicht verdickt, vordere Wurzeln frei (Taf. I-IV, Fig. 41).

\section{Graue Substanz.}

Sacralmark. Gefässe zeigen verdickte Wandungen, einzelne perivasculäre Blutungen. Ganglienzellen normal.

Unteres Lendenmark. Auf der linken Seite in der Mitte zwischen Vorder- und Hinterhorn ein grösseres, in der Weigert'schen Färbung blassgelb gefärbtes Exsudat, in dem rothe Blutkörperchen in mässig grosser Zahl erkennbar sind. An dieser Stelle sind die markhaltigen Nervenfasern völlig zu Grunde gegangen. Auch in der Umgebung machen dieselben einen gequollenen Eindruck; Blutungen sind in kleiner Ausdehnung auch dort nachzuweisen. Die Ganglienzellen der Vorderhörner beiderseits vollkommen normal, auch die Markfaserung der grauen Substanz im Uebrigen erhalten. Die Blutgefässe sind prall gefüllt, haben verdickte Wandungen; auch auf der rechten Seite sind einzelne perivas. culäre Blutungen nachweisbar.

Lendenanschwellung. In beiden Hälften der grauen Substanz theils freie, theils perivasculär gelegene, kleine Blutungen nachweisbar. Die feine Markfaserung der grauen Substanz erhalten. Die Ganglienzellen der Vorderhörner der Mehrzahl nach erhalten; an einzelnen lässt sich jedoch beträchtliche Vacuolisirung bei erhaltenem Kern nachweisen (Taf. I-IV, Fig. $6_{1}$ u. 2 ).

Oberes Lendenmark. Sehr vereinzelte kleine Blutungen. Gefässe prall gefüllt. Die nervösen Elemente gut erhalten.

Unteres Brustmark. Sehr spärliche Ganglienzellen in den Vorderhörnern. Die in den unteren Partien gut entwickelten Clarke'schen Säulen zeigen nach oben hin eine auffallend geringe Zabl von Ganglienzellen. Sehr reichliche Gefässbildung mit spärlichen, perivasculären Blutungen.

Im mittleren und oberen Brustmark dieselben Verhältnisse.

Unteres Halsmark. Es treten um die Gefässe herum zwischen zwischen Vorder- und Hinterhorn hyaline Massen und Blutungen auf. Sehr reichlich liegen diese Massen um die Gefässe des Sulcus ant. über der Commissura ant. und erstrecken sich von hier in die graue Substanz hinein. Ganglienzellen erhalten.

Markfaserung etwas spärlicher als normal.

Halsanschwellung. Anch hier perivasculäre, kleine Blutungen unterhalb der Ganglienzellen des Vorderhorns. Letztere in der inneren und mittleren Gruppe an Zahl vermindert, zum Theil deutlich atrophisch. 
Auch im Sulcus ant. Extravasate und rothe Blutkörperchen in der Umgebung der Gefässe.

Oberes Halsmark. Ganglienzellen der Vorderhörner in der inneren und ganz besonders der mittleren Gruppe an Zahl vermindert und zum Theil atrophisch. Sulcus ant. frei von Extravasaten. Markfaserung zum Theil zu Grunde gegangen. Die von den hinteren Wurzeln durch die Hinterhörner nach vorn ziehenden Fasern treten, als gut erhalten, besonders stark hervor. Dentliche perivasculäre Blutungen, einige von grösserer Ausdehnung.

Die Untersuchung des $\mathrm{N}$. cruralis dext. und sin. ergiebt normales Verhalten. In den $\mathbf{N}$. phrenici sehr vereinzelte Fasern degenerirt, die Mehrzahl derselben völlig normal.

In diesem Falle wurde die Diagnose intra vitam auf eine Erkrankung der Hinterstränge mit Leptomeningitis und secundärer Betheiligung der Seitenstränge gestellt. Dass die Hinterstränge intensiv erkrankt sein mussten, dafür sprachen das Verhalten der Patellarreflexe, die bereits bei der Aufnahme sehr schwach und schon wenige Tage später überhaupt nicht mehr auszulösen waren, ferner die Sensibilitätsstörung an den Unterschenkeln und dem Unterleib, die, anfangs kaum angedeutet, schliesslich zu totaler Aufhebung der Sensibilität and Schmerzempfindung gesteigert war, die Blasen- und Mastdarmstörungen, und die in den letzten Stadien beobachtete ausgesprochene Ataxie der oberen Extremitäten. Dem gegenüber traten die von der Erkrankung der Pyramidenbahnen im Allgemeinen und auch in unserem ersten Fall herrührenden spastischen Symptome zurück; bis auf krampf hafte, unwillkürliche, zeitweise auftretende Zuckungen in den Beinen fehlen dieselben vollkommen. Kein Fussclonus, keine Rigidität der Musculatur waren an den unteren Extremitäten vorhanden, und auch an den oberen Extremitäten fehlten selbst bei Beginn der Parese spastische Symptome vollkommen. Es blieb also als einziges, auf die Erkrankung der Pyramidenbahnen zu beziehendes Symptom die zuletzt vollkommene Paralyse der unteren Extremitäten und die in den letzten Tagen auftretende Parese der Arme ibrig. Eine Leptomeningitis wurde auf Grund der in der Wirbelsäule vorhandenen Schmerzen und der Empfindlichkeit derselben auf Druck, angenommen.

Arnold ${ }^{1}$ ) hat versucht, die combinirten Systemerkrankungen nach dem klinischen Bild in spastische und paraplegisehe Formen einzutheilen. Doch es ist wohl kaum möglich, an dieser Classificirung festzuhalten; denn einerseits werden eine grosse Reibe der ein-

1) Ueber combinirte Erkrankung der Stränge des Rückenmarks. Virchow's Archiv. Bd. CXXVII. 1892. 
schlägigen Fälle, die anfänglich zu den entschieden spastischen Formen gehörten, im weiteren Verlauf ausgesprochen paraplegisch, anderseits lässt es sich bei einer Reihe der vom Anfang der Beobachtung an zur paraplegischen Form zu rechnenden Fälle nicht mit Sicherheit feststellen, ob dieselben nicht nur zu spät unter ärztliche Aufsicht gelangten und in den Anfangsstadien spastische Symptome dargeboten hatten. Westphal hat bereits 1878 auf das Schwankende des Symptomencomplexes hingewiesen. „Bei einer combinirten strangförmigen Erkrankung der Hinter- und Seitenstränge tritt Rigidität der Musculatur und spastische Contractur nicht ein, wenn die Erkrankung der Hinterstränge sich bis in den Lendentheil des Rückenmarks herab erstreckt, und die als Wurzelzone bezeichneten Partien der Hinterstränge von der Degeneration betroffen sind."1) Da nun bald die Seitenstränge, bald die Hinterstränge früher befallen sind, die Erkrankung der letzteren ausserdem im Lendentheil bald nur die inneren Partien, bald auch die Wurzelzone ergreift, so ist die Mannigfaltigkeit des klinischen Bildes leicht verständlich. Es ist daher von vorn herein nicht eine derartige Conformität des Krankheitsverlaufes zu erwarten, wie sie den einfachen Systemerkrankungen, vor allem der Tabes und der reinen Form der spastischen Spinalparalyse zukommt.

Was nun den pathologisch-anatomischen Befund in diesem Falle betrifft, so waren die Hinterstränge vom obersten Sacralmark bis zum obersten Halsmark erkrankt; dabei nimmt die Intensität und Extensität der Erkrankung vom Sacralmark bis zum mittleren Brustmark andauernd $\mathrm{zu}$, um von der Halsanschwellung nach oben hin allmählich wieder geringer $\mathrm{zu}$ werden. Die Art der Degeneration unterscheidet sich wesentlich von der der Tabes; sie zeigt im Lendenmark nur wenige degenerirte Fasern in der hinteren Wurzelzone, während der innere Theil der Burdach'schen Stränge und die Goll'schen Stränge intensiv erkrankt sind; dabei bleibt jedoch eine schmale Zone unmittelbar an der Fissura posterior and die Partie an der Comissura post. frei von der Degeneration. Im Brustmark wird allerdings auch die Wurzelzone stärker ergriffen, aber doch nicht annähernd so intensiv wie die übrigen Abschnitte der Hinterstränge. Im Halsmark bilden sich dann neben einer schwächeren diffusen Erkrankung der übrigen Partien vor allen zwei stark degenerirte Streifen an jedem Hinterstrang aus, der eine keilförmig an der

1) C. Westphal, Ueber combinirte (primäre) Erkrankung der Rückenmarks* strănge. Archiv f. Psych. Bd. VII. 1878. 
Fissura post., vielleicht nur eine secundäre aufsteigende Degeneration tiefer unten ergriffener Fasern darstellend, der andere an der Grenze von Goll'schem und Burdach'schem Strang, den ersteren bogenförmig umfassend. In der Wurzelzone lassen sich von der Halsanschwellung ab nur noch wenige erkrankte Fasern nachweisen. Die Pia mater ist vornehmlich im Brustmark verdickt, jedoch nur in mässigem Grade. Noch mehr aber wie in dem ersten Falle, tritt bier die völlige Unversehrtheit der hinteren Wurzeln hervor, im schärfsten Gegensatz zur Tabes.

Die Pyramidenstränge zeigen bereits im untersten Lendenmark einzelne degenerirte Fasern in Seiten- und Vordersträngen. Aber erst im oberen Lendenmark tritt stärkeres Befallensein derselben auf, erstreckt sich durch das ganze Brustmark und untere Halsmark in typischer Weise in Seiten- und Vordersträngen und nimmt von der Halsanschwellung an nach oben ab, lässt sich jedoch bis ins oberste Halsmark deutlich nachweisen. Dagegen beginnt die Kleinhirnseitenstrangbahn erst im mittleren Brustmark mit sehr schwacher Degeneration; auch im oberen Brustmark ist dieselbe noch nicht sehr intensiv, um dann das ganze Halsmark hindurch in voller Entwicklung aufzutreten. In den übrigen Partien der Seiten- und Vorderstränge zeigen sich, namentlich im Brustmark, eine Reihe degenerirter Fasern, ohne dass es sich um eine Strangerkrankung handelte. Die Pia mater über den Seitensträngen ist deutlich verdickt, im Lendenmark von leichter Randdegeneration begleitet. Um so auffälliger ist es, dass im unteren Brustmark die degenerirten Py.S. von der Pia durch die vollkommen erhaltenen Fasern der KI.S. getrennt sind. Dieses Verbalten widerlegt wohl am besten für diesen Fall die Annahme einer durch die Leptomeningitis berrorgerufenen Seitenstrangerkrankung. Wir wollen erst später im Zusammenhang mit den anderen Theorien auf die Berechtigung dieser Annahme im Allgemeinen eingehen.

Im Grossen und Ganzen entspricht die Vertheilung der Degeneration auf die einzelnen Fasersysteme und die Ausdehnung derselben in diesem Falle den Verbältnissen des zuerst beschriebenen. Es fanden sich nun auch hier Veränderungen der grauen Substanz, die zwar nicht so ausgedehnt sind wie in dem anderen Falle, aber doch die Grenze des Normalen entschieden überschreiten. Es handelt sich um ziemlich umfangreiche Blutungen und Exsudate und spärliche Vacuolenbildung der Ganglienzellen des Vorderhorns im Lendenmark, um starke Entwicklung prall gefüllter Blutgefässe durch das ganze Rückenmark, um spärliche perivasculäre Blutungen und deutlichen 
Zellenschwund der Clarke'schen Säulen im Brustmark, und endlich um wieder etwas stärkere Blutungen, verbunden mit starken Exsudatmassen im Sulcus ant. an der vorderen Commissur und in der grauen Substanz selbst, im Halsmark. In den oberen Abschnitten des letzteren fällt ausserdem ein Schwund der Ganglienzellen der inneren und vor allem der mittleren Region der Vorderhörner auf, zugleich eine wesentliche Abnahme der feinen Markfaserung. Die Medulla oblongata ist in diesem Falle leider nicht aufbewahrt worden, so dass ein abschliessendes Urtheil über das Aufhören der Degeneration in derselben nicht zu fällen ist.

War der anatomische Befund im Ganzen wohl geeignet, das Krankbeitsbild zu erklären, so erfordern doch zwei Punkte noch eine eingehendere Betrachtung, das Verhalten der Patellarreflexe und die in den letzten Tagen eingetretene Zwerchfellslähmung. Wenn hier auch nicht, wie bei den typischen Tabes-Fällen, das Erlöschen des Patellarreflex es fast allen anderen Symptomen vorausging, so war derselbe doch bei der Aufnahme in das Krankenhans, also zu einer Zeit, wo die Beine schon stark paretisch waren, rechts nur noch mit Hulfe des Jendrassik'schen Handgriffs, links überhaupt nicht mehr deutlich auszulösen, und wenige Tage später war er beiderseits erloschen. Man musste daher, nach der von Westp hal aufgedeckten. Localisation der Reflexbahnen in den Hintersträngen, eine intensive Erkrankung der hinteren Wurzelzone im oberen Lendenmark erwarten, und dies um so mehr, da die den Patellarreflex im Allgemeinen steigernde Erkrankung der Seitenstränge in Betracht kam. Es fanden sich nun allerdings einige Fasern in der Wurzelzone des oberen Lendenmarks degenerirt, aber doch in so versehwindender Zahl, dass nach den vorliegenden Erfahrungen diese Degeneration allein das Erlöschen des Patellarreflexes kaum bedingen konnte. Eine Untersuchung der Nn. crurales ergab vollkommen normale Verbältnisse, so dass neuritische Processe nicht zur Erklärung herangezogen werden konnten. Da sich jedoch in der grauen Substanz des Lendenmarks ziemlich beträchtliche Blutungen und Vacuolisirungen der Vorderhornzellen fanden, so könnte möglicherweise hier die Ursache der Leitungsunterbrechung in der Reflexleitung zu suchen sein.

Die Zwerchfellslähmung war eine sehr ausgesprochene; die Athmung wurde mubsam, nicht beschleunigt, war ausschliesslich costal mit Zuhülfenahme der Halsmusculatur. Die Untersuchung ergab in den Nn. phrenici nur wenige degenerirte Fasern, dagegen schienen die dem Ursprung des $N$. phrenicus im oberen Halsmark entsprechenden Ganglienzellen der mittleren Gruppe des Vorderhorns entschieden 
vermindert und atrophisch. Es wird sich also die Zwercbfellslähmung am Besten als Affection des Phrenicuskerns auffassen lassen. Im übrigen war weder an den Muskeln der unteren Extremitäten noch an denen der oberen eine Entartungsreaction nachweisbar; auch entsprach die Abmagerung der Musculatur vollkommen der allgemeinen Macies. Es war daher gegeniuber der amyotrophischen Lateralsklerose, bei welcher bekanntlich auch Erkrankungen der Hinterstränge und der ausserhalb der Pyramidenbahnen gelegenen Theile der Vorderseitenstränge vorkommen, klinisch ein scharfer Unterschied gegeben; dem entsprach des völlige Erhaltensein der die Extremitäten versorgenden motorischen Ganglienzellen.

Eine Querschnittsmyelitis mit auf- und absteigenden Degenerationen war aus denselben Gründen wie in dem ersten Fall zurückzuweisen. Die Degeneration sämmtlicher befallener Stränge liess sich damit nicht vereinbaren. Wir baben es also anch bier wieder mit einer ihrem klinischen und pathologiseh-anatomischen Befunde nach sich scharf von allen bekannten Rïckenmarkskrankheiten absondernden Erkrankung, mit besonderer Betheiligung der Hinterstränge (obne hintere Wurzelzone und hintere Wurzeln), Pyramidenseitenund Vorderstränge und Kleinhirnseitenstrangbahnen und Erkrankung der grauen Substanz zu thun.

III. Fall. Gustav Reichert, 29 Jahre ait, Arbeiter. Aufgenommen 8. Februar 1893, gestorben 10. Juni 1893.

In früheren Jahren wiederholt Gelenkrheumatismus. Mitte December 1892, angeblich infolge von Durchnässung, Erkrankung mit Steifigkeitsgefühl in den Beinen und Schmerzen in Fussgelenken und Wadenmusculatur. 3 Wochen später plötzlich auftretende hochgradige Schwäche in den Beinen, bald darauf Urinbeschwerden. Bei der Aufnahme in das Krankenbaus schlaffe Paraparese der Beine mit erhaltenem Patellarreflex ohne motorische Reizerscheinungen. An den Beinen geringe Hyperästhesie. Leichte Stuhl- und Urinbeschwerden. Druckempfindlichkeit der Wirbelsäule. Im weiteren Verlauf andauernde Zunahme der Beinlähmung. 29. Mai totale Paralyse derselben. Zugleich langsame Abnahme der Patellarreflexe, die vom 29. Mai an gleichfalls total erloschen sind. Von Anfang April an Herabsetzung der Sensibilität und Schmerzempfindung an den Beinen und dem unteren Theil des Abdomens; am 9. Mai daseibst Aufhebung der Sensibilităt, am 29. Mai der Schmerzempfindung. Die Arme, anfangs völlig normal, verlieren in den letzten Stadien der Krankheit an grober motorischer Kraft, ohne paretisch zu werden. Tricepsreflex erhalten. Ende Mai leichte Hyperästhesie in den Armen. Zunabme der Blasen- und Mastdarmstörungen, schliesslich Incontinentia urinae et alvi. Pupillarreflex erbalten; keine anderen Hirnsymptome. Blutbefund normal. Rasch zunehmende Macies. Am 10. Juni 1893 geht Patient unter den Zeichen der Zwerchfellslähmung zu Grunde.

Normaler Hirnbefund. Im Rückenmark Degeneration der Hinterstränge, der Py.S. und Py.V., der KI.S. Unregelmässige und schwächere Degeneration in den 
äbrigen Theilen der Vorderseitenstrănge, besonders im Brustmark. In der grauen Substanz Blutungen, theilweiser Schwund des feinen Fasernetzes, partielle Atrophie und Vacuolisirung der motorischen Ganglienzellen, Atrophie der Zellen der Clarke'schen Săulen. Leptomeningitis.

Anamnese. Vater an unbekannter Krankheit gestorben, Mutter gesund. Von 2 Geschwistern leidet eines seit 11 Jahren an Rhenmatismus. Als Kind Windpocken und Masern. Mit 11 Jahren echte Pocken. Mit 15 Jahren 9 Monate dauernder Gelenkrheumatismus mit anschliessender Herzaffection. Seit dieser Zeit hat Patient oft Herzbeschwerden, so dass 'er schwere Arbeit nicht verrichten kann; er bekommt oft, ohne besondere Veranlassung starke schnell voriibergehende Anfälle von Dyspnoe. Bis 1891 hatte Patient jedes Jahr im Frühling und Herbst Gelenkrheumatismus mit heftigen Schmerzen in den verschiedensten Gelenken, besonders aber den Fussgelenken. Von Mitte September bis Anfang November 1892 machte Patient eine sechswöchentliche Uebung mit, bei der er zahlreichen Erkältungsschädlichkeiten (Durchnässung beim Marschiren, Liegen auf kaltnassem Boden) ausgesetzt war. Er vertrug den Dienst nur schlecht, theils wegen Athembeschwerden, theils infolge bei längerem Laufen sich bemerkbar machender Schwäche in den Beinen vom Knie abwärts. Mitte December 1892 bemerkte Patient ausgesprochene Steifigkeit in Knie- und Fussgelenken beim Gehen. Gleichzeitig traten krampfartige Schmerzen in den Fusssohlen auf, die später auch die Wadenmusculatur befielen. Leichte vorübergehende Schwellung der Knöchel. Etwa 3 Wochen später (erste Januarwoche 1893) bekam Patient plötzlich während der Nacht ein derartiges Schwächegefühl in beiden Beinen, dass er nicht mehr gehen noch stehen konnte. Seit dieser Zeit muss er das Bett hüten. Es traten nun Schmerzen in den Oberschenkeln auf, zuerst in der Musculatur der Extensoren, dann in den Flexoren, von krampfartigem Charakter. Ende Januar verloren sich die Schmerzen; Patient empfand jedoch starke Steifigkeit und Schwäche in den Beinen, besonders unterhalb der Knie. Zeitweises Kribbelgefühl in den Füssen. Seit Anfang Februar stärkere Parästhesien, besonders Klagen über ein Kältegefühl, das gürtelartig um den Leib herum und vom Nabel abwärts bis zur Mitte der Oberschenkel empfunden wird, am stärksten an den Genitalien. Das Gefühl ist von krampfartigen Schmerzen von mässiger Intensität begleitet. Weiter abwärts an den Beinen tritt dieses Kältegefühl, verbunden mit Schmerzen, seltener und nur fleckenweise auf, besonders an den Schienbeinen. Im Kreuz treten gleichfalls zeitweise Schmerzen auf, namentlich bei ungeschickten Bewegungen. Seit 8 Tagen Urinbeschwerden; der Urin kann nur selten und mit grosser Mühe gelassen werden; seit derselben Zeit Stuhlgang angehalten.

Seit 5-6 Wochen etwas trockener Husten, $\mathrm{zu}$ dem in letzterer Zeit reichlicher Auswnrf getreten ist. Starke Nachtschweisse. Patient klagt über Schlaflosigkeit, will in letzter Zeit schlechter hören und sehen. Specifische Infection und Potus werden entschieden in Abrede gestellt.

Status praesons (10. Februar 1893). Grosser, kräftig gebauter Mann mit blassem Colorit. Patient liegt in passiver Riickenlage, vermag sich nicht allein aufzurichten. Die unteren Extremitäten vermag er 
activ nicht von der Unterlage $z$ a erheben; die Füsse werden nur auf derselben geschleift und die Beine etwas an den Leib angezogen. Diese Bewegungen werden kraftlos und träge ausgeführt. Passive Bewegungen frei, ohne Rigidität der Musculatur. Patient vermag denselben nur geringen Widerstand entgegen zu setzen, links besser als rechts. Auf Ataxie ist der geringen activen Beweglichkeit wegen nicht zu prüfen.

Patellarreflexe beiderseits von normaler Intensität.

Kein Patellar-, kein Fussclonus.

Plantarreflex beiderseits $z \mathfrak{u}$ erzielen, desgleichen Abdominalreflex. Die oberen Extremitäten völlig frei beweglich.

Tricepsreflex normal, kein deutlicher Vorderarmreflex.

Sensibilität wegen unsicherer Angaben des Patienten nicht genau zu prüfen, scheint jedoch iberall erhalten zu sein. An den Beinen scheint leichte Hyperästbesie zu bestehen.

Temperatursinn normal.

Patient klagt ïber Schmerzen in beiden Kniegelenken und Unterschenkeln, links stärker als rechts. Zeitweises Kribbeln in den Fusssoblen.

Keine Blasen-, keine Mastdarmlähmung.

Die Wirbelsäule olne Difformität; bei Beklopfen erscheint die ganze Brustwirbelsäule sehr empfindlich.

Keine Druckempfindlichkeit der Muskeln und Nervenstämme.

Sensorium îrei. Keine Gedächtnissschwäche, keine Sprachstörungen.

Pupillen gleichweit, von mittlerer Grösse, reagiren prompt anf Lichteinfall und Accommodation.

Augenbewegungen frei, kein Doppeltsehen.

Leichte Schwerhörigkeit.

Lung en normal.

Herz in normalen Grenzen. Spitzenstoss nicht fühlbar. An der Herzspitze dumpfes, systolisches Geräusch.

$\mathrm{Puls}$ regelmässig, 84 in der Minute.

Bauchorgane normal.

U rin goldgelb, klar, ohne Eiweiss-, Zucker- oder Diazoreaction. Indicangehalt vermehrt.

Stuhlgang regelmässig.

13. Februar. Druckempfindlichkeit der Brustwirbelsäule noch immer ausgesprochen. Entschiedene Hyperästhesie der Haut der Unterschenkel.

Leichte Beschwerden beim Uriniren.

17. Febrnar. Das Allgemeinbefinden des Patienten hat sich wesentlich gebessert.

Sehr geringe active Beweglichkeit der unteren Extremitäten. Patient ist nicht im Stande das passiv erhobene rechte Bein längere Zeit zu halten; dasselbe fallt langsam auf die Unterlage zurück. Das linke Bein vermag er hente ein Weniges tiber die Unterlage zu erheben.

Patellarreflexe beiderseits deutlich, nicht gesteigert.

Abdominalreflex fehlt rechts, ist links vorhanden.

Arme normal beweglich, keine Ataxie. Tricepsreflex dentlich.

Die unregelmässig localisirte Hyperästhesie der Haut der Unterschenkel besteht fort. 
Wirbelsäule heute nicht druckempfindlich. Patient klagt über reissende Schmerzen oberhalb des Beckens.

Keine Stuhl- und Urinbeschwerden.

Normale Reaction der Pupillen.

1. März. Die grobe motorische Kraft der Beine hat in letzter Zeit wesentlich abgenommen, links stärker als rechts. Keine Bewegungsbeschränkung in den Gelenken. Passive Bewegungen frei, keine Spásmen, keine Contracturen. Active Bew e glichkeit der Beine stark vermindert. Patient hebt dieselben wenige Centimeter in die Höhe, um sie sogleich wieder fallen zu lassen. Etwa bestehende Ataxie nicht zu prüfen.

Reflexe unverändert.

Arme normal. Keine Sensibilitätsstörungen.

8. April. Patient klagt ïber Stechen in den Fusssohlen, Kribbeln im Kreuz und den Armen, bauptsächlich in den Fingern und im linken Oberarm.

Urin und Stuhl frei.

Patient ist stark anämisch.

Die Beine liegen gerade auf der Unterlage mit auffallend schlaffer Musculatur. Rechts hochgradiger Pes equinus, links ist derselbe nur angedeutet.

Patient vermag die Beine nur wenig über die Unterlage zu erheben.

Die Dorsalflexion des rechten Fusses ist auf ein Minimum beschränkt, links ist dieselbe gut ausführbar. In Knie- und Hüftgelenken freie Beweglichkeit, desgleichen bei passiven Bewegungen in allen Gelenken.

Die grobe motorische Kraft der Beine bedentend herabgesetzt, besonders rechts.

Keine trophischen, keine vasomotorischen Störungen. Reflexe unverändert.

Lagegefuhl an den unteren Extremitäten erloschen. Hyperästlesie verschwunden. Es besteht jetzt sogar an den unteren Extremitäten und am Bauche eine leichte Hypästhesie.

Auch der Temperatursinn ist etwas herabgesetzt.

Die Arme sind activ und passiv frei beweglich; doch will Patient selbst eine leichte Abnahme der groben motorischen Kraft bemerken.

Die Tricepsreflexe sind sehr lebhaft.

Keine Druckempfindlichkeit der Wirbelsäule.

Prompte Reaction der Pupillen. Augenbewegungen frei. Andeutung von Nystagmus.

Blutbefund normal.

28. April. Patient klagt über Schmerzen in der linken Brustseite und Schulter. Er vermag sich nicht allein im Bett aufzurichten.

Beide Beine, besonders das linke, sind heute activ nur wenig von der Unterlage zu erheben. Beide Füsse stehen in ausgesprochener Spitzfussstellung. Dorsal- und Plantarflexion im linken Fussgelenk nur in geringem Masse möglich; rechts fast völlige Unbeweglichkeit im Fussgelenk. Im Kniegelenk kann das rechte Bein bis zum rechten, das linke sogar bis zum spitzen Winkel gebeugt werden. Die grobe motorische Kraft der Beine, namentlich rechts, stark herabgesetzt.

Motorische Reizerscheinungen sind bei der Untersuchung nicht zu constatiren, doch giebt Patient an, dass er bisweilen Zuckungen 
in den Beinen verspürt. „Dieselben werden unwillkürlich in die Höhe geschleudert". Passive Bewegungen vollkommen frei.

Patellarreflex beiderseits erhalten, aber schwächer geworden.

Patellar- und Fusselonus bestehen nicht.

Plantarreflex erloschen.

Cremaster-, Bauchdeckenreflexe fehlen.

Sensibilität und Schmerzempfindung an den unteren Extremitäten und am Bauch herabgesetzt.

Lagegefühl an den Beinen stark herabgesetzt. Der Temperatursinn fast erloschen.

Keine Druckempfindlichkeit der Nervenstämme.

Die active Beweglichkeit der Arme vollkommen frei, doch hat die motorische Kraft, besonders rechts, etwas abgenommen.

Triceps-Reflex, Vorderarm-Reflex beiderseits lebhaft.

Sensibilität, Temperatursinn in der oberen Körperhälfte normal.

Beklopfen des Schädels und der Wirbelsäule nicht schmerzhaft.

Pupillen gleich weit, reagiren prompt. Augenbewegungen frei, beim Blick nach links Nystagmus angedeutet.

29. April. Patient klagt tiber Schmerzen in der linken Brustseite. Temperatur leicht erhöht $\left(38,2^{\circ}\right)$.

Ueber der linken Lunge hinten unten Dämpfung und Knisterrasseln. Schleimiges, leicht blutig tingirtes Sputum.

30. April. Temperatur wieder abgefallen. Knisterrasseln nur anf der Höhe des Inspiriums im Gebiet der Dämpfung hörbar.

1. Mai. Ueber den Lungen normale Verhältnisse.

9. Mai. Auffallende Blässe. An beiden Lungen über den beiden untersten Rippen Dämpfung, hinten links bronchiales Exspirium, hinten rechts abgeschwächtes Athmen.

Beide Füsse in Spitzfussstellung mit ziemlich starkem, bis zum Knie reichendem Oedem.

Nur noch sebr geringe active Beweglichkeit der Beine zu constatiren. Patient vermag dieselben nur wenig an den Unterleib heranzuziehen. Dabei sind die Beine andauernd im Kniegelenk leicht fiectirt.

Die Parese ist eine vollkommen schlaffe; passive Bewegungen frei.

Zeitweise unwillkürliche Zuckungen der Beine.

Patellarreflex beiderseits ungemein schwach.

Plantarreflex beiderseits schwach auszulösen.

In den oberen Extremitäten leichte Herabsetzung der motorischen Kraft; keine Spasmen, keine Ataxie, kein Intentionstremor.

A uffallend lebhafter Triceps-Reflex.

Sensibilität. Die tactile Empfindung bis fast zum unteren Rippenrand aufgehoben. Die Schmerzempfindung an den unteren Extremitäten und am Bauche bis zur Nabelgegend berabgesetzt, am Riucken bis zur Lendengegend. An den oberen Extremitäten Sensibilität normal.

Muskelsinn und Lagegefühl an den unteren Extremitäten herabgesetzt, an den oberen intact.

Stuhlgang angehalten, geht nach Abfthrmitteln von selbst ab.

Es besteht retentio und incontinentia urinae. 
Pupillarreaction etwas träge, besonders rechts.

U rin braunroth klar, mit mässigem Indican-Gehalt, sonst normal.

Bei der faradischen Prüfung sind Nerven und Muskeln der unteren Extremitäten nur scbwer erregbar, doch giebt die Prüfung mit dem constanten Strom keine Umkehr des Zuckungsgesetzes.

An den Armen sind Muskeln und Nervenstämme mit mittleren faradischen Strömen gut erregbar; auch mit dem constanten Strom sind von den Nerven normale Zuckungen zu erzielen; schwerer erregbar ist die Musculatur, und an einzelnen Muskeln der Streckseite des Unterarms ist K.S.Z. = A.S.Z., ja die letztere scheint am Interosseus quartus der rechten Hand sogar grösser zu sein.

18. Mai. Am 17. Abends steigt die Temperatur plötzlich auf $40,0^{\circ}$, beträgt auch heute Morgen über 39,0 .

Patient klagt über Stiche in der linken Brusthälfte. Hinten links vom Angulus abwärts intensive Dämpfung, hinten rechts über den drei untersten Rippen Schallabschwächung. Hinten links über der Dämpfung abgeschwächtes Athmen mit spärlichem crepitirendem Rasseln auf der Höhe des Inspiriums.

A uswurf spärlich, rein schleimig.

Herzdämpfung normal, systolisches Geräusch iuber der Spitze.

28. Mai. Die Temperatur andauernd leicht erhöht. Hinten links vom Angulus abwärts noch immer intensive Dämpfung mit abgeschwächtem Athmen. Probepunction ergiebt ein seröses Exsudat.

29. Mai. Patient klagt über zeitweilig auftretende zuckende Schmerzen in den unteren Extremitäten und Kriebeln in den Füssen. In den oberen Extremitäten hat sich in letzter Zeit, besonders Nachts, das Gefuhl vollkommener Abgestorbenheit eingestellt.

Die nnteren Extremitäten jetzt total gelähmt.

Patellarreflex beiderseits erloschen.

Plantarreflex desgleichen. Kein Fuss-, kein Patellarclonus. Die grobe motorische Kraft der oberen Extremitäten wesentlich herabgesetzt, doch kann Patient dieselben frei bewegen. Triceps- und Vorderarmreflex schwächer geworden.

Während die Verhältnisse der Sensibilität an den unteren Extremitäten unverändert sind, zeigt sich heute an den Armen zum ersten Male eine leichte Hyperästhesie.

Am Rumpf ist die Störung der Sensibilität etwas höher hinaufgeschritten.

Incontinentia urinae et alvi.

6. Juni. Ungemein kachectisches Aussehen.

Totale Paralyse der Beine mit starkem Oedem bis zur Schenkelbeuge.

Passive Bewegungen frei.

In den Armen Herabsetzung der groben motorischen $\mathrm{K}_{\mathrm{raft}}$, jedoch keine Spasmen, keine Ataxie, kein Intentionstremor. Tricepsreflex sehr schwach.

Grosser Decubitus am Kreuzbein, kleinerer an Malleolen und Hacken.

Respiration mühsam, fast rein costal, ohne Zwerchfellsaction.

Die Wirbelsäule beim Beklopfen empfindlich, besonders im Brusttheil. Sensorium frei. Keine Hirnsymptome. 
Beide Pupillen reagiren schwach, aber deutlich auf Lichteinfall, besser auf Accomodation.

Augenhintergrund normal.

Bei extremen Augenbewegungen deutlicher Nystagmus.

10. Juni. Rasche Verschlechterung des Allgemeinbefindens.

Exitus letalis.

Klinische Diagnose. Combinirte Systemerkrankung.

11. Juni. Section. Grosse männliche Leiche von mässigem Ernährungszustand, an den unteren Extremitäten starkes Oedem. Mehrfacher Decubitus. Schädeldach von mittlerer Dicke. Gehirn und Gehirnhäute normal.

Rückenmark. Leichte Trübung und Verdickung der Pia, besonders im Brustmark.

Consistenz des Marks mässig fest. Auf Durchschnitten im ganzen Verlauf deutliche Verfärbung der Seiten- und Hinterstränge.

L ungen. Im rechten Pleurarnum geringes, im linken reichliches, seröses Exsudat.

Starkes Oedem der Lunge.

Herz, Leber normal.

Milz vergrössert, von starker Consistenz (15:10:4).

Beide Venae crurales thrombosirt.

Das Rïckenmark wird 4 Monate in Müller'scher Flüssigkeit gehärtet und nach Alkoholbehandlung in einzelnen Stücken in Celloidin eingebettet. Zugleich werden Stiucke vom Plexus brachialis, von den Nn. ischiadici, phrenici und vagi ebenso behandelt.

Makroskopische Beschreibung der Rückenmarksstücke.

Medulla oblongata normal.

Pyramidenkreuzung. Deutliche Verfärbung im Gebiet der KI.S., schwächere in den Hintersträngen (Taf. I-IV, Fig. 51 ).

$\mathrm{Ob}$ eres Halsmark. Hinterstränge längs der Fissura posterior von der Peripherie $2 / 3$ derselben hinauf, keilförmig mit der Spitze nach vorn degenerirt. Ausserdem ein schmaler, den ersten bogenförmig umgebender schwächerer Degenerationsstreifen, auf beiden Seiten symmetrisch. Kl.S. stark degenerirt, leichte Verfürbung der Py.S. und Py.V. (Taf. I-IV, Fig. 5 2).

Halsanschwellung. Degeneration der Py.S. und besonders der Py.V. stärker geworden, sonst wie oben (Taf. I-IV, Fig. $5_{3}$ ).

Unteres Halsmark. Die intensiven Degenerationsstreifen der Hinterstränge weichen von der Fissura posterior auseinander. An letzterer nur in der Peripherie stärkere Degeneration. Nach aussen erstreckt sich die Degeneration bis in die hintere Wurzelzone, nach vorn bis zur Commissura posterior. Kl.S., Py. S. und Py.V. stark degenerirt, daneben Randdegeneration (Taf. I-IV, Fig. $5_{4}$ ).

Oberes Brustmark. Dieselben Verhältnisse wie im unteren Halsmark. Besonders intensive Degeneration der stark entwickelten Py.V. (Taf. I-IV, Fig. $5_{5}$ ).

Mittleres Brustmark. Degeneration beiderseits immer sym- 
metrisch. Hinterstränge intensiv in ganzer Ausdehnung der Peripherie degenerirt. Zwei stärker degenerirte Stränge ziehen längs der Fissura posterior bis zur Commissura posterior hinauf. Kl.S. und Py.S., besonders aber Py.V. intensiv degenerirt. Randdegeneration.

Unteres Brustmark. Langsame Abnahme der Degeneration der Kl.S, sonst die Degeneration wie im mittleren Brustmark (Taf. I-IV, Fig. 56 .)

$\mathrm{Ob}$ eres Lendenmark. Hinterstränge besonders an der Peripherie degenerirt von der Fissura posterior bis zur Wurzeleintrittszone. Starke Degeneration der Py. S., schwächere der Py.V. (Taf. I-IV, Fig. 5 7 ).

Le ndenansehwellung. Degeneration der Py.S. kaum noch nachweisbar, in Py.V. schwach entwickelt. Auch in den Hintersträngen Abnahme der Degeneration.

Unteres Lendenmark. Schwache Degeneration in Hintersträngen, leichte Verfärbung der Py.S. (Taf. I-IV, Fig. 5 8 ).

Sacralmark. Hinterstrangdegeneration schwach angedeutet, Seitenund Vorderstränge frei.

\section{Mlikroskopische Beschreibung.}

Die Färbemethoden sind dieselben, wie in den beiden anderen Fällen. Nur wurde zur besseren Darstellung der Blutungen eine Modification der alten Weigert'schen Färbung angewandt, indem der Kupferacetatlösung, in der die Schnitte bei Zimmertemperatur 24 Stunden blieben, eine wässerige Säure. fuchsinlösung zugesetzt wurde, während die Schnitte im Uebrigen in üblicher Weise behandelt wurden. Bei gelungenen Präparaten - der Erfolg ist kein ganz sicherer - heben sich sämmtliche rothe Blutkörperchen in rothvioletter, leuchtender Farbe aus dem ganzen übrigen, in mattröthlichem Tone gefärbten Weigert'schen Präparat scharf heraus, so dass sowohl die in den Gefässen gelegenen, als auch die in das Gewebe ausgetretenen Blutkörperchen leicht zu erkennen sind.

\section{Hinterstränge.}

Sacralmark. Vereinzelte degenerirte Fasern in den Goll'schen Strängen. Pia leicht verdickt. In den hinteren Wurzeln einzelne degenerirte Fasern.

Unteres Le ndenmark. Symmetrische leicht fleckförmige Degeneration, die nicht ganz die Peripherie erreicht und in den peripheren Theilen die Fissura posterior nicht beriihrt. Anch die änsseren Partien einschliesslich der hinteren Wurzelzone frei. An der Peripherie, mit der verdickten Pia einhergehend, ziemlich beträchtliche Randdegeneration. Leichte Degeneration der hinteren Wurzeln (Taf. I-IV, Fig. 5s).

Lendenanschwellung. Die Degeneration wesentlich intensiver und ausgebreiteter geworden, lässt jedoch die hintere Wurzelzone frei. Pia verdiekt. Gefässe mit verdickten Wandungen und geringen Blutextravasaten. Leichte Degeneration der hinteren Wurzeln.

Oberes Lendenmark. Weitere Zunabme der Degeneration, die 
am intensivsten in den medianen Theilen an der Peripherie ist und auch die hintere Wurzelzone erreicht. Pia verdickt. Hintere Wurzeln frei (Taf. I-IV, Fig. 57).

Unteres Brustmark. Ziemlich diffuse Degeneration der Hinterstränge, einschliesslich der hinteren Wurzelzone. Auch hier einzelne degenerirte Fasern in den hinteren Wurzeln. Pia mater mässig verdickt (Taf. I-IV, Fig. $5_{6}$ ).

Dieselben Verhältnisse bestehen im mittleren und oberen Brustmark (Taf. I-IV, Fig. $5_{5}$ ).

Unteres Halsmark. Pia mater stark verdickt. Hinterstränge noch immer diffus degenerirt. Leichte Degeneration der hinteren Wurzeln (Taf. I-IV, Fig. $5_{4}$ ).

Halsanschwellung. Die Degeneration beginnt lateralwärts an Intensität abzunehmen, ist am stärksten an der Fissura posterior; reichliche Gefässbildung mit perivasculären Blutungen (Taf. I-IV, Fig. $5_{3}$ ).

Oberes Halsmark. Dieselben Verhältnisse wie in der Halsanschwellung (Taf. I-IV, Fig. $5_{2}$ ).

Pyramidenkreuzung. Funiculi graciles stark, Funiculi cuneati nur schwach degenerirt (Taf. I-IV, Fig. $5{ }_{1}$ ).

Unterer Theil der Medulla oblongata. Hinterstränge frei.

\section{Seiten- und Vorderstränge.}

Sacralmark. Pia mater in den hinteren Partien der Seitenstränge deutlich verdickt mit mässiger Randdegeneration. In Py.S. und Py.V. beiderseits Degeneration einzelner Fasern. Auch in den übrigen Partien der Vorder- und Seitenstränge vereinzelte degenerirte Fasern. Gefässe der Pia prall gefüllt, mit verdickten Wandungen und kleinen Blutextravasaten. Einige gequollene Fasern in den vorderen Wurzeln.

Unteres Lendenmark. Pia mater stark verdickt. Gefässe derselben vermehrt, prall gefüllt mit reichlichen Blutextravasaten. Ausgesprochene Randdegeneration. Py. S. schwach degenerirt, Py.V. bis auf einige Fasern normal. Auch in den vorderen Wurzeln wenige Fasern degenerirt (Taf. I-IV, Fig. 58).

Lendenansehwellung. Pia mater verdickt, mit deutlicher Randdegeneration in den hintersten Partien der Seitenstränge unmittelbar am Hinterhorn. Py.S. beiderseits stark degenerirt, Py.V. dagegen fast normal. Vordere Wurzeln frei.

Oberes Lendenmark. Pia mater verdickt mit leichter Randdegeneration im Gebiet der Seitenstränge. Py.S. intensiv degenerirt; auch die Degeneration der Py.V. tritt deutlicher hervor und ist am Uebergang zum unteren Brustmark gut entwickelt. In den übrigen Partien der Vorder- und Seitenstränge wenige degenerirte Fasern zerstreut. Während jedoch in den Py.S. und Py.V. die Axencylinder fast sämmtlich zu Grunde gegangen sind, und das Gewebe mit Fettkörnchenzellen vollgestopft ist, zeigen die degenerirten Fasern der anderen Partien fast sämmtlich erhaltene Axencylinder, neben denen vereinzelt in den erweiterten Markscheiden anch Fettkörnchenzellen liegen, deren blauer Kern sich bei der Färbung nach Ira van Guison scharf von dem roth tingirten Axen- 
Die primären combinirten Strangerkrankungen des Rückenmarks.

cylinder abhebt. Leichte Degeneration der vorderen Wurzeln (Taf. I-IV, Fig. $5_{7}$ ).

Unteres Brustmark. Pia mater verdickt, mit reichlichen, prall gefüllten Gefässen und zahlreichen Blutextravasaten. Im Gebiet der Seitenstränge schwache Randdegeneration. Totaler Faserschwund der Py.S. Intensive Degeneration in den Py.V. Anch in den Kl.S. tritt etwas ausgeprägtere Degeneration hervor. In den ïbrigen Theilen der Vorderund Seitenstränge vereinzelte, zerstreute degenerirte Fasern. Die Pyramidenbahn ist vollgestopft mit Fettiörnchenzellen. Leichte Degeneration der vorderen Wurzeln (Taf. I-IV, Fig. 56 ).

Mittleres Brustmark. Py.S. vollständig degenerirt; um die verdickten Gefässe herum liegen die Fettkörnchenzellen in dichten Reihen, sind auch im übrigen Gewebe dieser Babnen zahlreich; starke Verdickung der Neuroglia. Auch Py.V. stark degenerirt; desgleichen die Kl.S. In den übrigen Theilen der Vorder- und Seitenstränge hier mehr degenerirte Fasern als weiter unten, ohne dass ein bestimmtes System befallen zu sein scheint. Doch ist die Degeneration im Gebiet der Gowers'schen Stränge am stärksten, während die Peripherie fast frei ist. Auch hier starke Verdickung der Pia mater mit zahlreichen Blatextravasaten. Vordere Wurzeln etwas stärker degenerirt.

Oberes Brustmark. Intensive Degeneration der KI.S., Py.S. und Py.V. Auch in den iubrigen Partien der weissen Substanz etwas stärkere Degeneration mit Freilassen der unmittelbaren Umgebung der grauen Substanz. Pia mater verdickt, mit ziemlich beträchtlicher Randdegeneration. Leichte Degeneration in den vorderen Wurzeln (Taf. I-IV, Fig. 55 ).

Unteres Halsmark. Degeneration ungefähr in derselben Ausdehnung wie im oberen Brustmark (Taf. I-IV, Fig. 54).

Halsanschwellung. Verdickung der Pia mater mit leichter Randdegeneration. Die Degeneration in den Py. S. lässt etwas an Intensität nach, während KI.S. und Py.V. noch stark afficirt sind. Auch in den anderen Theilen der weissen Substanz nimmt die Zahl der degenerirten Fasern ab. Leichte Degeneration der vorderen Wurzeln (Taf. I-IV, Fig. 53).

Oberes Halsmark. Intensive Degeneration der Kl.S. schwächere der Py.S. und Py.V. Namentlich die letztere nimmt rasch an Intensität nach oben ab. Auch in den vorderen Theilen der Vorder- und Seitenstränge noch immer deutliche Degeneration. Pia mater verdickt. Vordere Wurzeln zeigen geringe Degeneration (Taf. I-IV, Fig. 52).

Pyramidenkreuzung. Starke Degeneration der Kl.S. Vereinzelte, sich kreuzende Fasern in den Pyramiden degenerirt (Taf. I-IV, Fig. $5_{1}$ ).

Unterer Theil der Medulla oblongata. Pyramiden, Kleinhirnbahn normal.

\section{Graue Substanz.}

Sacralmark. Die Ganglienzellen der Vorderhörner zum grössten Theil erhalten, einzelne, besonders in den inneren und mittleren Abschnitten, atrophisch, darunter einige mit Vacuolenbildung. 
Unterhalb der Vorderhörner macht die Substanz einen leicht rareficirten Eindruck; dabei ist die feine Markfaserung im Grossen und Ganzen erhalten. Centralkanal frei. Die grossen Gefässe zeigen verdickte Wandungen, einzelne perivascnläre Blutungen von geringem Umfange.

Unteres Lendenmark. Zahlreiche Ganglienzellen der Vorderhörner in sämmtlichen Gruppen atrophisch; doch uberwiegt die Zahl der erhaltenen Zellen. Deutliche Rareficirung der mittleren Partien der grauen Substanz beiderseits. Vermehrung der Gefässe, die prall gefüllt sind und stark verdickte Wandungen besitzen. Keine Blutungen. Die feine Markfaserung an Weigert-Präparaten etwas spärlicher als normal.

Lendenanschwellung. Neben zahlreichen erhaltenen ein grosser Theil degenerirter Ganglienzellen in den Vorderhörnern, einzelne zeigen Vacuolisirung (Taf. I-IV, Fig. 63 u.4). Die graue Substanz unterhalb derselben bis in die Hinterbörner hinein stark rareficirt. Deutliche Verminderung der markhaltigen Nervenfasern. Blutgefässe, prall gefïllt, liegen in Hohlräumen. Vom Sulcus anterior aus, der selbst grosse Blutextravasate zeigt, dringen solehe in die um den Centralkanal gelegene Scheide der grossen Gefässe. Die Fasern der vorderen weissen Commissur zeigen ziemlich beträchtliche Degeneration.

Oberes Lendenmark. Verbältnissmässig viele Ganglienzellen der Vorderhörner atrophisch ohne Bevorzugung besonderer Gruppen. Gefässe vermehrt, prall gefüllt, um dieselben herum kleine Extravasate, in denen nur zum Theil rothe Blutkörperchen erkennbar sind. Dieselben liegen sowohl zu beiden Seiten des Centralkanals, als auch in den Vorderhörnern. Die ganze graue Substanz leicht rareficirt mit deutlicher Verminderung des feinen Fasernetzes. Die erste Anlage der Clarke'schen Säulen gut sichtbar; Ganglienzellen und Markfaserung daselbst erhalten.

Unteres Brustmark. Die Ganglienzellen sowohl in den Vorderhörnern wie in den Clarke'schen Säulen vermindert, zum Theil atrophisch. Die feine Markfaserung, besonders in den Clarke'schen Säulen, vermindert. Ueberall deutliche Rarefication; die Ganglienzellen liegen in mit amorphen Massen angefüllten Höhlen (Oedem?). Sehr zahlreiche, prall gefüllte Gefässe mit verdickten Wandungen. Viele frische, theils perivasculäre, theils freiliegende Blutungen von mässigem Umfange.

Mittleres Brustmark. Keine Blutungen nachweisbar, sonst derselbe Befund, wie im unteren Brustmark.

Oberes Brustmark. Die Erkrankung der granen Substanz entschieden stärker geworden; die Vorderhörner treten im SäurefuchsinPräparat bereits makroskopisch, heller als normal gefärbt, hervor. Unter dem Mikroskop sieht man starke Rarefication des Gewebes, vornehmlich in den Vorderhörnern, jedoch auch zwischen Vorder- und Hinterhorn. Um Ganglienzellen und Blutgefässe Litcken von zum Theil recht beträchtlicher Ausdehnung. Die Ganglienzellen der Vorderhörner in mässiger Zahl atrophisch. Die feine Markfaserung nur in Hinterhörnern und Clarkeschen Säulen einigermassen gut erhalten. In letzteren die Ganglienzellen spärlich, zum Theil atrophisch. Reichliche, prall gefüllte Gefässe mit zahlreichen perivasculären Blutungen von mässiger Ausdehnung. Daneben sind auch amorphe Massen, Reste alter Blutungen, erkennbar.

Unteres Halsmark. Rarefication geringer geworden. Dagegen 
sind in dieser Höhe die Blutungen ausserordentlich zahlreich, vor allem an der Basis und in den Vorderhörnern, zum Theil älteren Datums mit ausgedehnten amorphen Massen, zum Theil frisch, vielfach perivasculär gelegen. Ungemein starke Vermehrung der prall gefüllten Gefässe. Im Sulcus ant. an der Commissura ant. reichliche Exsudatmassen, in denen sehr zahlreiche, gut erhaltene rothe Blutkörperchen sichtbar sind. Die vordere weisse Commissur schwach entwickelt, mit einzelnen degenerirten Fasern. Starke Verminderung der feinen Markfaserung. Nur in den Clarke'schen Säulen ist dieselbe, sowie die Ganglienzellen ziemlich gut erhalten. Dagegen sind die Ganglienzellen der Vorderhörner zum grossen Theil atrophisch, liegen sämmtlicb in Höhlungen.

Halsanschwellung. Die Ganglienzellen der Vorderhörner in der medianen und mittleren Gruppe zum grossen Theil, in der lateralen nur vereinzelt atrophirt. Starker Schwund der Markfaserung, die nur in den Hinterhörnern etwas besser erbalten ist. Auch die Clarke'schen Säulen zeigen Schwund derselben und theilweise Atrophie der Ganglienzellen. Starke Füllung der Blatgefässe, Wandungen derselben verdickt. Keine wesentlichen perivasculären Blutungen. Im Sulcus ant. ein starkes Blutextravasat, das nach oben abnimmt.

Oberes Halsmark. Sehr starke Blutungen, theils frischeren Datums, theils älter mit amorphen Massen, vorwiegend in dem Raum zwischen Hinter- und Vorderhorn (Taf. I-IV, Fig. 7 u. 8); daselbst auch Vernichtung der feinen Markfaserung. Ein grosser Theil der Vorderhornganglienzellen atrophisch. Totale Atrophie der Clarke'schen Säulen; reichliches Blutextravasat im Sulcus ant., das anscheinend die vordere Commissur durchbrochen hat und die Gefässe zu Seiten des Centralcanals umgiebt.

Pyramidenkreuzung. Faserschwund und Atrophie der Ganglienzellen im Nucleus funiculi gracilis und funiculi cuneati. Keine Blatungen.

Medulla oblongata. Vereinzelte perivasculäre Blutungen, leichter Faserschwund in den Kernen der Hinterstränge. Im übrigen graue Sub. stanz normal, vor allem auch die Kerne der Hirnnerven.

Die mikroskopische Untersuchnng der $\mathrm{Nn}$. vagi und phrenici ergiebt normale Verhältnisse; desgleichen die Priffung des Plexus brachialis und des $\mathbf{N}$. ischiadicus beiderseits.

War in den beiden anderen Fällen die Diagnose dem klinischen Befunde nach nicht mit Sicherheit auf combinirte Systemerkrankung gestellt worden, so war man diesmal bereits intra vitam zu dieser Annahme gedrängt. Schon der rasche Verlauf der Krankheit, innerhalb eines halben Jahres vom Beginn bis zum Tode, ist unvereinbar mit sämmtlichen uns bekannten chronischen Rückenmarkskrankheiten und zwingt uns zu der Annahme eines subacuten Processes. Ferner liess die bereits in den ersten Stadien der Krankheit auftretende Paraparese der Beine und das Erhaltensein der Patellarreflexe und der Pupillarreflexe jeden Gedanken an Tabes verschwinden, während wiederum der Mangel ausgesprochener Reizerscheinungen, wie Spas- 
men, erhöhte Sehnenreflexe, ferner die im weiteren Verlauf hervortretenden Sensibilitätsstörungen eine spastische Spinalparalyse ausschlossen. Die klinischen Erscheinungen waren nur durch eine gemeinschaftliche Erkrankung der Seiten- und Hinterstränge zu erklären mit anfänglichem Ueberwiegen der Seitenstrangserkrankung, während in den letzten Stadien auch in den Hintersträngen der Process sich weiter ausbreitete. Da nun hier in Uebereinstimmung mit den beiden ersten Fällen die Druckempfindlichkeit der Wirbelsäule ohne nachweisbare Wirbelerkrankung hervortrat, ferner das eigenthümliche Verhalten der Patellarreflexe bestand, die nur sehr allmählich an. Intensität nachliessen, um kurz ante exitum total zu verschwinden, so wurde die Diagnose auf combinirte Systemerkrankung gestellt. Auffällig war dabei das Ergebniss der electrischen Prüfung, das an einigen Muskeln der Extremitäten eine Andeutung von Ea.R. ergab, während anch an den iubrigen eine Schwererregbarkeit sich bemerkbar machte. Doch war dabei die Atrophie der Musculatur keine grössere, als sie der starken Abmagerung des gesammten Körpers entsprach. Endlich war auch hier wieder, wie in dem voraufgegangenen Fall der Exitus durch Zwerchfellslähmung herbeigeführt worden.

Die Untersuchung des Rückenmarks ergab nun eine Degeneration der Hinterstränge, der Pyramidenseiten- und Vorderstrangbahnen und der Kleinhirnseitenstrangbahnen, wie in den beiden anderen Fällen. Jedoch ist die Erkrankung der Systeme hier nicht so scharf abgegrenzt wie in jenen. Schon die Degeneration in den Hintersträngen ist viel diffuser verbreitet, erstreckt sich vom unteren Brustmark bis zum unteren Halsmark über das ganze Gebiet derselben, um weiter oben und unten langsam abzunehmen. Nach unten weicht sie langsam aus den lateralen und centralen Partien zurück, erreicht im oberen Lendenmark noch gerade die hintere Wurzelzone, die weiter abwärts frei bleibt. Im unteren Lendenmark ist nur noch eine kleinere, auch die Peripherie nicht erreichende Zone degenerirt, während im Sacralmark bald jede Spur der Erkrankung verschwindet. Nach oben zu macht sich bereits in der Halsanschwellung stärkere Degeneration der unmittelbar an die Fissura post. angrenzenden Partien bemerkbar (secundäre aufsteigende Degeneration), während in den lateralen Partien die Degeneration abnimmt. Aber erst im unteren Theil der Medulla oblongata verschwindet die Erkrankung völlig, während sich in den Kernen der Funiculi graciles und cuneati noch ein leichter Faserschwund bemerkbar macht. Hierzu kommt eine Verdickung der Pia mater, besonders im Brust- und Halsmark mit deutlicher Randdegeneration 
und eine leichte Degeneration der hinteren Wurzeln, die allerdings hinter der bei der Tabes mit derartig intensiver Hinterstrangerkrankung gefundenen wesentlich zurückbleibt.

Es besteht nun auch in den Seitensträngen eine nicht unbeträchtliche Leptomeningitis, an die sich eine leichte Randdegeneration anschliesst. Von derselben ist die Erkrankung der Py.S. im Lendenmark scharf getrennt durch eine Schicht gesunder Fasern. Die Degeneration der Pyramidenbahnen ist eine streng systematische, gleichmässig die Seiten- und Vorderstränge befallend. Sie beginnt mit wenigen Fasern bereits im Sacralmark, wird in den Py. S. schon in der Lendenanschwellung intensiv, in den Py.V. erst im obersten Lendenmark. Bis zum unteren Halsmark besteht totale Degeneration der Py.S. und Py.V. mit besonders starker Entwicklung der Py.V. In der Halsanschwellung nimmt die Degeneration der Py.S. an Intensität ab, im oberen Halsmark die der Py.V., doch sind noch in der Pyramidenkreuzung einige degenerirte Fasern nachweisbar, während die Pyramiden total gesund sind. Die KI.S. beginnen im unteren Brustmark mit schwächerer Degeneration und zeigen vom mittleren Brustmark bis hinauf zur Pyramidenkreuzung starke Erkrankung, die weiter aufwärts rasch verschwindet. $\mathrm{Zu}$ dieser Erkrankung der beiden Systeme gesellt sich eine regellose Degeneration einzelner Fasern in den übrigen Partien der Vorder- und Seitenstränge, welche wesentlich stärker ist, als in den beiden anderen Fällen. Dieselbe ist am ausgesprochensten im oberen Brustund unteren Halsmark, jedoch auch in den ïbrigen Theilen des Rückenmarks bis herab zum Sacralmark nachweisbar. Dabei tritt jedoch deutlich hervor, dass auch diese Degeneration nicht von der Leptomeningitis abhängig ist, indem die peripheren Theile nur schwach oder gar nicht befallen sind; ausserdem sind die unmittelbar an die graue Substanz anschliessenden Partien in allen Abschnitten des Marks frei von der Degeneration.

Auch histologisch ist $\mathrm{z}$ wischen diesen nicht systematischen Degenerationen und den Pyramidenbahnen ein deutlicher Untersehied festzustellen. Während in den letzteren die Fasern fast sämmtlich zu Grunde gegangen sind, und neben beträchtlicher Verdickung der Neuroglia eine Vollstopfung mit Fettkörnchenzellen, vor allem in den Seitensträngen, zu constatiren ist, die sich am stärksten um die Wandungen der verdickten und prall gefüllten Gefässe anhäufen, ist in den Vorderseitensträngen an den erkrankten Nervenfasern zwar deutliche Quellung des Marks, aber nur selten eine Zerstörung des Axencylinders zu constatiren. Derselbe liegt im Allgemeinen von normaler 
Grösse oder gequollen und blasser gefärbt in der Mitte der gequollenen Markscheide, theils allein, theils in Begleitung von Fettkörnchenzellen. Es steht also nicht nur der Ausdehnung, sondern auch der Schwere der Erkrankung nach diese Degeneration weit hinter der der Systeme zurück.

Ein weiterer Befund in diesem Falle ist nun den beiden ersten Fällen gegenüber neu, das ist die Degeneration einzelner Fasern in den vorderen Wurzeln in der ganzen Ausdehnung des Rückenmarks. Man konnte daraus von vornherein auf eine Betheiligung der Vorderhornganglienzellen an der Erkrankung schliessen, die ja auch in dem Fall II bereits in geringem Umfange zu constatiren war. Es zeigte sich nun die graue Substanz im Ganzen in dem vorliegenden Fall weit schwerer erkrankt als in den anderen Fällen. Die Entwicklung der Gefässe war eine weit stärkere, die Blutungen im ganzen Rückenmarke, besonders aber im Halsmark waren sehr zahlreich; ferner zeigte sich, dem Fall I entsprechend, eine beträchtliche Rarefication der grauen Substanz, am stärksten ausgeprägt in den Vorderhörnern des oberen Brustmarks, verbunden mit einer Verminderung der feinen Markfaserung. Während die Clarke'schen Säulen an Ganglienzellen und Nervenfasern keine schweren Störungen erkennen liessen, zeigten die Ganglienzellen der Vorderhörner nicht unbeträchtliche Veränderungen. Bereits im Lenden- und Brustmark liessen sich einige atrophische Ganglienzellen, besonders in den medianen Gruppen, nachweisen, in ersterem ausserdem eine geringe Zahl vacuolisirter Zellen. Besonders reichlich traten aber die atrophischen Ganglienzellen im Halsmark auf, auch hier vorwiegend in der inneren and mittleren Gruppe. Dabei lagen die Ganglienzellen grösstentheils in kleinen Hohlräumen, als wenn sie intra vitam von einem Oedem umgeben waren. Diese Atrophie der Ganglienzellen entspricht dem electrischen Verhalten der Musculatur; aber auch die zum Tode führende Zwerchfellslähmung findet, wie in dem Fall II, hierdurch eine befriedigende Erklärung.

Diese Erkrankung der Vorderhornganglienzellen, gleichsam das Befallensein eines vierten Systems darstellend, ist bei den combinirten Systemerkrankungen wiederholt beobachtet worden. In der neusten einschlägigen Arbeit von Karl Mayer ${ }^{1}$ ) fanden sich in einem der beiden beschriebenen Fälle im Halsmark eine grössere Zahl der Vorderhornzellen atrophisch, eine geringere auch im Lendenmark,

1) Ueber die combinirten systematischen Erkrankungen der Rückenmarksstränge der Erwachsenen. Beitr. z. klin. Med. u. Chir. Heft 4. 1894. 
daneben ziemlich zahlreiche Vacuolenbildung. Eine Angabe über das Verhalten der vorderen Wurzeln fehlt, ebenso eine electrische Prüfung der Musculatur; jedoch ist theilweise Atrophie der Extremitätenmusculatur angegeben. Ferner gehört hierher der Fall von Sioli ${ }^{1}$ ), bei dem Schwund der medialen Zellgruppe der Vorderhörner vom 4. Cervicalnerv bis herab zum Sacralmark angegeben wird, und welcher auch in der Erkrankung der Vorderhörner in toto im mittleren Dorsalmark mit unserem Fall Analogie zeigt. Von klinischen Symptomen war hier die starke Macies der unteren Extremitäten und vielleicht die Herabsetzung der faradischen Erregbarkeit auf die Erkrankung der Ganglienzellen zu beziehen.

Es liegt ja nun nahe, bei dieser Combination von Erkrankung der Pyramidenstränge und der Ganglienzellen der Vorderhörner an amyotrophische Lateralsklerose zu denken, zumal bei vorgeschrittenen Fällen derselben eine ausgedehntere Erkrankung der vorderen Partien der Seitenstränge fast die Regel ist, und auch die Goll'schen Stränge nicht selten befallen sind. Jedoch ist bei näherer Betrachtung der Unterschied zwischen der amyotrophischen Lateralsklerose und der hier vorliegenden Erkrankung ein sehr beträchtlicher. Die Atrophie der Ganglienzellen ist hier nicht entfernt so ausgebreitet wie bei der ersteren Krankheit, bei der in manchem Abschnitte die Ganglienzellen ganz verschwunden sein können. Dem entsprechend sind auch die an den Muskeln auftretenden Atrophien hier nur angedeutet, dort ungemein stark entwickelt. Vor allem aber fehlen in unserem Falle gänzlich die bulbären Symptome, welche der amyotrophischen Lateralsklerose erst ihr charakteristisches Gepräge geben. In wieweit die Atrophie der Ganglienzellen bei der combinirten Systemerkrankung von den der letzteren zu Grunde liegenden Riickenmarksveränderungen bedingt wird, lässt sich bei dem heutigen Stande unserer Kenntnisse nicht sicher sagen. Jedenfalls besteht eine Analogie mit den mitunter in den letzten Stadien der Tabes sich entwickelnden Affectionen der Vorderhörner.

Dass auch in unserem letzten Fall die peripheren Nerven, einschliesslich Vagus und Phrenicus, frei von Degeneration waren, ist bemerkenswerth. Bis jetzt ist kein hierher gehöriger Fall bekannt, bei dem eine periphere Neuritis mit der Riuckenmarkserkrankung verbunden wäre, und auch hierin ist ein scharfes Unterscheidungsmerkmal gegenüber der Tabes gegeben.

1) Ein Fall von combinirter Erkrankung der Rückenmarksstränge mit Erkrankung der grauen Substanz. Arch. f. Psych. Bd. XI. 1881. 
Fassen wir nun noch einmal den klinischen und pathologischanatomischen Befund der drei hier berichteten Fälle zusammen, so waren alle drei Patienten Männer der arbeitenden Klasse, im beginnenden Mannesalter, 36, 38 und 29 Jahre alt. Aetiologisch kommt in dem ersten Fall perniciöse Anämie in Betracht, in dem zweiten Lues, in dem dritten Durchnässung und rheumatische Beschwerden. Erbliche Belastung fehlt vollkommen. Die Entwicklung der Krankheit erfolgte in allen Fällen ziemlich rasch, bei Fall III wird sogar plötzlich auftretende Schwäche der Beine angegeben. Die ges a m $\mathrm{m}$ te Krankheitsdauer betrug in allen 3 Fällen ungefähr ein halbes Jahr, im Vergleich mit der Mehrzahl der uns bekannten Rïckenmarkskrankheiten ein ungewöhnlich schneller Verlauf. Als erstes Symptom war stets Schwäche der unteren Extremitäten und Parästhesien in denselben zu constatiren. Nur der erste Fall zeigte noch bei der Aufnahme stärkere spastische Erscheinungen, die auch bis zum Tode nachweisbar blieben, in den beiden anderen bestand schlaffe Paraparese mit vorübergehenden unwillktirlichen Zuckungen. Die Patellarreflexe waren in allen drei Fällen bei der Aufnahme noch vorhanden; während sie jedoch im Fall II damals bereits auf ein Minimum herabgesetzt waren und bald ganz verschwanden, waren sie in Fall III von normaler Intensität, in Fall I sogar lebhaft gesteigert. Jedoch auch in den letzteren beiden Fällen nahmen sie langsam ab, um in Fall I schliesslich nur noch sehr schwach, in Fall III überhaupt nicht mehr auslösbar zu sein. Hierzu ist zu bemerken, dass Fall II erst $3 \frac{1}{2}$ Monate nach den ersten Bewegungsstörungen, Fall I dagegen bereits $1 \frac{1 / 2}{2}$ Monate, Fall III 13/4 Monate danach in das Krankenhaus kam, es wäre also wohl möglich, dass damit die Erklärung des Unterschiedes im Verhalten der Patellarreflexe gegeben wäre, und auch in Fall II in früberen Phasen der Krankheit der Patellarreflex erhöht war. Ferner ist Fall I derjenige, welcher am schnellsten letal verlief, wahrscheinlich infolge der perniciösen Anämie, so dass auch das wenn auch schwache Erhaltensein der Patellarreflexe bis zum Tode seine Erklärung fände. Dem entspricht, dass die Zwerchfellslähmung, welche in den beiden anderen Fällen die letzte Todesursache war, hier nicht zur Entwicklung kam. In allen 3 Fällen traten die Sensibilitätsstörungen der unteren Extremitäten anfangs gegen die motorischen zurück, um erst im weiteren Verlauf stärker zu werden, so dass es in Fall II und III schliesslich sogar bis zur totalen Aufhebung der Sensibilität und Schmerzempfindung kam. Ebenso stellten sich jedesmal hochgradige Blasenund Mastdarmstörungen ein. Vor allem aber zeigte sich der gleich- 
artige Charakter der Erkrankung in allen Fällen in der aufsteigenden Tendenz derselben. Dieselbe trat nicht nur in der Sensibilitätsstörung, die langsam von den Unterschenkeln bis zur Oberbauchgegend sich entwickelte, sondern vor allem in dem in den letzten Stadien der Krankheit auftretenden Befallensein der oberen Extremitäten hervor. Dabei kam es wieder nur in Fall $\Pi$ zu ausgesprochener Parese und Ataxie derselben, während in Fall III nur Abnahme der groben motorischen Kraft mit Schwächerwerden des vorher gesteigerten Tricepsreflexes and leichter Hyperästhesie, in Fall I nur sehr geringe Herabsetzung der motorischen Kraft mit leichten Spasmen im rechten Arm constatirt wurde.

Dem entspricht auch das Verhalten der Pyramidenbahnen, deren Degeneration in Fall $I$ bereits in der Halsanschwellung nach oben rasch an Intensität abnimmt und im oberen Halsmark kaum noch nachweisbar ist, in Fall III zwar auch in der Halsanschwellung nachlässt, aber in einzelnen Fasern bis zur Pyramidenkreuzung zu verfolgen ist, im Fall II endlich selbst im oberen Halsmark nur wenig Abnahme zeigt (höhere Abschnitte waren nicht aufbewahrt). Die Erkrankung der Hinterstränge ist, besonders in Bezug auf das Verhalten der Patellarreflexe, bereits bei den einzelnen Fällen ausfübrlich besprochen worden; es sei hier noch einmal darauf hingewiesen, dass sich dieselbe von der tabischen Erkrankung hauptsächlich durch das Freibleiben oder wenigstens nur sehl geringe Befallensein der hinteren Wurzeln und die erst in den letzten Stadien der Erkrankung degenerirende hintere Wurzelzone unterscheidet. Während bei der Tabes gerade diese Zone zuerst erkrankt, und der Degenerationsprocess erst im weiteren Verlauf nach innen vorschreitet, vollzieht sich die Entwicklung der Hinterstrangserkrankung bei der combinirten Systemerkrankung im Wesentlichen von innen nach aussen. Es sind also die beiden Krankheiten, ganz abgesehen vom klinischen Verlauf, am besten in den ersten Stadien auseinander zu halten. Jedoch wird selbst bei vorgeschrittenerem Process das Verhalten der hinteren Wurzeln eine Unterscheidung ermöglichen, zu der sich auch das Verhalten der Clarke'schen Säulen zu gesellen scheint. Während nämlich bei stark entwickelter tabischer Degeneration der Hinterstränge das feine Fasernetz der Clarke'schen Säulen total verschwindet, sodass bei der Weig ert'schen Färbung dieselben makroskopisch bereits als helle Flecke sich aus der grauen Substanz hervorheben, dagegen die Ganglienzellen erhalten bleiben, sind in unseren Fällen, selbst in dem dritten mit ziemlich diffuser Hinterstrangserkrankung, die feinen Markfasern nur wenig vermindert. 
$\mathrm{Ob}$ und in wieweit die Degeneration der Kleinhirnseitenstrangbahnen das klinische Bild beeinflusst, lässt sich nach unseren heutigen Kenntnissen nicht bestimmen. Jedenfalls ist es dieses System, dessen Degeneration sich am weitesten nach oben erstreckt, in allen Fällen bis zur Pyramidenkreuzung. Nach abwärts reicht die Degeneration in Fall $I$ und II bis zur mittleren, in Fall III bis zum unteren Brustmark, so dass die untersten Partien dieser Stränge frei von der Degeneration bleiben. Die Ganglienzellen der Clarke'schen Säulen erscheinen im Brustmark in allen Fällen an Zahl etwas vermindert and zum Theil atrophisch. Was aber diesen Fällen ganz besonders eigenthümlich ist, das ist die Erkrankung der grauen Substanz, bestehend in reichlicher Vermebrung der Gefässe, praller Füllung der-

Zusammenstellung der drei Fälle von primärex

\begin{tabular}{|c|c|c|c|c|c|c|c|c|c|c|c|}
\hline \multirow{2}{*}{ Fall } & \multirow{2}{*}{ 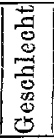 } & \multirow{2}{*}{$\stackrel{\stackrel{4}{ \pm}}{\stackrel{4}{4}}$} & \multirow{2}{*}{$\begin{array}{l}\text { Aetio- } \\
\text { logie }\end{array}$} & \multirow{2}{*}{ 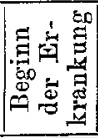 } & \multirow{2}{*}{ Tod } & \multicolumn{3}{|c|}{ Untere Extremitäten } & \multicolumn{3}{|c|}{ Obere Extremitätex } \\
\hline & & & & & & Sensibil. & Motilität & Reflexe & Sensib. & Motilität & Refiex \\
\hline $\begin{array}{c}\text { I. } \\
\text { (Plotzki). }\end{array}$ & M. & $36 \mathrm{~J}$. & $\begin{array}{c}\text { Perni- } \\
\text { ciöse } \\
\text { An- } \\
\text { âmie. }\end{array}$ & $\begin{array}{c}\text { Anfang } \\
\text { Sept. } \\
1890\end{array}$ & $\begin{array}{c}27 . \text { XII. } \\
1890 \\
\end{array}$ & $\begin{array}{c}\text { Anfangs } \\
\text { Parästhe- } \\
\text { sien. Dann } \\
\text { langsam } \\
\text { aufftei- } \\
\text { gende Her- } \\
\text { absetzung } \\
\text { der Sensi- } \\
\text { bilität der } \\
\text { beiden } \\
\text { Beine. }\end{array}$ & $\begin{array}{l}\text { Spastische } \\
\text { Parese mit } \\
\text { deutlicher } \\
\text { Ataxie } \\
\text { und Con- } \\
\text { tracturen. }\end{array}$ & $\begin{array}{l}\text { Patellar- } \\
\text { reflexe an- } \\
\text { fang's er- } \\
\text { höht, dann } \\
\text { langsam } \\
\text { schwächer } \\
\text { werdend. } \\
\text { Fussclonus } \\
\text { vorhanden. } \\
\text { Lebhafter } \\
\text { Plantar- } \\
\text { reflex. }\end{array}$ & $\begin{array}{l}\text { nor- } \\
\text { mal. }\end{array}$ & $\begin{array}{c}\text { Herabsetz. } \\
\text { der motor. } \\
\text { Kraft, in } \\
\text { der letzten } \\
\text { Zeit mit } \\
\text { Spasmen } \\
\text { im rechten } \\
\text { Arm. }\end{array}$ & $\begin{array}{l}\text { Tricep } \\
\text { reflex } \\
\text { fangs } t \\
\text { halten, } \\
\text { ter nic } \\
\text { geprit } \\
\text { : }\end{array}$ \\
\hline $\begin{array}{c}\text { IT. } \\
\text { (Algner). }\end{array}$ & M. & $38 \mathbf{J}$. & Lues. & $\mid \begin{array}{c}\text { Herbst } \\
1892\end{array}$ & $\begin{array}{c}30 . \mathrm{III} . \\
1893 \\
\end{array}$ & \begin{tabular}{|} 
ZuerstPar- \\
ästhesien, \\
dann Ab- \\
nahme der \\
Sensibil. u. \\
Schmerz- \\
empfindg. \\
biszumvö- \\
lig. Verlust \\
derselben.
\end{tabular} & $\begin{array}{l}\text { Schlaffe } \\
\text { Parese bei- } \\
\text { der Beine } \\
\text { mit zeit- } \\
\text { weise auf- } \\
\text { tretenden } \\
\text { unwillkür- } \\
\text { lichen } \\
\text { Zuckun- } \\
\text { gen. }\end{array}$ & $\begin{array}{l}\text { Patellar- } \\
\text { reflexe anf. } \\
\text { schwach, } \\
\text { dann ganz } \\
\text { erloschen. } \\
\text { Plantarre- } \\
\text { flex zuerst } \\
\text { erhalten, } \\
\text { spät. nicht } \\
\text { zuerzielen. }\end{array}$ & $\begin{array}{c}\text { Par- } \\
\text { ästhe- } \\
\text { sien. } \\
\\
\end{array}$ & $\begin{array}{l}\text { Langsame } \\
\text { Abnahme } \\
\text { der motor. } \\
\text { Kraft, in } \\
\text { der letzten } \\
\text { Zeit deut- } \\
\text { liche Pa- } \\
\text { rese mit } \\
\text { Ataxie. }\end{array}$ & . \\
\hline $\begin{array}{c}\text { III. } \\
\text { (Reichert). }\end{array}$ & M. & $29 \mathrm{~J}$. & $\begin{array}{l}\text { Rheu- } \\
\text { matis- } \\
\text { mus. } \\
\text { Durch- } \\
\text { näs- } \\
\text { sung. }\end{array}$ & $\begin{array}{c}\text { Mitte } \\
\text { Decbr. } \\
1892 \\
\end{array}$ & $\begin{array}{c}10 . \mathrm{VI} . \\
1893 \\
\end{array}$ & $\begin{array}{c}\text { Parästhe- } \\
\text { sien, dann } \\
\text { leichte Hy- } \\
\text { perästhe- } \\
\text { sie, zuletzt } \\
\text { totale Auf- } \\
\text { hebung der } \\
\text { Sensibil. u. } \\
\text { Schmerz- } \\
\text { empfin- } \\
\text { dung. }\end{array}$ & $\begin{array}{c}\text { Schlaffe } \\
\text { Parese bei- } \\
\text { der Beine } \\
\text { mit Spitz- } \\
\text { fussstel- } \\
\text { lung. } \\
\end{array}$ & $\begin{array}{l}\text { Patellar- } \\
\text { reflex an- } \\
\text { fangs er- } \\
\text { halten, } \\
\text { erlischt } \\
\text { später. } \\
\text { Plantar- } \\
\text { reflex des- } \\
\text { gleichen. }\end{array}$ & $\begin{array}{l}\text { In der } \\
\text { letzten } \\
\text { Zeit } \\
\text { Hyper- } \\
\text { ästhe- } \\
\text { sien. } \\
\end{array}$ & $\begin{array}{l}\text { Abnabme } \\
\text { der mota- } \\
\text { rischen } \\
\text { Kraft. }\end{array}$ & $\begin{array}{l}\text { Tricep } \\
\text { refiex } \\
\text { erst se } \\
\text { lebhal } \\
\text { später } ~ \\
\text { sehr } \\
\text { schwac }\end{array}$ \\
\hline
\end{tabular}


selben und theils perivasculären, theils frei liegenden Blutungen frischen und älteren Datums. Hierzu kommt in allen Fällen eine wesentliche Verminderung der feinen Markfaserung, besonders in dem zwischen Vorder- und Hinterhorn gelegenen Theil der granen Substanz, und in Fall I und III die Rareficirung der Vorderhörner in der oberen Hälfte des Brustmarks. Das Befallensein der Ganglienzellen der Vorderhörner in Fall II und III hat schon oben eine eingehende Besprechung erfahren.

Seit Kahler und Piek 1) 1878 zuerst bei einem gewöhnlich der Friedreich'schen Ataxie zugerechneten Fall das anatomische

1) Ueber combinirte Systemerkrankung des Rückenmarks. Archiv für Psychiatrie. VIII. 1878.

combinirter Strangerkrankung des Rückenmarks.

\begin{tabular}{|c|c|c|c|c|c|c|c|}
\hline \multirow{2}{*}{ ¿umpf } & \multirow{2}{*}{ Gehirn } & \multirow{2}{*}{$\begin{array}{l}\text { Blase und } \\
\text { Mastdarm }\end{array}$} & \multirow{2}{*}{$\mid \begin{array}{l}\text { Trophische } \\
\text { und vaso- } \\
\text { motorische } \\
\text { Störungen }\end{array}$} & \multirow{2}{*}{$\begin{array}{l}\text { Blut- } \\
\text { befund }\end{array}$} & \multirow{2}{*}{$\begin{array}{l}\text { Todes- } \\
\text { ursache }\end{array}$} & \multicolumn{2}{|c|}{ Ruckenmarksbefund } \\
\hline & & & & & & Weisse Substanz & Graue Substanz \\
\hline $\begin{array}{l}\text { Jekem- } \\
\text { Jlich- } \\
\text { it am } \\
\text { Brust- } \\
\text { irbel. }\end{array}$ & $\begin{array}{l}\text { Pupillar- } \\
\text { reaction } \\
\text { erhalten, } \\
\text { sonst nor- } \\
\text { maler } \\
\text { Befund. }\end{array}$ & $\begin{array}{l}\text { Jnconti- } \\
\text { nentia } \\
\text { urinae et } \\
\text { alvi. }\end{array}$ & $\begin{array}{c}\text { Oedem des } \\
\text { recht. Beins. } \\
\text { Driusenan- } \\
\text { schwellun- } \\
\text { gen. Decu- } \\
\text { bitus am } \\
\text { Kreuzbein. }\end{array}$ & $\begin{array}{l}\text { Poikilocy- } \\
\text { tose. Kern- } \\
\text { halt rothe } \\
\text { Blutkör- } \\
\text { perchen. } \\
\text { Hämoglo- } \\
\text { bin } 50 \% \text {. }\end{array}$ & Kachexie. & $\begin{array}{l}\text { Degeneration der } \\
\text { H. - Str., Kl. - S., } \\
\text { Py. - S. und V. } \\
\text { Hintere Wurzein } \\
\text { fast, vordere ganz } \\
\text { frei. }\end{array}$ & $\begin{array}{l}\text { Blutungen. Rare- } \\
\text { fication der Vorder- } \\
\text { hörner des oberen } \\
\text { Brustmarks. }\end{array}$ \\
\hline $\begin{array}{l}\text { npfind- } \\
\text { keitder } \\
\text { sstwir- } \\
\text { lsäule. } \\
\text { absetz. } \\
\text { sensibi- } \\
\text { iät an } \\
\text { leh und } \\
\text { leken. }\end{array}$ & $\begin{array}{l}\text { Pupillar- } \\
\text { reaction } \\
\text { erhalten. }\end{array}$ & $\begin{array}{l}\text { Ineonti- } \\
\text { nentia } \\
\text { urinae et } \\
\text { alvi. } \\
\text { Blasen- } \\
\text { katarrh. }\end{array}$ & $\begin{array}{l}\text { Oedem der } \\
\text { Beine und } \\
\text { des Abdo- } \\
\text { men. Decu- } \\
\text { bitus an } \\
\text { Fersen und } \\
\text { Kreuzbein. }\end{array}$ & normal. & $\begin{array}{l}\text { Zwerch- } \\
\text { fells- } \\
\text { läbmung. }\end{array}$ & $\begin{array}{l}\text { Degeneration der } \\
\text { H. - Str., Kl. -S., } \\
\text { Py.-S. und V. } \\
\text { Hintere und vor- } \\
\text { dere Wurzeln nor- } \\
\text { mal. }\end{array}$ & $\begin{array}{l}\text { Blutungen. Vacuo- } \\
\text { lisirung und Atro- } \\
\text { phie einiger Gan- } \\
\text { glienzellen der Vor- } \\
\text { derhörner. Exsudat } \\
\text { im Sulcus anter. des } \\
\text { Halsmarks. }\end{array}$ \\
\hline $\begin{array}{l}. t w e i s e \\
. c k e m- \\
\text { alichk. } \\
\text { Brust- } \\
\text { jelsäu- } \\
\text { In der } \\
\text { teren } \\
\text { debge- } \\
\text { i Sensi- } \\
\text { iat her- } \\
\text { esetzt. }\end{array}$ & $\begin{array}{l}\text { Pupillar- } \\
\text { reaction } \\
\text { erhalten. }\end{array}$ & $\begin{array}{l}\text { Inconti- } \\
\text { nentia } \\
\text { urinae et } \\
\text { alvi. }\end{array}$ & $\begin{array}{c}\text { Deoubitus } \\
\text { am Kreuz- } \\
\text { bein. }\end{array}$ & normal. & $\begin{array}{c}\text { Zwerch- } \\
\text { fells- } \\
\text { lähmung. }\end{array}$ & $\begin{array}{l}\text { Degeneration der } \\
\text { H. - Str, Kl. - S., } \\
\text { Py.-S. und V. Un- } \\
\text { regelmässige Be- } \\
\text { theiligung des Re- } \\
\text { stes der Vorder- } \\
\text { und Seitenstränge. } \\
\text { EinzelneFasern in } \\
\text { hinteren und vor- } \\
\text { deren Wurzeln de- } \\
\text { generirt. }\end{array}$ & $\begin{array}{l}\text { Blutungen. Vacuo- } \\
\text { lisirung und Atro- } \\
\text { phie v. Vorderhorn- } \\
\text { zellen. Rarefication } \\
\text { d. Vorderhörner des } \\
\text { oberen Brustmarks. } \\
\text { Exsudat im Sulcus } \\
\text { ant. des Halsmarks. }\end{array}$ \\
\hline
\end{tabular}


Bild der combinirten Systemerkrankung aufgestellt haben, sind eine grosse Zahl von Fällen publicirt worden, die theils mebr, theils weniger diesem Bilde entsprechen. Die erstgenannten Autoren definirten den Begriff der combinirten Systemerkrankung folgendermaassen: ,Combinirte Systemerkrankung im Rückenmark ist die gleichzeitige und durch eine gemeinsame Krankheitsursache bedingte Erkrankung mebrerer Fasersysteme. Derselben muss ein ebenso genau zu umschreibendes Krankheitsbild entsprechen, als der isolirten Erkrankung der einzelnen Fasersysteme". Dieser Definition entspricht unbedingt das von Friedreich ${ }^{1}$ ) klinisch dargestellte und von ihm und Schultze ${ }^{2}$ ) zuerst pathologisch-anatomisch untersuchte Krankheitsbild der Friedreich'schen Ataxie. Es soll hier nur kurz auf diese Krankheit eingegangen werden, welche sich durch ibren hereditären Charakter, durch Beginn in der Pubertätszeit und sehr chronischen Verlauf bereits scharf genug von den oben beschriebenen Fällen abgrenzt. Dazu kommt das starke Hervortreten der spastischen Ataxie, der Verlust der Sehnenreflexe bereits in frühem Stadium der Krankheit, das späte und nur unvollkommene Auftreten von Paresen, so dass der gesammte Symptomencomplex eine genaue Scheidung von Tabes einerseits, von den combinirten Systemerkrankungen andererseits gestattet. Dem reiht sich der anatomische Befund an, der in combinirter Erkrankung der Hinterstränge, der Pyramidenseiten- und Vorderstrangbahnen und der Kleinhirnseitenstränge besteht. Dabei sind die Hinterstränge, fast in allen Fällen, in der Totalität, höchstens mit Freilassung eines schmalen Streifens unversehrten Gewebes längs des Randes der Hinterhörner, mit starker Betheiligung der hinteren Wurzelzone und besonders intensiver Degeneration der Goll'schen Stränge afficirt.

Stets sind die hinteren Wurzeln stark an der Erkrankung betheiligt, ein Befund, der also den ausgeprägtesten Fällen der Tabes entspricht, dagegen scharf von dem Hinterstrangsbefund meiner Fälle abweicht. Wie diese Degeneration der Hinterstränge sich entwickelt, darüber fehlen freilich die Angaben vollkommen; denn in sämmtlichen zur Untersuchung gelangten Fällen ist der Tod erst nach jahrelanger Krankheit und völliger Entwickelung des Processes eingetreten, während natürlich die Entstehung der Degeneration, insbesondere die der Tabes gegeniiber bestehenden Unterschiede, nur an in den Anfangsstadien befindlichen Fällen zu erkennen wären.

In allen Fällen Friedreich'scher Krankheit fand sich nun eine

1) Virchow's Archiv. Bd. XXVI, XXVII, LXVIII, LXX.

2) Ebenda. Bd. LXXIX. 1880. - Deutsche Zeitschrift für Nervenheilkunde. Bd, V. 1894. 
Seitenstrangserkrankung; denn die Angabe Friedreich's selbst, dass in 2 Fällen die Seitenstränge nicht befallen waren, bezieht sich nur auf makroskopische Betrachtung und kann daher nicht als beweisend angesehen werden. Dass die Degeneration in allen diesen Fällen eine streng systematische, nur auf Py.V. und S. und Kl.S. beschränkte wäre, lässt sich nicht aufreeht erhalten. Denn auch hier fand sich oft eine in den Seitensträngen weit nach vorn reichende Randdegeneration und zerstreute degenerirte Fasern in den Vorderseitenstrangresten. Doch treten diese Veränderungen gegenüber Pyramiden- und Kleinhirnbahnen so weit zuriuck, dass der systematische Charakter im Grossen und Ganzen gewahrt bleibt. Wenn nun auch wiederbolt, zuletzt mit ausfuibrlicher Begründung von Senato $\left.\mathrm{r}^{1}\right)$ noch eine Kleinhirnerkrankung zur Erklärung des Symptomencomplexes der Friedreich'schen Ataxie herangezogen worden ist, so fehlen doch bisher die anatomischen Untersuchungen, um diese Anschauung zu einer gesicherten zu machen. So können wir denn die Friedreich'sche Ataxie immerhin als ein gutes Beispiel der combinirten Systemerkrankung betrachten. Klinischer und anatomischer Befund schliessen gut zusammen und gestatten den Aufbau eines feststehenden Krankheitsbildes.

Wie steht es nun aber mit den übrigen in der Literatur bekannten Fällen gemeinschaftlicher Seiten- und Hinterstrangserkrankung? Handelt es sich hier gleichfalls im Wesentlichen um Erkrankung von Systemen? Lässt sich ein einheitliches Krankheitsbild aus klinischem Verlauf und anatomischem Befund herausschälen, oder sind hier mehrere, von einander scharf $z u$ trennende Krankheitsformen zu unterscheiden?

Schon ein kurzer Ueberblick der bisher veröffentlichten Arbeiten zeigt die grosse Mannigfaltigkeit der Einzelbeobachtungen. Es ist daher auch von allen Autoren, die versucht haben, die einschlägigen Fälle zu ordnen, eine Eintheilung in verschiedene Klassen dem anatomischen Process gemäss vorgeschlagen worden.

Ballet und Minor ${ }^{2}$ ) theilen die combinirten Erkrankungen der Seiten- und Hinterstränge ein in:

1. Diffuse Sklerosen von pseudosystematischem Charakter.

2. Typische Tabes mit Erkrankung der Kl.S.

3. Tabes mit Leptomeningitis, von der aus chronische Entzündungsprocesse die Seitenstränge befallen.

1) Berliner klin. Wochenschrift. 1893. Nr. 21.

2) Étude d'un cas de fausse sclérose systématique combinée de la moëlle. Arch. de Neurologie. VII. 1884. 
4. Interstitielle diffuse Myelitis, besonders des Brustmarks, mit auf und absteigender Degeneration.

5. Wahre combinirte Systemerkrankungen. ein in:

Ganz ähnlich und in Anlehnung an diese Autoren theilt Marie ${ }^{1}$ )

1. Wahre systematische Sklerosen:

a) typische tabische Hinterstrangserkrankung mit Degeneration der Py.S. bei allgemeiner Paralyse;

b) Goll'sche und Burdach'sche Stränge mit Kl.S.

2. Systematische Sklerose der Hinterstränge mit durch Leptomeningitis verursachter diffuser Myelitis der Seitenstränge.

3. Diffuse Myelitis mit auf- und absteigender Degeneration.

4. Diffuse Sklerose von pseudosystematischem Charakter.

Diesen Zusammenstellungen, welche theils der von Kahler und Pick aufgestellten Trias der Systeme nur eine bescheidene Rolle einräumen, theils dieselben ganz übergehen, reiht sich Leyden ${ }^{2}$ ) an, der bereits 1880 zwar das gelegentliche Vorkommen combinirter Systemerkrankungen in gemeinschaftlicher Erkrankung der Hinterstränge und der Pyramidenseitenstrangbahnen zugiebt, jedoch die grosse Mehrzahl der hierher gerechneten Fälle, so auch den ersten von Kahler und Pick beschriebenen, zur Myelitis circumscripta mit auf- und absteigender Degeneration rechnet. Auch in seiner neuesten Publication (1892) hält Leyden ${ }^{3}$ ) diesen Standpunkt fest, indem er in den bisher veröffentlichten Fällen sowohl ein hinreichend scharf umschriebenes Krankheitsbild als auch eine genïgende Präcision der Localisation der Strangerkrankung vermisst, um eine combinirte Systemerkrankung annehmen zu können. Er unterscheidet alte Tabesfälle mit Randdegeneration in den Hinterseitensträngen und chronische spastische Spinalparalysen, denen das Bild der chronischen Myelitis entspricht. Grasset ${ }^{4}$ ) stellt sämmtlicbe bis 1886 bekannten Fälle ohne Rücksicht auf klinische und anatomische Unterschiede zusammen and kommt zu dem Schluss: „La sclérose, systematisée aux cordons postérieurs est diffusée dans les cordons latéraux". Es sind gemischte Myelitiden, denen er den Namen Tabes combiné beilegt wegen der Verbindung der Symptome von Tabes ataxique mit Tabes spasmodique. In demselben Jahre (1886) versuchte Strüm-

1) Lecons sur les maladies de la moëlle. Paris 1892.

2) Zeitschrift für klin. Medicin. I. 1880.

3) Ueber chronische Myelitis und die Systemerkrankungen im Rückenmark. Zeitschr. für klin. Medicin. XXI. 1892.

4) Du Tabes combiné. Arch. de Neurol. XI, XII. 1886. 
pell ${ }^{1)}$ eine bestimmte Form der primären combinirten Systemerkrankung abzugrenzen, aufbauend auf drei von ihm selbst beobachteten Fällen. Diese Erkrankung, mit Degeneration der Py.S., Kl.S., Gollschen Stränge und der hinteren äusseren Felder der Hinterstränge einhergehend, bezeichnet er als spastische Form der combinirten Systemerkrankung im Gegensatz zur Friedreichschen Ataxie und zur Tabes mit secundärer Seitenstrangserkrankung. Eine sichere Diagnose intra vitam ist dabei nicht möglich, doch gehört nach der Ansicht Str ümpell's der grösste Theil der sogenannten „Spastischen Spinalparalysen" in diese Kategorie. In jüngster Zeit hat sich Mayer (l. c.) dieser Auffassung angeschlossen und, indem er selbst zwei dem Strümpell'schen Typus zuzurechnende Fälle mittheilt, folgende Eintheilung aufgestellt:

I. Gleichzeitige nicht systematische Erkrankung mebrerer Rückenmarksstränge mit secundärer, auf- und absteigender Degeneration (chronische Myelitis, Meningitis, multiple Sklerose).

II. Gleichzeitige systematische Erkrankung mebrerer Rückenmarksstränge.

a) Combination der Hinter- und Seitenstrangbahndegeneration bei Paralytikern.

b) Ausserbalb der Paralyse stehende gleichzeitige systematische Erkrankung der Vorder- und Hinterseitenstränge.

Hierron zwei Typen:

1. Str ü m pell'scher Typus.

2. Typus mit tabischem Hinterstrangsbefund.

c) Systematische Degeneration in Vorderseitensträngen (Py.S., Kl.S., eventuell Py.V.). Hinterstrang frei.

III. Es kann systematische Degeneration in einem Strange sich combiniren mit nicht systematischer Erkrankung eines anderen Stranges. In diese Kategorie gehören die Fälle von alter Tabes mit terminal hinzugetretener nicht systematischer Vorderseitenstrangsdegeneration.

Strumpel12) selbst hat dann wieder eine weitere Eintheilung gemacht, indem er seinen letzten klinisch und anatomisch untersuchten Fall (Gaum), dessen nur klinisch beobachteten Bruder und einen neuerdings gleichfalls nur klinisch beobachteten, hereditär belasteten Fall (Polster) zusammen mit einer einschlägigen, 4 von 6 Brüdern betreffenden klinischen Beobachtung Bernhardt's zu der Form „der

1) Archiv für Psych. XI. 1881 u. XVII. 1886.

2) Ueber die hereditäre spastische Spinalparalyse. Deutsche Zeitschrift für Nervenheilkunde. IV. 1893. 
hereditären spastisehen Spinalparalyse“ zusammenfasst. Derselben soll als anatomisches Substrat starke primäre Erkrankung der Pyramidenbahnen mit aufsteigendem Charakter und spätere leichte Degeneration anderer Systeme (besonders der Kl.S. und Goll'schen Stränge) entsprechen.

Ueberblicken wir nun die vorliegenden Arbeiten, so fällt es sofort ins Auge, dass ein grosser Theil derselben entschieden der Tabes zugerechnet werden muss. Es sind dies Fälle mit chronischem Verlauf, zuerst vollkommen dem typischen Symptomencomplex der Tabes entsprechend, mit frühem Verlust der Patellarreflexe und Pupillenstarre. Im weiteren Verlauf entwickelt sich motorische Schwäche der unteren, seltener der oberen Extremitäten, oft bis zur Parese gesteigert. Die Section ergiebt den typischen Befund der Tabes in den Hintersträngen mit Degeneration in den hinteren Wurzeln, vielfach von einer Leptomeningitis begleitet. Dazu gesellt sich eine theils nur den Rand der Seiten- und zuweilen der Vorderstränge einnehmende, theils auch tiefer in die Substanz der Seitenstränge eingreifende Degeneration, die keinesfalls auf bestimmte Systeme beschränkt ist, mit wenigen Ausnahmen jedoch beide Seiten symmetrisch befällt. Diese Degeneration der Seitenstränge ist von Déjerine, Ballet und Minor, Marie u. A. als eine Folge der uiber den Hintersträngen sich entwickelnden und auf das Gebiet der Seitenstränge sich fortpflanzenden Leptomeningitis aufgefasst worden. Doch lässt sich diese Anschauung wohl kaum aufrecht erhalten, denn es giebt:

1. Fälle von Tabes mit starker Leptomeningitis ohne die geringste Affection der Seitenstränge, z. B. der Fall von Dinckler ${ }^{1}$ ). Einen gleichen Fall von intensiver Degeneration der Hinterstränge und nngemein starker Leptomeningitis bei total intacten Seitensträngen habe ich selbst beobachtet.

2. Fälle von Tabes mit Seitenstrangserkrankung ohne Leptomeningitis.

3. Fälle von Tabes mit Leptomeningitis, bei denen die Seitenstrangserkrankung entweder von den Hintersträngen durch ein Gebiet gesunder Nervenfasern getrennt ist oder nicht an die Peripherie heranreicht.

$\mathrm{Zu}$ diesen Tabesfällen mit secundärer, nicht symmetrischer Erkrankung der Seitenstränge sind zu rechnen die Fälle von Pierret ${ }^{2}$ )

1) Tabes dorsalis incipiens mit Meningitis spinalis syphilitica. Deutsche Zeitschrift für Nervenheilkunde. III. 1893.

2) Arch. de physiol. norm. et path. 1871/72. IV. p.576. 
und Prévost ${ }^{1}$ ), Fall I, II, III und V von Westphal ${ }^{2}$ ), der Fall von Damaschino ${ }^{3}$ ), Fall I von Déjerine ${ }^{4}$ und der Fall von Schmaus ${ }^{5}$.

Diesen Fällen reihen sich dann diejenigen an, in denen der Verlauf gleichfalls dem der Tabes entspricht, mit leichter Parese in den letzten Stadien, und der anatomische Befund neben der typischen Hinterstrangserkrankung der Tabes thatsächlich eine systemartige Erkrankung der Seitenstränge ergiebt. Dabei finden sich folgende Unterabtheilungen:

1. Tabes mit Degeneration der Kl.S. Hierher gehört der Fall von Hadden und Sherington ${ }^{6}$ ) und ein von Ballet und Minor (1. c.) erwähnter, nicht näher beschriebener Fall.

2. Tabes mit Degeneration der Py.S. In diese Kategorie gehört der Fall von Erlicki und Rybalkin ${ }^{7}$, bei dem die Py.S. vom untersten Lendenmark bis zum obersten Halsmark degenerirt waren, bei völligem Erhaltensein der Kl.S.

3. Tabes mit Degeneration der Py.S. und Kl.S. Hier kommt nur der 3. Striumpell'sche Fall ${ }^{8}$ ) von 1881 in Betracht, in dem zu typischer Tabes Paralyse der unteren, Parese der oberen Extremitäten hinzutrat. Im Ruickenmark zeigte sich neben der tabischen Hinterstrangserkrankung Degeneration der gesammten Kl.S. und der Py. S. im unteren Brust- und Lendenmark.

In scharfem Gegensatz zu diesen Fällen von Tabes mit secundärer Erkrankung der Seitenstränge stehen nun die Fälle von typischer spastischer Spinalparalyse mit primärer Er krankung der Seitenstränge und secundärer der Hinterstränge. Hierher gehören der 4. Fall Westphal's (l. c.) von 1878, die Fälle von Reymond ${ }^{9}$ ) und Popof ${ }^{10}$ ), ein weiterer Fall West. phal's ${ }^{11)}$ von 1884, der Fall Strü mpell's ${ }^{12}$ ) von 1886 und der Fall von Dana 13). Diese Fälle zeichnen sich sämmtlich durch einen sehr chronischen Verlauf aus. Die Krankheitsdauer beträgt 3 bis

1) Arch. de physiol. norm. et path. 1877. II. Série. IV. p. 764.

2) Archiv für Psychiatrie. Bd. VIII. 1878.

3) Gazette des Hôpitaux. 1883.

4) Arch. de physiol. 1884. p. 454.

5) Deutsches Archiv für kin. Medicin. Bd. XLVI. 1890.

6) Brain XI. p. 325.1888.

7) Archiv für Psychiatrie. Bd. XVII. 1886. $\quad$ 8) Ebenda. Bd. XI. 1881.

9) Arch. de Phys. 1882.

10) Arch. de Neurolog. X. 1885.

11) Archiv für Psychiatrie. Bd. XV. 1884. 12) Ebenda. Bd. XVII. 1886.

13) Brain XI. 1888. 
24 Jahre, die spastischen Symptome stehen bis zum Tode im Vordergrunde des Krankheitsbildes, die Sehnenreflexe sind andauernd stark erhöht. Dagegen fehlen auf die Erkrankung der Hinterstränge zu beziehende Symptome entweder vollkommen (Reymond, Strilimpell) oder bestehen nur in geringen Störungen der Sensibilität, Schmerzempfindung oder des Temperatursinns; nur in einem Falle (Westphal 1878) sind leichte Störungen der Blase und des Mastdarms notirt. Damit stimmt der Hinterstrangsbefund gut überein, indem nur die Goll'schen Stränge, und zwar in den meisten Fällen, mit Freilassung des Lendenmarks Degeneration zeigten. Nur in dem Strumpell'schen Falle sind die Hinterstränge etwas ausgedehnter befallen; die Degeneration überschreitet jedoch auch hier nur an der Peripherie und in geringer Intensität die Grenze der Goll'schen Stränge. Dieser Befund erklärt sich vielleicht durch die lange Krankeitdauer, die uiber 24 Jabre betrug.

Die Pyramidenseitenstrangbahnen waren in allen Fällen dieser Gruppe vom Lendenmark bis zur Halsanschwellung ergriffen, während das oberste Halsmark gewöhnlich freiblieb. Dagegen waren die Py.V. in fast allen Fällen frei von der Degeneration; nur in dem Strümpell'schen Fall, der allerdings eine weit nach vorn sich erstreckende Randdegeneration aufwies, schienen dieselben leicht degenerirt, in dem Reymond'schen Fall waren sie nur im oberen Halsmark ergriffen. Daneben bestand nun in allen Fällen Erkrankung der Kl.S., von der oberen Hälfte des Brustmarks bis zum obersten Halsmark sich erstreckend. Randdegeneration war wieder nur im Stru mpell'sehen Fall in nennenswerther Form zu constatiren.

Im Grossen und Ganzen stellt sich diese Gruppe sowohl dem klinischen wie dem anatomischen Befunde nach sehr einheitlich dar. Der einzige Fall, der etwas stärkere Abweichungen zeigt, ist der Strümpell'sche, der auch durch das hereditäre Moment ausgezeichnet ist. $\mathrm{Ob}$ es thatsächlich möglich ist, eine hereditäre Form abzutrennen, wird sich erst entscheiden lassen, wenn weitere Sectionsbefunde vorliegen. Der systematische Charakter dieser Form der combinirten Systemerkrankung springt sehr ins Auge. Dabei wird man die Erkrankung der Py.S., auf die das klinische Bild oft viele Jahre allein hinweist, als das Primäre auffassen müssen und die Erkrankung der Goll'schen Stränge und wohl auch der K1.S. als secundär betrachten. Auf das Zustandekommen dieser combinirten Strangerkrankung soll erst weiterhin genauer eingegangen werden; jedenfalls wird sich bei der beträchtlichen räumlichen Entfernung der erkrankten Partien der Hinterstränge von den Pyramidenbahnen 
wohl Niemand versucht fühlen, meningitische Reize zur Erklärung zu verwenden.

Dieser Gruppe reihen sich nnmittelbar die beiden bisher bekannten Fälle von spastischer Spinalparalyse mit Erkrankung der Py.S. und V. und Kl.S. bei normalen Hintersträngen und geringer Veränderung der Vorderhornganglienzellen an. Es sind die Fälle von Minkowski ${ }^{1}$ ) und $M$ ünzer ${ }^{2}$ ). Der letztere erfordert insofern eine Einschränkung, als nur das dritte Dorsalsegment des Rückenmarks aufgehoben war. Es wäre sehr wohl möglich, dass in höheren Partien des Marks doch eine Degeneration der Hinterstränge sich gefunden hätte, wie es in dem Fall Dana's thatsächlich der Fall war. Da nun auch in dem Minkowski'schen Fall im Halsmark intensive Carminfärbung der Goll'schen Stränge mit geringfügiger Rareficirung der Nervenfasern angegeben ist, so sind diese Fälle vielleicht nur als solche der vorhergehenden Gruppe mit noch in den Anfangsstadien befindlicher Hinterstrangserkrankung zu betrachten.

Kurz erwähnen will ich dann nur die combinirte SkIerose von Seiten- und Hintersträngen bei der progressiven Paralyse. Die beträchtlichen Veränderungen des Gehirns, die bei dieser Krankheit gefunden werden, die zahlreichen apoplektischen Insulte, die in dem Krankheitsbild eine so wesentliche Rolle spielen, lassen die Verhältnisse derartig complicirt erscheinen, dass es sich kaum entscheiden lässt, welche Veränderungen des Rüickenmarks primäre, wellche secundäre, von Gehirnveränderungen bedingte sind. So sind denn auch die Fälle Zacher's ${ }^{3}$ ) theils nicht genau beobachtet, theils in dem asymmetrischen Befallensein der Riuckenmarksstränge so wesentlich von den zur combinirten Systemerkrankung zu rechnenden Fällen abweichend, dass sie besser hier ganz ausser Acht gelassen werden.

Wir kommen nun zu der eigentlichen Gruppe der combinirten Systemerkrankungen oder, wie sie besser nach dem Vorgang Westphal's zu nennen sind, der primären combinirten Erkrankung der Rückenmarksstränge. Hierher müssen alle die Fälle gerechnet werden, bei denen nicht die Erkrankung des einen Systems dem klinischen Bild vollkommen sein Gepräge giebt, und höchstens in den letzten Stadien einige Symptome auf die be-

1) Deutsches Archiv für klin. Medicin. Bd. XXXIV. 1884.

2) Wiener klin. Wochenschr. 1892.

3) Beiträge zur Pathologie und pathologischen Anatomie der progressiven Paralyse. Arch. f. Psych. Bd. XIV, XV. 1883/84. 
ginnende Degeneration eines weiteren Systems hinweisen, sondern zu gleicher Zeit oder wenigstens kurz nacheinander Seiten- und Hinterstrangserkrankung sich bemerkbar machen und durch ibre Complication ein eigenthümliches Krankbeitsbild schaffen, dem dann auch das ungefähr gleichmässige Befallensein der verschiedenen Systeme im anatomischen Befunde entspricht. Hierher rechne ich den Fall von $\mathrm{Babesiu}{ }^{1}$ ), 2 Fälle Strümpell's ${ }^{2}$ ), die Fälle von Sioli ${ }^{3}$ ) und Stadelmann ${ }^{4}$ ), 2 Fälle von Westphal ${ }^{5}$ ), die Fälle von Babinski und Charrin ${ }^{6}$, Francotte ${ }^{7}$ ), Clarke ${ }^{8}$, 2 Fälle von $S$ chmaus ${ }^{9}$, die Fälle von Arnold (l. c.) und $\mathrm{Hochhaus}{ }^{10}$ ), die beiden Fälle Mayer's (l. c.) und endlich meine drei eigenen, oben ausführlich geschilderten Fälle, im Ganzen also 19 Beobachtungen. Ferner müssen hier eingereiht werden die mit perniciöser Anämie verbundenen, oben bereits besprochenen Fälle, Fall IV und $V$ von Minnich, je einer von v. Noorden, Eisenlobr, Leyden und Bowman und zwei von Nonne, also weitere acht Fälle. Endlich ist der nur anatomisch untersuchte, soeben veröffentlichte Fall von Jakobi1) hierher zu lechnen.

In diesen 27 Fällen (der Jak o b'sche bleibt hier ausser Betracht) bestehen sowohl klinisch wie anatomisch sehr beträchtliche Unterschiede; auch hier überwiegen bald mehr die spastischen, bald mebr die atactischen Symptome. Doch sind alle Fälle durch verhältnissmässig raschen Verlauf ausgezeichnet; die Krankheitsdauer überstieg in keinem Fall 3 Jahre. Denn der einzige, im Ganzen 5 Jahre dauernde Fall, der von Sioli, zeigte zuerst fast völligen Rückgang der durch einen Fall entstandenen Rückenmarkssymptome innerhalb 4 Jah. ren und erst dann im Verlauf von $3 / 4$ Jahr rasche Entwicklung des zum Tode führenden Krankheitsbildes. Dagegen bestand in vielen Fällen die Krankheit nur 1 Jahr und darunter. Das männliche Geschlecht wurde wesentlich häufig er befallen; es waren 19 Mänuer und 8 Frauen. Von den 19 Männern war das Alter in 18 Fällen bekannt, es schwankte zwischen 19 und 66 Jahren mit einer Durchschnitts-

1) Virchow's Archiv. Bd. LXXVI. 1879.

2) Archiv für Psychiatrie. Bd. XI. 1881.

3) Ebenda.

4) Deutsches Archiv für klin. Medicin. Bd. XXXIII. 1888.

5) Archiv für Psychiatrie. XVII. 1886.

6) Revue de médecine. 1886. p. 962.

7) Arch. de Neurolog. XIX. $1890 . \quad 8)$ Brain 1890.

9) Virchow's Archiv. Bd. CXXII. 1890.

10) Deutsche Zeitschrift für Nervenheilkunde. IV. 1893.

11) Ein anatomischer Beitrag zur Lehre ron den combinirten Systemerkrankungen des Rückenmarks. Deutsche Zeitschr. f. Nervenheilk. Bd. VI. S. 115. 1894. 
ziffer von $44 \frac{1}{2}$; bei den 7 Frauen, deren Alter angegeben ist, schwankt die Zahl zwischen 32 und 62 mit einer Durchschnittsziffer von $481 / 2$. Bei allen Fällen zusammen betrug das Durchschnitsalter $46 \mathrm{Jahr}$. Manche der hier zusammengefassten Fälle, so vor allem der Fall Strü mpell's und der Fall von Leyden, sind ihrem klinischen Verlauf nach kaum von der reinen spastischen Spinalparalyse zu unterscheiden; denn die Blasenstörung in dem ersteren, der acute Verlauf in dem letzteren Fall sind doch nur unbedeutende $A b$ weichungen. Es war bier für das Einreihen in diese Gruppe das stärkere Befallensein der Hinterstränge vom Lenden- bis. zum Halsmark mit Ergriffensein lateral gelegener Abschnitte und Freibleiben der unmittelbar der Fissura posterior benachbarten Partien des unteren Brust- und Lendenmarks maassgebend. Doch zeigt es sich gerade an solchen Fällen, dass eine scharfe Abgrenzung der einzelnen Gruppen ungemein schwer ist, und uiberall Uebergänge zu constatiren sind. Unbedingt hierher zu rechnen sind meiner Ansicht nach die 2 Fälle von Westphal, obwobl dieser selbst sich gegen die Annahme einer „sogenannten Systemerkrankung" verwahrt hat. Aber dass auch in den Vorder- und Seitenstrangresten sich eine schwächere Degeneration bei längerem Bestehen der Krankheit einstellt, ist eine bekannte Thatsache, und das Verbalten der Hinterstränge mit dem späten Befallenwerden der hinteren Wurzelzone, die Erkrankung der Pyramidenbahnen in Seiten- und Vordersträngen, die Erkrankung der Kl.S., vor Allem aber das geradezu systematische Freibleiben des Gowersschen Strangs im mittleren und unteren Brustmark in dem ersten dieser Fälle zwingen dazu, diese Fälle hier einzureihen.

Ausser den ubrigen, in der Literatur bereits hinreichend gewürdigten Fällen erfordern dann noch die Schmaus'schen Beobachtungen eine Besprechung. Dieselben, bereits durch die Aetiologie der Rückenmarkserschütterung bemerkenswerth, sind klinisch nicht sehr genau beobachtet, ohne dass jedoch die Krankheitsymptome der Annahme einer combinirten Strangerkrankung widersprächen. Der anatomische Befund aber, vor Allem, in dem ersten Fall, entspricht so gut den sonst bekannten Verhältnissen, dass es wohl nicht za gewagt ist, die Fälle bier einzureihen. Die beiden jüngst berichteten Mayer'schen Fälle gehören mit zu den bestbeobachteten Fällen dieser Gruppe und haben die Kenntniss derselben wesentlich gefördert; in beiden Fällen besonders bemerkenswerth ist die von der Mitte des Brustmarks nach oben hin beobachtete Erkrankung der eintretenden hinteren Wurzel. Dieser Befund, in Verbindung mit der auch sonst der combinirten Strangerkrankung eigenen Veränderung der 
Hinterstränge gestattet eine gewisse Annäherung an den Hinterstrangsbefund der Friedreich'schen Ataxie. Denn es ist leicht verständlich, dass eine Combination von Erkrankung der hinteren Wurzeln und der bei der combinirten Strangerkrankung befallenen Hinterstrangspartien bei langer Lebensdauer schliesslich zu so excessiven Degenerationen fübren muss, wie sie bei der Friedreich'schen Ataxie unser Staunen erregen. Man könnte dann die letztere als com. binirte Strangerkrankung mit dem bekannten Befund und Erkrankung der binteren Wurzeln auffassen. Inwieweit diese Anschauung berechtigt ist, wird sich jedoch erst nach der Untersuchung von Anfangsstadien der Friedreich'schen Ataxie entscheiden lassen.

Ganz besonders typische Fälle sind alsdann die neuesten, der bereits oben eingehend gewürdigte Fall von $\mathrm{Bow} \mathrm{m}$ an mit perniciöser Anämie, und die Fälle von $\mathrm{Hochhaus} \mathrm{und} \mathrm{Jakob,} \mathrm{die} \mathrm{durch} \mathrm{die}$ strenge Begrenzung der Erkrankung auf die Systeme ausgezeichnet sind.

Ist es nun bei der so grossen Verschiedenheit des Krankheitsbildes überhaupt möglich, intra vitam die richtige Diagnose auf combinirte Strangerkrankung zu stellen? In einer Reihe der hier berichteten Fälle, in denen die Symptome der Hinterstrangs- oder Seitenstrangserkrankung lange Zeit allein bestehen, um sich erst in den letzten Stadien der Krankheit oder überhaupt nicht mit anderen Systemen zukommenden Symptomen zu combiniren, ist dies allerdings unmöglich. Jedoch in der Mehrzahl der Fälle sind eine Reihe von Anhaltspunkten zu gewinnen, von denen aus die richtige Diagnose gestellt werden kann. Hier steht an erster Stelle das Verhalten des Patellarreflexes; derselbe ist in allen Fällen, die nicht erst in einem sehr vorgeschrittenen Stadium der Krankheit zur Beobachtung kommen, erhalten. Es sind überhaupt nur sehr wenige Fälle vorhanden, die bereits bei der ersten Untersuchung Fehlen der Sehnenreflexe zeigten, und keiner derselben befand sich auch nur 2 Monate ante exitum in klinischer Beobachtung. Schon das Erhaltensein des Patellarreflexes bei dem Bestehen vieler auf die Hinterstränge zu beziehender Krankheitssymptome, wie Blasen- und Mastdarmstörungen, Ataxie, Sensibilitätsstörungen, ist für unsere Krankheit charakteristisch; noch viel mehr aber gilt das für diejenigen Fälle, bei denen es gelingt, das langsame Verschwinden des zuerst sogar oft erhöhten Patellarreflexes in späten Stadien der Erkrankung zu beobachten. Hierher gehören beide Fälle Westphal's, in deren erstem die Patellarreflexe 4 Monate, in dem zweiten einem Tag vor dem Tode verschwinden, nachdem sie vorher bereits herabgesetzt waren, ferner Fall $V$ von Minnich, bei dem die 
Patellarreflexe anfangs als normal, 3 Tage vor dem Tode als schwach angegeben sind; dann der erste Fall Mayer's mit anfangs ungewöhnlich stark erhöhten Reflexen, während 3 Monate ante mortem der Reflex rechts kaum noch, links in normaler Stärke nachweisbar ist. Dazu kommen sämmtliche 3 von mir beobachteten Fälle. In Fall I war der Patellarreflex anfangs sehr erhöht, während er am Tage vor dem Tode nur noch sebr schwach zu erzielen war; in Fall II war er bei der Aufnahme, $1 \frac{1 / 2}{2}$ Monate vor dem Tode, rechts sehr schwach, links nicht mehr dentlich auszulösen und in der Folge beiderseits erloschen; in Fall III endlich bestanden bei der Aufnahme normale Reflexe, $1 \frac{1}{2}$ Monate vor dem Tode beginnen sie abzunehmen, um 12 Tage ante exitum zu verschwinden.

An diese 7 Fälle reihen sich nun die beiden Nonne'schen an, bei denen die Patellarreflexe zuerst langsam abnahmen, in dem ersten Fall sogar verschwanden, um bei Besserung des gesammten Rückenmarkleidens wieder normale Intensität darzubieten, während die $\mathrm{Pa}$ tienten an perniciöser Anämie zu Grunde gingen. Es ist begreiflich, dass, wenn überhaupt die Rückenmarksveränderungen sich zurückbilden, die zuletzt erkrankten Partien sich am ehesten dabei betheiligen, eine Thatsache, die mit dem späten Ergriffenwerden der für die Auslösung des Patellarreflexes wichtigen hinteren Wurzelzone gut in Einklang steht.

Es ist im Ganzen bei 26 Fällen, in denen das Verhalten des Patellarreflexes angegeben ist, derselbe $11 \mathrm{mal}$ während der ganzen Beobachtungszeit erhöht, 5 mal erloschen; 7 mal verschwand er während der Beobachtung oder wurde wenigstens wesentlich schwächer, $2 \mathrm{mal}$ endlich verschwand er, um in den letzten Stadien wiederzukehren. Indem wir so alle Uebergänge beobachten, können wir schliessen, dass es hierbei lediglich auf die Entwickelung des Rückenmarksprocesses zur Zeit des Todes ankommt. Ehe nicht ein typischer Fall combinirter Strangerkrankung zar Beobachtung gelangt, in dem bereits im Beginn der Erkrankung der Patellarreflex erlosehen war, können wir das Verschwinden des PateJlarreflexes als ein $\mathrm{Spätsymptom}$ betrachten und hierin das beste differential-diagnostische Zeichen der Tabes gegenüber aufstellen.

Bemerkenswerth ist ferner das Erhaltensein der Pupillarreaction in sämmtlichen Fällen mit Ausnahme der beiden Mayerschen, in deren zweitem Complication mit Opticusatrophie bestand. Dies ist besonders der Tabes gegenüber gleichfalls ein werthvolles diagnostisches Zeichen. Auch, dass die Arme später und schwächer wie die Beine ergriffen werden, ist charakteristisch; nur in dem 
Fall von Babesin, in dem zweiten Strümpell'schen Fall, in dem Fall von Babinski and Charrin, in dem ersten Fall von Schmaus und dem ersten von Nonne - im Ganzen also in 5 Fällen - blieben die Arme bis zum Tode frei. In allen anderen Fällen werden Veranderungen derselben notirt von leichter Parästhesie bis zur schweren spastischen Parese. In den Fällen von v. Noorden und Arnold, in dem Eisenlohr'schen und dem zweiten Schmans'schen Falle wurden alle 4 Extremitäten ungefähr gleichzeitig befallen. In den ỉbrigen 14 Fällen ging die Erkrankung der Beine der der Arme voraus, zum Theil beträchtliche Zeit.

Was endlich die Verbindung von Parese und Ataxie betrifft, die Gowers wichtig genuge erschienen ist, um die Krankheit danach zu benennen (ataxic paraplegia), so ist in ca. der Hälfte der hier zusammengefassten Fälle keine Ataxie der unteren Extremitäten angegeben. Dieses auffällige Verhalten erklärt sich einerseits dadurch, dass alle echten Tabes-Fälle mit secundärer Seitenstrangerkrankung von vorne herein ausgeschieden sind; andererseits sind ein Theil der Fälle wohl nur zu spät zur Beobachtung gelangt,, indem die Parese der Beine bereits zu beträchtlich war, um die Ataxie hervortreten zu lassen. Dafür spricht, dass in einer Reihe von Fällen mit Lähmung der Beine an den Armen Ataxie zu constatiren war.

Was aber der grossen Mehrzahl dieser Fälle von Beginn der Erkrankung an ihr eigenthümliches Gepräge giebt, das ist die Verbindung von Seitenstrangs - und Hinterstrangssymptomen, anfangs spastische Parese und Ataxie, weiterbin schlaffe Parese, Sensibilitätsstörungen, Lähmungen von Blase und Mastdarm. Wenn es anch in weitaus den meisten Fällen nicht möglich sein wird, auf einen einmaligen Status hin die richtige Diagnose zu gewinnen, so sind es doch nur wenige Fälle, in denen nicht unter Berücksichtigung aller Symptome bei längerer Beobachtungszeit die combinirte Strangerkrankung festzustellen wäre.

Gehen wir nun zu dem pathologisch-anatomischen Befund über, so finden sich in allen Fällen Degenerationen im Gebiet der Hinterstränge, Py.S. und Kl.S.; in den Py.V. fehlt die Erkrankung nur in 8 Fällen. Die Erkrankung der Kl.S. und noch mehr der Py.S. und Py.V. macht in den meisten Fällen einen entschieden systematischen Eindruck, indem die Pyramidenbahnen vom Lenden- bis zum Halsmark, die Kl.S. vom unteren oder mittleren Brustmark bis zur Höhe der Pyramidenkreuzung befallen sind. Nur in den von Min$\mathrm{nich}$ und $\mathrm{N}$ on ne bei perniciöser Anämie beobachteten Fällen tritt ein mehr fleckenförmiger Charakter der Erkrankung hervor; 
Nonne lässt hier die grösseren Degenerationsherde aus dem Confluiren kleinster um hyalin degenerirte Capillaren gelegener Herdchen entstehen, während auch in noch nicht degenerirten Partien ähnlich veränderte Gefässe zu beobachten sind. In der grossen Mehrzahl der Fälle findet sich nun eine wesentlich schwächere, keinerlei Anlehnung an Systeme zeigende Erkrankung der Reste der Vorder- und Seitenstränge, welche nur die der grauen Substanz benachbarte Grenzschicht freizulassen pflegt. Nur in den beiden Strü mpell'schen Fällen und in den Fällen von Clarke, Hoehhaus and Jakob scheint die Begrenzung auf die Systeme eine strenge zu sein. Die Erkrankung der Hinterstränge ist in allen Fällen im Brustmark am ausgedehntesten, befällt daselbst oft das ganze Gebiet einschliesslich der hinteren Wurzelzone, wäbrend im Lendenmark mit Vorliebe ein schmales Gebiet der Goll'schen Stränge, das weder Peripherie noch Fissura post. erreicht und auch von der Commissura post. durch gesundes Gewebe getrennt ist, befallen wird, und im Halsmark eine aufsteigende Degeneration in den Goll'schen Strängen sich bemerkbar macht. Doch sind in dem Hinterstrangsbefund so wesentliche Verschiedenheiten der einzelnen Fälle zu constatiren, dass es auch hier schwierig sein dürfte, eine feste Anlehnung an bestimmte Systeme festzustellen. Das von Strümpell zuerst betonte Ergriffensein der hinteren medialen Wurzelzone im Halsmark, das auch Mayer in seinen beiden Fällen constatiren konnte, ist gleichfalls durchaus nicht constant; von meinen 3 Fällen zeigte nur der zweite ein stärkeres Hervortreten dieser Zone im Halsmark. Die hinteren Wurzeln waren theils ganz frei, theils in einzelnen Fasern degenerirt, jedoch in keinem Falle ähnlich stark erkrankt wie bei Tabes und Friedreich'scher Ataxie. Wenn also auch zuzugeben ist, dass die Erkrankung in den Seiten- und Vordersträngen in der Hauptsache dieSysteme der Kl.S., Py.S. und Py.V. befällt und auch in den Hintersträngen einen eigenartigen, wenn auch nicht auf die Systeme im Fle ch sig'schen Sinne beschränkten Charakter hat, so werden wir, bei der so häufigen nicht systemartigen Degeneration in anderen Bahnen, zumal die Systeme ja auch stets nur in einem kleineren oder grösseren Theil befallen sind, jedenfalls gut thun, die Krankheit nicht als primäre combinirte Systemerkrankung zu bezeichnen, sondern als primäre combinirte Strangerkrankung, im Gegensatz zu den oben geschilderten secundär combinirten Strangerkrankungen. Damit soll nur die ungefähr gleichzeitige Affection der Hinter- und Seitenstränge hervorgehoben werden, dagegen über den ersten Angriffspunkt der Rückenmarkserkrankung nichts Bestimmtes ausgesagt werden. 
Eine primäre Sklerose irgend eines Ruickenmarkabschnittes mit auf- und absteigenden Degenerationen lässt sich in sämmtlichen hier zusammengefassten Fällen nicht annehmen. Denn, wo man aucb dieselben hinverlegen möchte, und bei der verhältnissmässig stärksten Ausdehnung der Erkrankung müsste das in der Mehrzahl der Fälle das obere Brustmark sein, die Erkrankung der weissen Substanz wäre weder oberhalb noch unterhalb dieser Partie mit den bisher bekannten Gesetzen der secundären Degeneration vereinbar. Nun kann zwar nicht verkannt werden, dass die letzteren noch manche Modification erleiden werden. So haben wir in den letzten Jahren, vorwiegend durch Schultz e ${ }^{1}$, die kommaförmige absteigende Degeneration im Hinterstrang kennen gelernt, und erst im letzten Jahre (1894) haben Gombault et Philippe ${ }^{2}$ ) eine Reihe von Fällen mitgetheilt, in denen aufsteigende Degeneration der Py.S. nach Querschnittsmyelitiden zu beobachten war. Aber in unseren Fällen ist die Degeneration in den Hintersträngen nirgends der Kommaform entsprechend, und in den Py.S. und Py.V. lässt sich nicht, wie in den Fällen von G o m bault and Philippe, ein histologischer Unterschied zwischen den oberhalb und unterbalb des Herdes gelegenen Degenerationen constatiren, sondern die völlig gleichartige Affection erstreckt sich vom Lendenmark bis zum Halsmark, um dann langsam zu versehwinden. Endlich würde es in vielen Fällen, in denen die Kl.S. bereits im unteren Brustmark degenerirt sind, bei der Annahme einer Sklerose im mittleren oder oberen Brustmark Schwierigkeiten machen, diese Degeneration als eine aufsteigende aufzufassen, wie es bei der secundären Degeneration doch der Fall sein müsste. Bekanntlich hat S tr ü mpell sogar die Vermuthung ausgesprochen, dass der Process bei der kombinirten Strangerkrankung gerade umgekehrt verläuft, wie bei der secundären Degeneration, in den Pyramidenbahnen aufsteigend, in H.Str. und Kl.S. absteigend. Doch scheint mir, vor allem dem klinischen Verlauf entsprechend, in den meisten hierher" gehörigen Fällen der gesammte Process einen aufsteigenden Charakter zu haben, jedenfalls muss man an dieser Annahme für die beiden durch klinische Symptome sich bemerkbar machenden Stränge festhalten, für Py.Str. und H.Str., während für die Kl.S. uns allerdings jeder brauchbare Anbalt fehlt.

Es ist, gelegentlich der Besprechung der 3 von mir beobachteten Fälle, bereits der diesen allen gemeinsame auffällige Befund $\mathrm{der}$ Erkrakkung der grauen Substanz hervorgehoben worden. Es ergiebt nun eine Durchsicht der übrigen hier zusamınengefassten Fälle,

1) Archiv für Psychiatrie. Bd. XIV. 1883.

2) Arch. de médecine expérim. et d'anat. pathol. VI. 1894. 
dass Veränderungen der grauen Substanz nicht allzu selten sind. Zwar finden sich eine Reihe von Beobachtungen, in denen die graue Substanz entweder nicht erwähnt oder als normal angegeben ist - im Ganzen 10 Fälle, Hieran reihen sich diejenigen Fälle, die nur Veränderung der Clarke'schen Säulen aufweisen, theils Schwund der Ganglienzellen (Hochhaus, beide Strü mpell'sche und der zweite Mayersche Fall), theils der feinen Faserung (erster Fall Nonne's), theils beide Veränderungen gemeinsam (beide Fälle Westphal's und der von Clarke). Es bleiben dann aber mehrere Fälle ïbrig, in denen wesentlich stärkere Veränderungen notirt sind. In dem Fall von Si oli war die mediale Zellgruppe in den Vorderhörnern rom 4. Cervicalnerv abwärts bis ins Sacralmark geschwunden. Dazu kam Erkrankung der gesammten grauen Substanz der Vorderbörner im mittleren Theil des Dorsalmarks und Schwund der Substanz und der Ganglienzellen der Clarke'schen Säulen durch das ganze Dorsalmark.

Stadelmann fand in seinem Fall neben Affection der Clarkeschen Säulen multiple Blutungen in der grauen Substanz des Brustmarks. Dieselben liegen zum grössten Theil an der Basis der Hinterund Vorderhörner unregelmässig vertheilt und sind sämmtlich von miliarer Ausdehnung.

Die wesentlichsten Veränderungen jedoch fand Schmaus in dem ersten seiner Fälle von Rückenmarkserschütterung. In demselben zeigten die Clarke'schen Säulen vom oberen Brustmark an Verlust der Fasern. Auch die spongiöse Substanz der Hinterhörner wies im unteren Brustmark leichten Fasernverlust auf. In der grauen Substanz des Brustmarks fanden sich vereinzelte fleckige Stellen, die von einer homogenen, durch Eosin roth gefärbten Substanz ausgefullt waren, in der Reste von Ganglienzellen, dagegen keine Fasern zu erkennen waren. Im untersten Brustmark erreichte diese Substanz beiderseits eine grössere Ausdehnung, sie erstreckte sich von der Basis des Hinterhorns bis zur Spitze des Vorderhorns, nur den medialen Theil freilassend. In der Mitte derselben befand sich eine kleine, unregelmässig gestaltete Höhle. In der Lendenanschwellung fanden sich in beiden Vorderhörnern kleine Höhlen, vielleicht durch Zerreissung aufgelockerter Partien bei der Härtung entstanden. Schmaus fasst die homogene Substanz als eine durch das Trauma erzeugte Neubildung der Glia auf; dieselbe erinnert sehr an die in unserem zweiten und dritten Fall gefundenen homogenen Partien, die sich theils durch den Nachweis rother Blutkörperchen, theils durch die Nachbarschaft frischerer Blutungen als die Residuen älterer Blutextravasate darstellen, eine Erklärang, die für diese nach starker 
Rückenmarksersehütterung zu Stande gekommenen Veränderungen vielleicht auch berechtigt sein dürfte.

Der zweite Schmaus'sche Fall zeigte nur einen Erweichungsherd im rechten Hinterhorn der Halsanschwellung. Dagegen ergab der Arnold'sche Fall in der Halsanschwellung eine bröcklige Stelle zwischen Vorder- und Hinterhorn, die als Folgeerscheinung eines zwischen 6. und 7 . Cervicalnerven an derselben Stelle gelegenen kleinen Blutextravasats mit Kernanhäufung aufgefasst werden muss. Ferner zeigten sich die Ganglienzellen der medialen vorderen Gruppe an Zahl etwas vermindert, zum Theil atrophisch.

Endlich fand sich in dem ersten Fall Mayer's eine beträchtliche Atrophie der Ganglienzellen der Clarke'schen Säulen bei normaler Markfaserung. Die Ganglienzellen der Vorderhörner waren im Halsmark deutlich vermindert; auch die vorhandenen Ganglienzellen waren zum Theil atrophisch, einige zeigten Vacuolenbildung. Die letztere zeigte sich wesentlich ausgebildeter im unteren Lendenmark. Ausserdem bestand Ganglienzellenschwund im VI., VII. und XII. Hirnnervenkern.

Da nun in unseren 3 Fällen gleichfalls Blutungen und Exsudate und zum Theil auch Atrophie und Vacuolisirung der Ganglienzellen mit Schwund der Markfaserung zu constatiren waren, so erhebt sich die Frage, welche Rolle diese Veränderungen der grauen Substanz in dem ganzen Krankheitsbild spielen. Sind sie secundärer Natur, erst durch die Erkrankung der weis. sen Substanz bedingt, stehen sie unabhängig neben der letzteren, oder nimmt von hierder ganze Process seinen Anfang? Hiermit kommen wir überhaupt auf die Frage der Entstebung der combinirten Strangerkrankungen.

Kahler und Pick ${ }^{1}$ ) sprechen bereits bei der Publication ihres ersten Falles, der vielleicht der Friedreich'schen Ataxie zuzurechnen ist, jedenfalls durch seinen frühen Beginn und chronischen Verlauf von der hier behandelten Gruppe abgesondert werden muss, die Vermuthung aus, dass es sich um eine angeborene mangelhafte Markscheidenbildung im Gebiet der H.Str., Kl.S. und Py.Str. handele, welche bereits in der Pubertätszeit zur Functionsunfähigkeit dieser Fasersysteme führe. Auch Westphal ${ }^{2}$ ) unterzieht die Frage nach dem Ursprunge gemeinsamer Seiten- und Hinterstrangserkrankung einer eingehenden Betrachtung und kommt dabei auf die Beziehungen zar grauen Substanz in folgenden bemerkenswerthen Ausführungen zu sprechen: „Es
1) Archiv für Psych. VIII. 1878.
2) Ebenda. 
wäre denkbar, dass gewisse Classen von Fasern, obwohl sie in gesonderten "Systemen" nach verschiedenen Endpunkten verlaufen, dennoch gewisse Beziebung zu gemeinsehaftlichen in der grauen Substanz gelegenen Apparaten hätten, so dass etwa durch Theilnahme der letzteren an der Erkrankung zu ihnen in Beziehung stehende Fasern erkrankten, welche übrigens in der Marksubstanz selbst in sehr verschieden gelegenen Bahnen verlaufen. So enden beispielsweise die Pyramidenfasern in unbekannter Weise in der grauen Substanz und es wäre denkbar, dass ein Theil derselben mit dem Ursprunge der Kleinhirnseitenstrangbahn in irgend einem Zusammenhange stände. Allerdings kann sich diese Vorstellung nicht auf Befunde in der grauen Substanz stützen, allein es ist doch darauf hinzuweisen, dass wir bisher nur sehr grobe Veränderungen derselben mit einiger Sicherheit zu erkennen im Stande sind.";

Diesem Bestreben, einen gemeinsamen Ausgangspunkt der Erkrankung der weissen Stränge zn finden, gegenüber betont $S$ tr ü m p ell, dass die verschiedene Intensität der Degeneration in den einzelnen Strängen auf ein Nacheinander des Ergriffenseins hinweist, und jedes System selbstständig für sich erkrankt. Er betont, dass gerade die Markscheidenbildung der Py. Str., Kl.S. und Go. Str. am spätesten auftritt und hält es für möglich, dass alle primären systematischen Erkrankungen congenitalen Ursprungs sind. Neuerdings bat dann Pierre Marie ${ }^{1)}$ den vasculären Ursprung für einen grossen Theil der Fälle von combinirter Sklerose in den Vordergrund gestellt, indem er eine Erkrankung der Arteria spinalis posterior and ihrer Aeste als das Primäre betrachtet. Marie betont besonders das Freibleiben der Py. V. bei starker Sklerose der Py. S., um die systematische Erkrankung abzulehnen; für die Fälle jedoch, in denen die Py. V. auch befallen sind, nimmt er einfach eine partielle Betheiligung des Gebietes der Arteria spinalis anterior an, besonders der Arteria sulci anterioris. Diese Fälle sollen als combinirte Pseudosklerosen bezeichnet werden. Aber auch für die wahren combinirten Systemerkrankungen spielen nach Marie's Auffassung die Gefässvertheilungen die wesentlichste Rolle. Er bezieht sich dabei auf die nach Verschluss der Aorta abdominal. bei Kaninchen beobachteten Rückenmarksveränderungen und unterscheidet zwei Gruppen der weissen Stränge, erstens diejenigen, die nach diesem Verschluss Degeneration zeigen, neben der grauen Substanz die Masse der Vorder- und Seitenstränge und zweitens die intact bleibenden Bahnen, Hinterstränge, Kl.S. und Gow ers'sche Stränge. Diese letztere Gruppe

1) Leçons sur les maladies de la moëlle. Paris 1992. 
soll bei der combinirten Systemerkrankung, die erstere bei der amyotrophischen Lateralsklerose erkranken. Dieser Auffassung Marie's kann ich jedoch nicht beitreten; denn abgesehen von dem Thierexperiment, das weiter unten seine Betrachtung finden soll, erlaubt es bereits der pathologisch-anatomische Befund kaum, in dieser Weise eine Scheidung der bei amyotrophischer Lateralsklerose und combinirter Systemerkrankung befallenen Stränge vorzunehmen. Denn bei der ersteren findet sich oft genug Erkrankung der Hinterstränge, die Vorderseitenstrangreste sind oft nur wenig intensiv degenerirt, die graue Substanz gewöhnlich nur im Gebiet der Vorderhörner befallen, bei der combinirten Systemerkrankung wiederum sind die Py. S. und V. stets, die Vorderseitenstrangreste sehr oft befallen, die graue Substanz ist durchaus nicht immer intact, und gerade das Gebiet der Kl.S. ist oft bereits im unteren Brustmark von jeder Degeneration frei.

Experimentelle Arbeiten, die auf die Entstehung der combinirten Systemerkrankungen Licht zu werfen im Stande wären, fehlen beinahe gänzlich. Am wichtigsten ist hier jedenfalls die zuerst von Ehrlich und Brieger ${ }^{1}$ ) festgestellte Thatsache, dass beim Kaninchen, nach temporärem Verschluss der Aorta unterbalb des Abgangs der Nierenarterien, eine Nekrose der grauen Substanz des Lendenmarks zu Stande kommt, an welehe sich im weiteren Verlauf eine Degeneration der weissen Stränge anschliesst, welche nur Py. V., Hinterstränge und eine schmale Randzone der Seitenstränge freilässt. Dieser zuerst von $\mathrm{Sin} g \in \mathrm{r}^{2}$ ) bestätigte Befund wurde später von Singer und Münzer ${ }^{3}$ ) mit Hülfe der Marchi'schen Methode dahin erweitert, dass auch die Hinterstränge eine diffuse, Fasern feinen Kalibers betreffende, nicht allzu intensive Degeneration aufweisen, während in den Vorderseitensträngen eine dichte Degeneration mit geringer Betheiligung der perjpheren Partie des Hinterseitenstrangs nachweisbar ist. Das grosse Interesse dieses Befundes liegt erstens in dem Nachweis, dass die graue Substanz gegen die nur vortubergehende Blutleere weit empfindlicher ist als die weisse, indem die letztere za der Zeit, in der Nekrose der grauen Substanz nachweisbar ist, keinerlei Veränderungen aufweist, zweitens in dem Auftreten so beträchtlicher secundärer Degenerationen in der weissen Substanz

1) Ueber die Ausschaltung des Lendenmarkgrau. Zeitschr. f. kl. Med. Bd.VII.

2) Ueber die Veränderungen am Rückenmark nach zeitweiser Verschliessung der Bauchaorta. Sitz.-Ber. der kais. Akademie der Wissenschaften. Bd. XLVI. III. Abth. Wien 1888.

3) Beiträge zur Anatomie des Centralnerrensystems, insbesondere des Rückenmarkes. Wien 18990 . 
nach Erkrankung' der grauen. Leider ist es bisher nicht gelungen, an einer anderen Thierspecies dieses Experiment nachzumachen. Singer giebt bereits in seiner ersten Arbeit an, dass einige Versuche an Hunden nicht glïckten, indem keine Lähmungen nach der Abklemmung eintraten, und die Thiere sämmtlich an traumatischer Peritonitis zu Grunde gingen. Da diese letztere Complication die Ursache des Misserfolges sein konnte, so habe ich selbst in dem Laboratorium des Herrn Prof. H. Munk, dem ich für seine liebenswürdige Unterstiitzung bei diesen Versuchen zu wärmstem Dank verpflichtet bin, 3 Hunden die Aorta unmittelbar unter dem Abgang der Arteria renalis abgeklemmt. Das erste Mal blieb die Klemme 1 Stunde, bei beiden anderen Versuchen sogar 11/2 Stunden liegen. Der Erfolg war jedoch ein völlig negativer. Die Hunde zeigten, aus der Narkose erwacht, keinerlei Lähmungserscheinungen. Der erste starb 8 Tage nach der Operation ohne erkenntliche Ursache, die beiden anderen wurden nach 1 und 2 Monaten getödtet. Die Untersuchung des Rückenmarks nach Marchi'scher Methode ergab in allen 3 Fällen normale Verhältnisse. Es bestehen also beim Hunde offenbar zu reichliche Anastomosen von den höher entspringenden Gefässen. Vielleicht sind die Verbältnisse bei anderen Thieren ähnlich günstig, wie beim Kaninchen. Erfahrungen dariber fehlen jedoch bisher. ${ }^{1}$ )

Weiterhin ist hier bemerkenswerth die Arbeit von Fürstne ${ }^{2}$ ), der Hunde mehrere Monate hindurch täglich 1-2 Minuten nach einer bestimmten Richtung drehen liess, mit 60-80 Drehungen in der Minute. Dabei entwickelt sich, wie M endel zuerst gefunden hat, hochgradige Demenz mit deutlichen Veränderungen an der Hirnrinde. F ürstner vermochte jedoch bei einem $1 \frac{1}{4} \mathrm{Jahr}$ nach rechts gedrehten Hunde ausserdem Degeneration beider Py. S., am stärksten im Brustmark, schwächer im Hals- und Lendenmark, und der Hinterstränge im Brust-, oberen Lenden- und unteren Halsmark in einer kleinen Partie, die sich aus einem Streifen an der Grenze vom Goll- und Burdach'schen Strange und einem von diesem in spitzem Winkel nach innen abgehenden, parallel zur Peripherie verlaufenden und die Fissura posterior erreichenden Streifen zusammensetzt, nachzuweisen. In der Medulla oblongata war keine Spur einer Degeneration zu be-

1) Auch Münzer und Wien er berichten in einer soeben erschienenen Arbeit "Ueber die Ausschaltung des Lendenmarkgrau", dass sie bei 5 Hunden trotz Compression der Bauchaorta von einer Stunde Dauer keine Lähmungen erzielen konnten. Archiv für experim. Pathologie. Bd. XXXV. 1895.

2) Experimentelle Untersuchungen im Bereiche des Centralnervensystems. Berliner klin. Wochenschr. 1886. Nr. 40 . 
merken. Der Gefässapparat erschien völlig normal. Bei einem zweiten, $3 / 4$ Jahre nach links gedrebten Hunde fand sich nur die Py. S. beiderseits degenerirt, am stärksten im Brustmark, bei sonst normalem Befund. Allerdings giebt $F$ ü rstner selbst an, dass die Degenerationen mit der Weigert'schen Färbung nur schwer erkennbar waren, wie es bei frischer Degeneration ja auch sonst bekannt ist. Vermuthlich würde die Marchi'sche Methode in solchen Fällen von grossem Nutzen sein, vor allem auch die Frage entscheiden, ob sich nicht degenerirte Fasern in die graue Substanz hinein verfolgen lassen.

Diese Fälle von chronischer Rückenmarkserschütterung reihen sich eng an die beim Menschen beobachteten Fälle von acuter Rückenmarkserschütterung mit nachfolgender combinirter Strangerkrankung an. Wie weit hierher die Fälle von railway spine gehören, soll hier nicht erörtert werden. Jedenfalls haben wir in den beiden Schmausschen Fällen gute Beispiele dafür. Da aus den oben ausführlich besprochenen Fällen von Abklemmung der Aorta beim Kaninchen die wesentlich grössere Empfindlichkeit der grauen Substanz zur Genïge hervorgeht, so wird es uns nicht wundern, auch bei Fällen von Rückenmarkserschïtterung die letztere stark afficirt zu finden.

Wenn wir nun bedenken, dass feinere Veränderungen der grauen Substanz uns durch unsere Untersuchungsmethoden zum grossen Theil nicht erschlossen werden, dass vor allem die für die Structur der Ganglienzellen so werthvollen $\mathrm{N}$ issl'schen Methoden bei dem in Müller'scher Flüssigkeit gehärteten Rückenmark überhaupt nicht anwendbar sind, so werden wir erstens den trotzdem erkennbaren Veränderungen der grauen Substanz um so grössere Beachtung schenken müssen, zweitens aber die Angabe, dass die graue Substanz normal war, besonders in den älteren Arbeiten nicht als absolut sicher ansehen dürfen.

Bemühen wir uns aber, eine einheitliche Ursache für die Erkrankung der verschiedenen Stränge zu finden, so müssen wir die für die Friedreich'sche Ataxie wohl zu beachtende Erklärung der mangelhaften Markscheidenbildung ganz ausser Acht lassen. Denn hier handelt es sich nicht um langsam sich mit der Pubertätszeit entwickelnde Krankheitsbilder heriditärer Form, sondern um acut einsetzende Störungen bei Menschen mit abgeschlossener Entwickelung. Aber auch eine völlig selbständige Erkrankung der einzelnen Bahnen, theils auf-, theils absteigend, lässt sich mit der ganzen Entwickelung: der combinirten Strangerkrankung nicht gut vereinbaren; auch müssten wir dann weit häufiger die Combination nur zweier degenerirter Bahnen antreffen und in der Ausdehnung der Degeneration weit grössere Verschiedenheiten der einzelnen Systeme erwarten. Dazu 
kommt die Verbindung systemartiger Erkrankung einzelner Bahnen mit diffuser Affection anderer. So müssen wir im Hinblick sowohl auf die experimentellen Ergebnisse, als auch den pathologisch-anatomischen Befund der Westphal'schen Vermuthung wieder näher treten, dass die Erkrankung der grauen Substanz das Primäre des Processes sei. Hier liegen auf verhältnissmässig kleinem Raume nebeneinander die Endigungen der verschiedenen in der weissen Substanz getrennt verlaufenden Bahnen. Hier treten die aus den Hintersträngen in die graue Substanz einstrahlenden Fasern mit den Ganglienzellen der Vorderhörner in engste Verbindung, hier bilden die mit den Hintersträngen in Verbindung stehenden feinen Markfaseln der Clarke'schen Säulen enge Netze um die zusammen mit der Degeneration der Kl. S. der Atrophie verfallenden Ganglienzellen derselben. Hier müssen die Fasern der Kl. S. und Py. S. bei ihrem Eintritt resp. Austritt aus der grauen Substanz sich eng verflechten. Dass also Schädigungen der grauen Substanz an der Basis von Vorder- und Hinterhorn die Endigungen der verschiedenen Systeme treffen, ist nicht zu bezweifeln. Es fragt sich nur, ob eine derartige Schädigung auch zu Degenerationen in der weissen Substanz fübren kann.

$\mathrm{Am}$ ersten zuzugeben ist dies für die Kl. S.; es wird allgemein angenommen, dass diese von den Clarke'schen Säulen ihren Ursprung nehmen; eine Abtrennung von denselben müsste daher eine aufsteigende Degeneration zur Folge haben. Thatsächlich hat nun Borgherini ${ }^{1}$ ) nach Verletzung der grauen Substanz in einem Fall eine aufsteigende Degeneration der Kl. S. derselben Seite beobachtet. Weit schwieriger liegen die Verhältnisse für die Hinterstränge. Hier ist fürs erste nochmals hervorzuheben, dass das Freibleiben der hinteren Wurzeln, das erst in den letzten Stadien erfolgende Ergriffensein der hinteren Wurzelzone den Process scharf von dem der Tabes trennt, den wir als die Folge einer Erkrankung der hinteren Wurzeln kennen gelernt baben. Ist man bei der Tabes immer mehr dazu gedrängt worden, eine Erkrankung der Spinalganglien als der trophischen Centren der hinteren Wurzeln als das Primäre zu betrachten, so werden wir bei der gerade umgekehrt die äussersten Partien zuletzt ergreifenden Hinterstrangsaffection der combinirten Strangerkrankung naturgemäss auf die Ganglienzellen der grauen Rückenmarkssubstanz hingewiesen.

Bechterew ${ }^{2}$ ) giebt an, dass in die Hinterstränge ausser den Fasern der hinteren Wurzeln von den Ganglienzellen der grauen Sub-

1) Beiträge zur Kenntniss der Leitungsbahnen im Rückenmarke. Wien 1886.

2) Die Leitungsbahnen im Gehirn und Ruckenmark. Leipzig 1894. 
stanz aus Fasern eintreten, und zwar von der inneren und hinteren Seite der Clarke'schen Säulen zu den inneren und binteren Partien der Burdach'schen Stränge und zum Theil auch zu den Goll'schen Strängen und von den Zellen der Hinterhörner zu den Goll'schen Strängen. Wenn nun auch experimentelle und pathologisch-anatomische Erfahrungen über Degeneration der Hinterstränge nach Erkrankung der grauen Substanz, abgesehen von dem von Singer und Münzer nach Abklemmung der Aorta abdominalis beim Kaninchen erhobenen Befund, gänzlich fehlen, so werden wir doch nach diesen Ausführungen die Möglichkeit eines solchen Verbältnisses zugeben müssen. Auch die Erkrankung gerade der Goll'schen Stränge unmittelbar an der Fissura posterior in den letzten Stadien der spastischen Spinalparalyse würde damit gut übereinstimmen, indem man hier eine secundäre Erkrankung der grauen Substanz und weiterbin eine tertiäre der Goll'schen Stränge annehmen könnte.

Wir kommen nun za den Pyramidenbahnen, von denen es bisher festzustehen schien, dass dieselben eine centrifugale Verbindung zwischen Hirnrinde und motorischen Ganglienzellen der Vorderhörner darstellten und nur absteigend, nach Abtrennung von der Hirnrinde degenerirten. Nun hat bereits S trü mpell die Behauptung aufgestellt, dass der Process bei der combinirten Strangerkrankung gerade umgekehrt in den Pyramidenbahnen einen aufsteigenden Charakter hat. Hierzu kommt dann die bereits oben erwähnte Arbeit von Gombault und Pbilippe, welche in 3 Fällen aufsteigende Degeneration der Py. S. nachweisen konnten. In dem ersten dieser Fälle handelte es sich um eine Querschnittsmyelitis traumatischen Ursprungs in der Höhe der Lendenanschwellung nach einem 10 Meter tiefen Sturz; weit bemerkenswerther sind jedoch die beiden anderen Fälle, in denen auf- und absteigende Degeneration mit Syringomyelie verbunden war. In dem ersten dieser Fälle erstreckte sich dieselbe vom 4. Hals- bis 9. Brustnerv; die graue Substanz war rareficirt mit Schwund der feinen Nervenfasern, Schwellung der Vorderhornzellen und perivasculären Blutungen; in dem anderen war die vom 8. Cervicalnerr bis zum unteren Dorsalmark sich erstreckende Höhlenbildung mit einer Pachymeningitis hypertrophica combinirt. Vielleicht könnte man auch hier annehmen, dass die Rückenmarkserschïtterung in dem ersten, die Syringomyelie mit Veränderung der grauen Substanz in den beiden anderen Fällen zu den aufsteigenden Degenerationen in den Py.S. geführt habe, da diese Beobachtung mit unseren sonstigen Kenntnissen von secundärer Degeneration nach Rückenmarkscompression oder Querschnittsmyelitis nicht $z \mathfrak{u}$ vereinbaren wäre. Aller- 
dings giebt Gowers ${ }^{1}$ ) an, dass bei der acuten Myelitis von den Entzündungsherden aus neben den bekannten Degenerationen der langen Faserzüge auch eine aufsteigende Degeneration der Pyramidenbahnen auftreten kann, die sich 1-2 Zoll über die obere Grenze der Allgemeinentzündung herauf erstreckt. ${ }^{2}$ )

Man hat ferner stets angenommen, dass in den Pyramidenbahnen ausser den langen Leitungsbahnen kurze Commissurenfasern verlaufen, die höher und tiefer gelegene Partien der grauen Riickenmarkssubstanz mit einander verbinden. Durch die Existenz dieser Fasern bat man zum Theil die Thatsache zu erklären gesucht, dass das degenerirte Feld des Pyramidenstranges nach Riickenmarksherden wesentlich grösser ist, als nach Hirnläsionen. Auch scheint mir die Thatsache, dass man bei frischen absteigenden Degenerationen in den Py. S. nach Rindenläsionen der motorischen Regionen die afficirten Fasern selbst mit der Marchi'schen Methode niemals in die graue Substanz des Rückenmarks hinein verfolgen kann, dafür zu sprechen, dass von den Ganglienzellen der grauen Rü̈ckenmarkssubstanz aus ein gewisser Einfluss auf die Pyramidenfasern ausgeübt wird.

Jedenfalls scheint es nach all diesen Thatsachen nicht unwahrscheinlich, dass eine Erkrankung der grauen Substanz des Rückenmarks von theils auf-, theils absteigenden Degenerationen der Py. S. in beschränkter Ausdehnung gefolgt sein kann. Grosse Schwierigkeiten macht es allerdings, die gleichzeitige Erkrankung der Py. V. zu erklären, wenn man nicht annehmen will, dass Py. S. und Py. V. sich vor der Verbindung mit den motorischen Ganglienzellen der Vorderbörner im Innern der grauen Substanz vereinigen.

1) Handbuch der Nervenkrankheiten. 1892. Bd. 1. S. 321.

2) Auch in der soeben erschienenen Arbeit von D. Gerhardt "Ueber das Verhalten der Reflexe bei Querdurchtrennung des Rückenmarks" (Deutsche Zeitschrift für Nervenheilkunde. Bd. VI. 1894) wurde bei einem 18jährigen Mann mit totaler Rückenmarkscompression vom j. bis 9. Brustwirbel durch vom Knochen ausgegangenes Angiom eine bis zum unteren Theil der Halsanschwellung reichende, nach oben allerdings an Intensität rasch abnehmende aufsteigende Degeneration der Pyramidenbahnen constatirt. Dem reiht sich der Fall von F. Egger an (Arch. f. Psych. Bd. XXVII. 1895. S. 129), bei dem nach Compression des untersten Halsmarks infolge einer alten Halswirbelfractur neben den typischen Degenerationen aufsteigende Degeneration beider Py.S. und Py.V. bis zur oberen Grenze der Halsanschweliung gefunden wurde. Hierher gehört auch der soeben von J. Déjerine und J. Sottas veröffentlichte Fall von Myelitis transversa syphilitica zwischen 4. und 9. Brustnerven mit aufsteigender Degeneration in beiden Py. S. und Py.V. bis zur Pyramidenkreuzung herauf. Société de Biologie. 14. VI. 1895. p. 436. 
Fassen wir diese Ausftubrungen nochmals zusammen, so sehen wir, dass Thatsachen, die den Einfluss der grauen Substanz des Rückenmarks auf die einzelnen Fasersysteme beweisen, nur äusserst spärlich vorhanden sind, dass aber doch eine Reibe von Beobachtungen existiren, die ein derartiges Abhängigkeitsverhältniss der weissen Stränge nicht unwahrscheinlich machen. Um uns in der Erkenntniss weiter lommen zu lassen, wird die experimentelle Physiologie und die pathologische Anatomie wesentlicbe Fortschritte machen müssen. Aber das Bestreben, derartige Krankheitsformen, wie die combinirten Strangerkrankungen, als eine Einheit und nicht als das Nebeneinander verschiedener Degenerationsprocesse aufzufassen, weist uns mit Nothwendigkeit auf eine primäre Erkrankung der grauen Substanz hin. Dieselbe hätten wir uns so vorzustellen, dass die graue Substanz nicht nur in einer bestimmten Höhe des Rlickenmarks erkrankt, sondern dass die Affection derselben säulenförmig sich durch das ganze Rückenmark oder wenigstens einen beträchtlichen Theil desselben erstreckt, so dass die weissen Stränge von verschiedenen Punkten aus zu degeneriren beginnen. Ist erst einmal eine Degeneration in den bestimmten Fasersystemen gesetzt, dann kann auch in denselben von den erkrankten Fasern her eine Einwirkung auf die übrigen angenommen werden, so dass schliesslich der gesammte Strang der Degeneration anheimfällt.

In allen Fällen, wo eine Rückenmarkserschütterung zur Entstehung der Krankheit geführt hat, oder greifbare Veränderungen der grauen Substanz erkennbar sind, wird diese Erklärung einen guten Rückhalt haben. Aber auch in den Fällen von perniciöser Anämie wird man es leicht verstehen können, dass eine Schädigung der Ganglienzellen durch ungenuigende Ernährung seitens des erkrankten Blntes erzeugt wird, wenn auch die nach Härtung in Müller'scher Flüssigkeit angewendeten Färbemethoden nichts davon erkennen lassen. Und gerade hier ermöglicht es uns der Uebergang von den leichteren, nur fleckenförmige Degenerationen zeigenden zu den gut entwickelten, mit Erkrankung der ganzen Systeme einhergehenden Fällen, uns die Entwickelung des Krankheitsprocesses deutlich vor Augen zu führen.

Aber anch bei einer primären Erkrankung der grauen Substanz werden wir angesichts der Exsudate und Blutungen, vor allem auch im Sulcus anterior und um den Centralcanal, die Gefässerkrankung in den Vordergrund stellen mitssen, indem wir eine Affection der von der Arteria spinalis ant. entspringenden Arteria sulci (A d amkiewicz) annebmen. Dieselbe rersorgt die um den Centralcanal 
und an der Basis von Vorder- und Hinterhorn gelegenen Partien, in denen wir am hänfigsten Blutungen und Exsudate finden, und von denen aus am leichtesten eine gemeinsame Erkrankung der weissen Substanz ausgelöst werden kann. Ob allerdings diese Erklärung für alle Fälle ausreicht, steht dahin; vermuthlich wird, wie durch Elschiitterung, so auch durch Gifte und andere Schädlichkeiten, eine Erkrankung der in Betracht kommenden Theile der grauen Substanz bewirkt werden können, und auf diesem Wege gleichfalls das Bild der combinirten Strangerkrankung zu Stande kommen.

Ich bin mir wohl bewusst, in dem hier Vorgetragenen nur Ansichten geboten zu haben, die erst nach längerer Zeit ibre Bestätigung erhoffen dürfen. Lässt sich aber diese Anschauung aufrechterhalten, so haben wir nicht nur die primären combinirten Strangerkrankungen in ihrer Entstehung gut erklärt, sondern auch die beiden anderen, oben zusammengefassten Gruppen, die der Tabes mit secundärer Seitenstrangserkrankung und die der spastischen Spinalparalyse mit securdärer Erkrankung der H. Str. und Kl. S. Denu auch hier würden wir die bei langem Bestehen der Degeneration eines Fasersystems eintretenden Veränderungen der grauen Substanz für die in den Endstadien beobachtete Degeneration der anderen Systeme verantwortlich machen.

Was nun die weitere Entwickelung des Processes nach der primären Affection der grauen Substanz betrifft, so fehlt uns jeder Anhalt für die Bestimmung, welcher der weissen Stränge zuerst degenerirt. Nach der klinischen Beobachtung treten bald die Spasmen, bald die Ataxie, bald Sensibilitätsstörungen an erster Stelle auf; fernerhin lässt sich nur schwer von dem klinischen Bild ein Rückschluss auf die Anfangsstadien des anatomischen Processes machen, die vịelleicht ganz symptomlos verlaufen. Hier könnte uns nur eine anatomische Untersuchung der Anfangsstadien selbst fördern, und hierzu würden sich Fälle von Rückenmarkserschütterung, in denen bereits einige Wochen nach dem Unfall der Exitus eintritt, am besten eignen. Denn nach den vorliegenden Erfahrungen können wir erwarten, hier wenigstens in einigen Fällen die erste Entwickelung einer combinirten Strangerkrankung anzutreffen. Hat sich dagegen der Degenerationsprocess erst voll ausgebildet, so können wir höchstens noch hoffen, mit Hülfe der Marchi'schen Methode die Richtung, in der der Process sich ausbreitet, zu erschliessen, da mittelst derselben bekanntlich nur das frisch degenerirte Mark eine Schwarzfärbung annimmt.

Der A usgang der primären combinirten Strangerkrankung ist, 
soweit bis jetzt bekannt, in allen Fällen ein letaler. Es ist daher die Prognose bei dem schnellen Verlauf der Krankbeit absolut infaust zu stellen. Doch ist dabei bemerkenswerth, dass in einer Reihe von Fällen im Verlauf der Krankheit wesentliche Besserungen beobachtet sind. Hierher gehört der Fall von Sioli, in dem die nach schwerer Rückenmarkserschütterung eintretende Lähmung der Arme und Beine in 3 Monaten bis auf leicht persistirende Schwäche der Beine zurückging, 41/2 Jahre später dann der Symptomencomplex der combinirten Systemerkrankung sich entwickelte; dann der Fall von A rnold, bei dem eine anfänglich sich ausbildende Lähmung der Arme später fast ganz zurückging, so dass in den letzten Stadien nur motorische Schwäche und Ataxie zu constatiren war. Die wichtigsten derartigen Beobachtungen jedoch sind die beiden Fälle Nonn e's und der Fall von B ow man, ihrer Verbindung mit perniciöser Anämie wegen. Ist in den Nonne'schen ein Zusammenhang zwischen der wesentlichen Besserung der Rückenmarkssymptome und dem Blutbefund nicht zu constatiren, so ist dagegen in dem Bow man'schen Fall der Zusammenhang zwischen Blutbefund und spinalen Symptomen ungemein auffällig. Bessert sich der Blutbefund unter geeigneter Behandlung, so bessert sich auch der Gang; tritt wieder Verschlechterung der Blutmischung ein, so entwickelt sich auch Parese

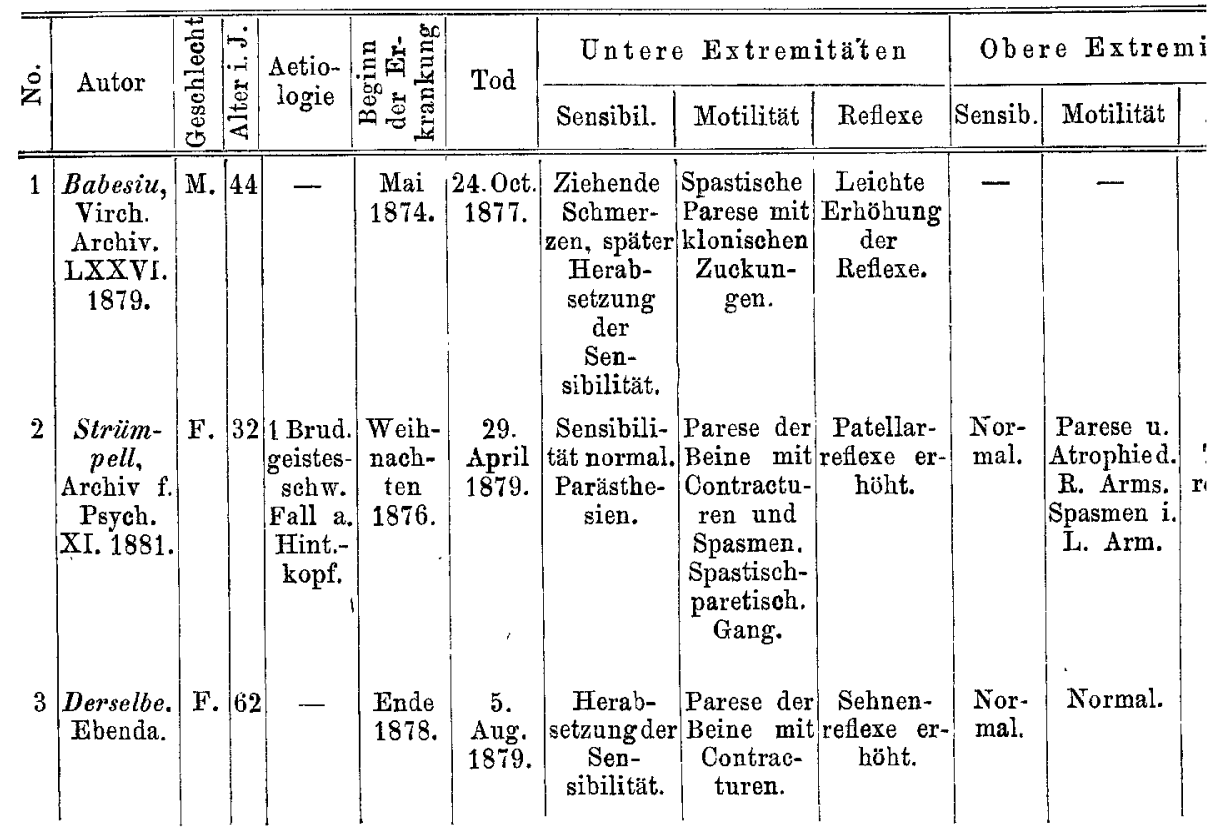


der Beine. Gerade diese Beobachtung lässt es bei der sonstigen Aussichtslosigkeit der Behandlung dringend nothwendig erscheinen, in jedem hierher gehörigen Falle eine sorgfältige Blutantersuchung vorzunebmen, da man bei Constatirung einer perniciösen Anämie immerhin hoffen kann, das Fortschreiten der spinalen Erkrankung, wenn auch nur voribbergehend, zum Stillstand zu bringen. Dagegen zeigen mehrere Beobachtungen, vor allem unser zweiter Fall (A $\lg$ ner), dass antisyphilitische Kuren selbst in Fällen mit sicher festgestellter Lues keine Besserung, oft sogar eine Verseblechterung der spinalen Erkrankung hervorrufen. Inwieweit die nach Rückenmarkserschütterung sich entwickelnden Symptome (railway spine) auf combinirte Strangerkrankungen zurückgeführt werden können, und ob die hier gesetzten Veränderungen der Rückenmarkssubstanz sich in einzelnen Fällen wieder ganz zurïckbilden, lässt sich jetzt noch nicht mit Sicherheit bestimmen. Jedenfalls werden wir, wenn bei der combinirten Strangerkrankung überhaupt Heilungen vorkommen, was gewiss nicht unwahrscheinlich ist, gerade hier zuerst einschlägige Beobachtungen erwarten können.

Im Anschluss an diese Ausführungen gebe ich endlich eine tabellarische Zusammenstellung der 28 unter dem Bilde der primären combinirten Strangerkrankung hier zusammengefassten Fälle.

\begin{tabular}{|c|c|c|c|c|c|c|c|}
\hline \multirow{2}{*}{ 'umpf } & \multirow{2}{*}{ Geairn } & \multirow{2}{*}{$\begin{array}{l}\text { Blase und } \\
\text { Mastdarm }\end{array}$} & \multirow{2}{*}{$\mid \begin{array}{c}\text { Trophische } \\
\text { und vaso- } \\
\text { motorische } \\
\text { Störungen }\end{array}$} & \multirow{2}{*}{$\begin{array}{l}\text { Blut- } \\
\text { befund }\end{array}$} & \multirow{2}{*}{$\begin{array}{l}\text { Todes- } \\
\text { ursache }\end{array}$} & \multicolumn{2}{|c|}{ Ruckenmarksbefund } \\
\hline & & & & & & Weisse Substanz & Graue Substanz \\
\hline- & \begin{tabular}{|} 
Er- \\
blindung. \\
Iseichte \\
Atrophied. \\
Opticus.
\end{tabular} & $\begin{array}{l}\text { Lähmung } \\
\text { v. Blase u. } \\
\text { Mastdarm. }\end{array}$ & $\begin{array}{l}\text { Deoubitus } \\
\text { am Kreuz- } \\
\text { bein; Gan- } \\
\text { grän der } \\
\text { Blase. }\end{array}$ & - & - & $\begin{array}{l}\text { H. Str., } \\
\text { Py. S. u. V., } \\
\text { Kl. S. }\end{array}$ & Normal. \\
\hline \multicolumn{8}{|l|}{ i } \\
\hline $\begin{array}{l}\text { :oliose } \\
\text { Brust- } \\
\text { irbel- } \\
\text { ïule. }\end{array}$ & $\begin{array}{l}\text { Träge } \\
\text { Pupillen- } \\
\text { reaction. } \\
\text { Leichter } \\
\text { Nystag- } \\
\text { mus. }\end{array}$ & $\begin{array}{l}\text { Incon- } \\
\text { tinentia } \\
\text { urinae. } \\
\text { Cystitis. }\end{array}$ & - & - & $\begin{array}{l}\text { Marasmus } \\
\text { durch } \\
\text { Fieber. }\end{array}$ & $\begin{array}{l}\text { H. Str., Kl. S., } \\
\text { Py. S. u. rechter } \\
\text { Py. V. }\end{array}$ & $\begin{array}{l}\text { Abnahme der } \\
\text { Ganglienzellen der } \\
\text { Clarke'sehen Säu- } \\
\text { len, sonst normal. }\end{array}$ \\
\hline- & - & $\begin{array}{l}\text { Incon- } \\
\text { tinentia } \\
\text { urinae. }\end{array}$ & - & - & Phthise. & $\begin{array}{l}\text { H. Str., Kl. S., } \\
\text { Py. S. }\end{array}$ & $\begin{array}{c}\text { Ganglienzellen- } \\
\text { schwund der Clarke- } \\
\text { schen Säulen, sonst } \\
\text { normal. }\end{array}$ \\
\hline & Deutsch $\theta$ & Zeitschr. f. B & Nervenheilkun & & & 17 & \\
\hline
\end{tabular}




\begin{tabular}{|c|c|c|c|c|c|c|c|c|c|c|c|c|}
\hline \multirow{2}{*}{$\dot{z}$} & \multirow{2}{*}{ Antor } & \multirow{2}{*}{ 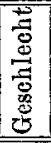 } & \multirow{2}{*}{ 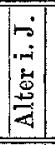 } & \multirow{2}{*}{$\begin{array}{l}\text { Aetio- } \\
\text { logie }\end{array}$} & \multirow{2}{*}{ 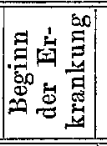 } & \multirow{2}{*}{ Tod } & \multicolumn{3}{|c|}{ Untere Extremitäten } & \multicolumn{3}{|c|}{ Obere Extremitatef } \\
\hline & & & & & & & Sensibil. & Motilität & Reflexe & Sensib. & Motilität & Reflir \\
\hline 4 & $\begin{array}{l}\text { Sioli, } \\
\text { Ebenda. }\end{array}$ & M. & 44 & $\begin{array}{c}1874 \\
\text { Fall v. } \\
3 . \text { Stck. } \\
\text { herab. }\end{array}$ & $\begin{array}{l}\text { Anf. } \\
1879 .\end{array}$ & $\begin{array}{c}5 . \\
\text { Nov. } \\
1879 . \\
\end{array}$ & \begin{tabular}{|c|}
1874 \\
voruber- \\
gehende \\
Sensibili- \\
tätsstö- \\
rung nach \\
Fall. 1879 \\
Hyper- \\
ästhesien.
\end{tabular} & $\begin{array}{c}1874 \\
\text { vortuber- } \\
\text { gehende } \\
\text { Lähmung } \\
\text { nach Fall. } \\
1879 \quad \mathrm{~Pa}- \\
\text { rese. }\end{array}$ & $\begin{array}{c}\text { Patellar- } \\
\text { reflex er- } \\
\text { loschen. }\end{array}$ & . & $\begin{array}{c}1874 \\
\text { vortsber- } \\
\text { gehende } \\
\text { Lühmung } \\
\text { der Arme } \\
\text { nach Fall. } \\
1879 \\
\text { Parese der } \\
\text { Arme. } \\
\text { R. stärker. }\end{array}$ & $\therefore$ \\
\hline 5 & $\begin{array}{c}\text { Stadel- } \\
\text { mann, } \\
\text { Deutsch. } \\
\text { Archiv f. } \\
\text { klin.Med. } \\
\text { XXXIII. } \\
1883 .\end{array}$ & F. & 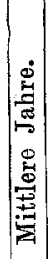 & - & $\begin{array}{r}\text { Anf. } \\
1877 .\end{array}$ & $\begin{array}{c}23 . \\
\text { Juli } \\
1881 .\end{array}$ & $\begin{array}{c}\text { Sensibili- } \\
\text { tätsstö- } \\
\text { rung. } \\
\text { Analgesie. }\end{array}$ & \begin{tabular}{|} 
Starke mo- \\
torische \\
Schwäohe \\
der Beine, \\
links mehr \\
als rechts.
\end{tabular} & $\begin{array}{l}\text { Sehnen- } \\
\text { reflexe anf- } \\
\text { gehoben. }\end{array}$ & $\begin{array}{c}\text { Hyper- } \\
\text { ästhe- } \\
\text { sie. }\end{array}$ & - & 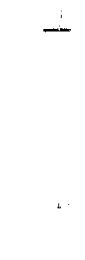 \\
\hline 6 & $\begin{array}{c}\text { West- } \\
\text { phal, } \\
\text { Archiv f. } \\
\text { Psych. } \\
\text { XVII. } \\
1886 .\end{array}$ & M. & .50 & - & $\begin{array}{c}\text { Som- } \\
\text { mer } \\
1882 .\end{array}$ & $\begin{array}{c}4 . \\
\text { Febr. } \\
1884 .\end{array}$ & $\begin{array}{c}\text { Sensibili- } \\
\text { tätsstörun- } \\
\text { gen. Stö- } \\
\text { rung des } \\
\text { Muskelge- } \\
\text { fuhls. }\end{array}$ & $\begin{array}{c}\text { Starke } \\
\text { motorische } \\
\text { Sehwäche } \\
\text { mit Ataxie. }\end{array}$ & $\begin{array}{c}\text { Patellar- } \\
\text { reflex An- } \\
\text { fangs er- } \\
\text { halten, er- } \\
\text { liseht erst } \\
\text { Oetober } \\
1883 .\end{array}$ & $\mid \begin{array}{c}\text { Sensi- } \\
\text { bili- } \\
\text { tätsstö- } \\
\text { rung. } \\
\text { Stör. d. } \\
\text { Musk. - } \\
\text { gef. }\end{array}$ & $\begin{array}{l}\text { Motor. } \\
\text { Schwäche } \\
\text { u. Ataxie. }\end{array}$ & 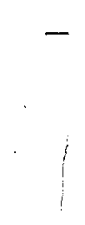 \\
\hline 7 & $\begin{array}{c}\text { Derselbe } \\
\text { Ebenda. }\end{array}$ & M. & 53 & $\begin{array}{c}\text { Erkäl- } \\
\text { tung. } \\
(?)\end{array}$ & $\begin{array}{c}\text { Deobr. } \\
1882\end{array}$ & $\begin{array}{c}24 . \\
\text { Januar } \\
1885 .\end{array}$ & $\left\{\begin{array}{c}\text { Sensibili- } \\
\text { tätsstö- } \\
\text { rung und } \\
\text { Schmer- } \\
\text { zen. }\end{array}\right.$ & $\begin{array}{c}\text { Ataxie, } \\
\text { motorische } \\
\text { Schwäche. }\end{array}$ & $\begin{array}{l}\text { Patellar- } \\
\text { reflex An- } \\
\text { fangs er- } \\
\text { halten, erst } \\
\text { 1 Tag vor } \\
\text { d. Tode er- } \\
\text { loschen. }\end{array}$ & \begin{tabular}{|c|c|} 
Sensi- \\
bili- \\
tätsstö- \\
t rung. \\
r
\end{tabular} & - & - \\
\hline 8 & $\begin{array}{c}\text { Babinski } \\
\text { et Char- } \\
\text { rin, Re- } \\
\text { vue de } \\
\text { Médec. } \\
1886 .\end{array}$ & M. & • 43 & - & $\begin{array}{l}\text { Anf. } \\
1883 .\end{array}$ & $\begin{array}{l}17 . \\
\text { Aug. } \\
1884 .\end{array}$ & $\begin{array}{c}\text { Analgesie } \\
\text { u. Verspä- } \\
\text { tung der } \\
\text { Sensibili- } \\
\text { tät in den } \\
\text { letzten } \\
\text { Stadien. }\end{array}$ & \begin{tabular}{|} 
Motor. \\
Schwäche \\
u. starke \\
A taxie, \\
epileptoi- \\
des Zittern \\
der Beine.
\end{tabular} & $\begin{array}{c}\text { Patellar- } \\
\text { reflex er- } \\
\text { höht. }\end{array}$ & - & - & - \\
\hline 9 & $\begin{array}{c}J . M . \\
\text { Clarke, } \\
\text { Brain } \\
1890 .\end{array}$ & F. & 49 & - & $\begin{array}{c}\text { Beginn } \\
1886 .\end{array}$ & $\begin{array}{r}\text { 13. Mai } \\
1889 .\end{array}$ & $\begin{array}{c}\text { Leichte } \\
\text { Sensibili- } \\
\text { täts- } \\
\text { störungen. }\end{array}$ & $\begin{array}{l}\text { Motorische } \\
\text { Schwäche. } \\
\text { Ataktisch- } \\
\text { paretischer } \\
\text { Gang. } \\
\text { Romberg- } \\
\text { sches } \\
\text { Symptom. }\end{array}$ & $\begin{array}{c}\text { Patellar- } \\
\text { reflex } \\
\text { erhöht. }\end{array}$ & $\begin{array}{l}\text { Leich- } \\
\text { te Sen- } \\
\text { sibili- } \\
\text { täts- } \\
\text { störun- } \\
\text { gen. }\end{array}$ & $\begin{array}{c}\text { Seit } \\
9 \text { Monaten } \\
\text { Ieichte } \\
\text { Schwäche } \\
\text { ohne Ata- } \\
\text { xie, mit } \\
\text { Tremor. }\end{array}$ & - \\
\hline
\end{tabular}




\begin{tabular}{|c|c|c|c|c|c|c|c|}
\hline \multirow{2}{*}{ Rumpf } & \multirow{2}{*}{ Gehirn } & \multirow{2}{*}{$\begin{array}{l}\text { Blase und } \\
\text { Mastdarm }\end{array}$} & \multirow{2}{*}{$\begin{array}{l}\text { Trophische } \\
\text { und vaso- } \\
\text { motorisehe } \\
\text { Störungen }\end{array}$} & \multirow{2}{*}{$\begin{array}{l}\text { Blut- } \\
\text { befund }\end{array}$} & \multirow{2}{*}{$\begin{array}{l}\text { Todes- } \\
\text { ursache }\end{array}$} & \multicolumn{2}{|c|}{ Rü oken marksbefund. } \\
\hline & & & & & & Weisse Substanz & Graue Substanz \\
\hline$\zeta$ & $\begin{array}{c}\text { Demenz. } \\
\text { Pupillen- } \\
\text { reaction } \\
\text { normal. }\end{array}$ & Cystitis. & - & - & $\begin{array}{l}\text { Pneu- } \\
\text { monie. }\end{array}$ & $\begin{array}{l}\text { H. Str., Kl. S., } \\
\text { Py. S. u. V. }\end{array}$ & $\begin{array}{c}\text { Schwund der } \\
\text { medialenZellgruppe } \\
\text { d. Vorderhörner. } \\
\text { Erkrankung d. ges. } \\
\text { Vorderhörner im } \\
\text { mittler. Brustmark. } \\
\text { Schwund der Gang- } \\
\text { lienzellen d. Clarke- } \\
\text { schen Säulen im } \\
\text { Brustmark. }\end{array}$ \\
\hline $\begin{array}{l}\text { yphose } \\
\text { Wirbel- } \\
\text { säule. } \\
\text { Iruek- } \\
\text { pfind- } \\
\text { keit d. } \\
\text { is spin. } \\
\text { :3.-7. } \\
\text { 3: rust- } \\
\text { jubels. }\end{array}$ & $\begin{array}{l}\text { Normale } \\
\text { Pupillen. }\end{array}$ & Cystitis. & - & - & Marasmus. & $\begin{array}{l}\text { H. Str., Kl. S., } \\
\text { Py. S. }\end{array}$ & $\begin{array}{l}\text { Zahlreiche Blutun- } \\
\text { gen in der grauen } \\
\text { Substanz des Brust- } \\
\text { marks. Affection der } \\
\text { Clarke'schenSäulen. }\end{array}$ \\
\hline$i$ & $\begin{array}{c}\text { Schwin- } \\
\text { delanfälle. } \\
\text { Pupillar- } \\
\text { reaction } \\
\text { erhalten. } \\
\text { R. etwas } \\
\text { träge. }\end{array}$ & $\begin{array}{l}\text { Incon- } \\
\text { tinentia } \\
\text { urinae. }\end{array}$ & $\begin{array}{c}\text { Oedeme der } \\
\text { Beine. } \\
\text { Cyanose der } \\
\text { Finger. } \\
\text { Decubitus } \\
\text { der Hacken. }\end{array}$ & - & - & $\begin{array}{l}\text { H. Str. } \\
\text { Py. S. u. V. Kl. S. } \\
\text { Vorderseiten- } \\
\text { strangreste. } \\
\text { ceichte Degene- } \\
\text { ration der hinte- } \\
\text { ren Wurzeln. }\end{array}$ & $\begin{array}{l}\text { Schwund d. Nerven- } \\
\text { netzes u. leichte } \\
\text { Atrophie der Gang- } \\
\text { lienzellen d. Clarke- } \\
\text { schen Säulen. }\end{array}$ \\
\hline - & $\begin{array}{c}\text { Pupillar- } \\
\text { reaction } \\
\text { normal. } \\
\text { Zuletzt } \\
\text { Som- } \\
\text { nolenz. }\end{array}$ & - & $\begin{array}{l}\text { Decubitus } \\
\text { am } \underset{\text { bein. }}{\text { Kreuz- }}\end{array}$ & - & $\begin{array}{c}\text { Aeusserste } \\
\text { Macies. }\end{array}$ & $\begin{array}{l}\text { H. Str., Py. S. u. } \\
\text { V., Kl. S.; nioht } \\
\text { typisch. Hintere } \\
\text { Wurzeln im Len- } \\
\text { denmark degene- } \\
\text { rirt; vorderekaum } \\
\text { im unteren Dor- } \\
\text { saltheil. }\end{array}$ & $\begin{array}{l}\text { Markfaserung der } \\
\text { Clarke'schen Säulen } \\
\text { fehlt. Leichte } \\
\text { Atrophie der Gang- } \\
\text { lienzellen. Linkes } \\
\text { Vorderhorn in der } \\
\text { Halsanschwellung } \\
\text { abnorm configurirt. }\end{array}$ \\
\hline $\begin{array}{l}\text { ises } \\
\text { triques. }\end{array}$ & - & $\begin{array}{c}\text { Blasen- u. } \\
\text { Mastdarm- } \\
\text { störung. }\end{array}$ & - & - & - & $\begin{array}{c}\text { H. Str., KI. S., } \\
\text { Py. S. nur bis in } \\
\text { die untere Dorsal- } \\
\text { gegend. }\end{array}$ & - \\
\hline - & \begin{tabular}{|} 
Leichte \\
Sprachstö- \\
rung, \\
Tremor des \\
Kopfes, \\
Pupillarreac \\
mal. Abn \\
Sehfähigk \\
weisser atr \\
Pupille. \\
Nystag
\end{tabular} & \begin{tabular}{|l|}
$\mid$ \\
cetion nor- \\
aahme der \\
keit mit \\
rophisoher \\
Leichter \\
gmus.
\end{tabular} & $\begin{array}{c}\text { Oedem } \\
\text { der Beine. }\end{array}$ & - & $\begin{array}{c}\text { Herz- } \\
\text { fehler. } \\
\text { Nephritis } \\
\text { chron. }\end{array}$ & $\begin{array}{c}\text { H. Str., Py. S., } \\
\text { Kl. S. }\end{array}$ & $\begin{array}{c}\text { Clarke'sche Säulen } \\
\text { leicht afficirt, sonst } \\
\text { graue Substanz } \\
\text { normal. }\end{array}$ \\
\hline
\end{tabular}




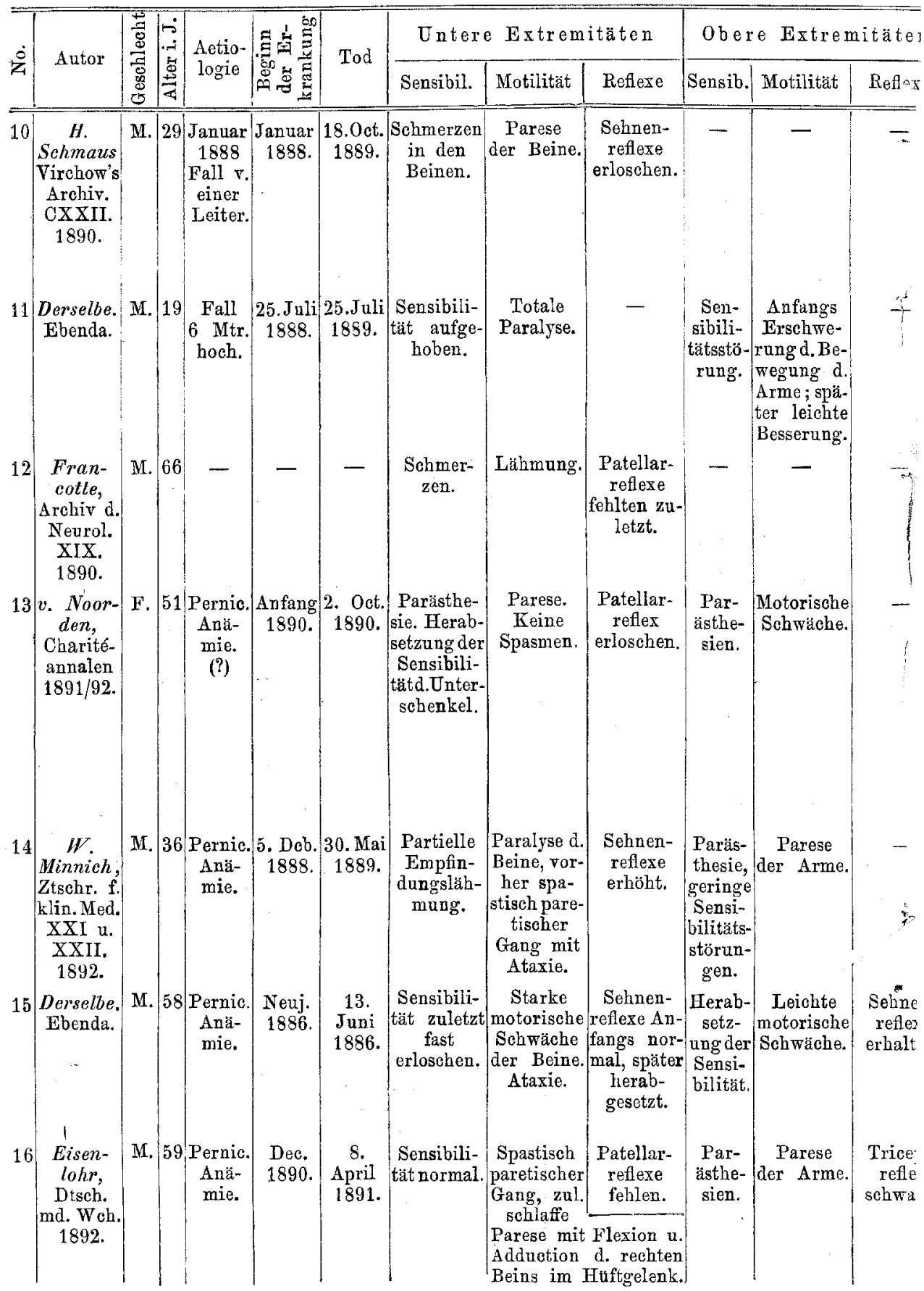


Die primären combinirten Strangerkrankungen des Rückenmariks.

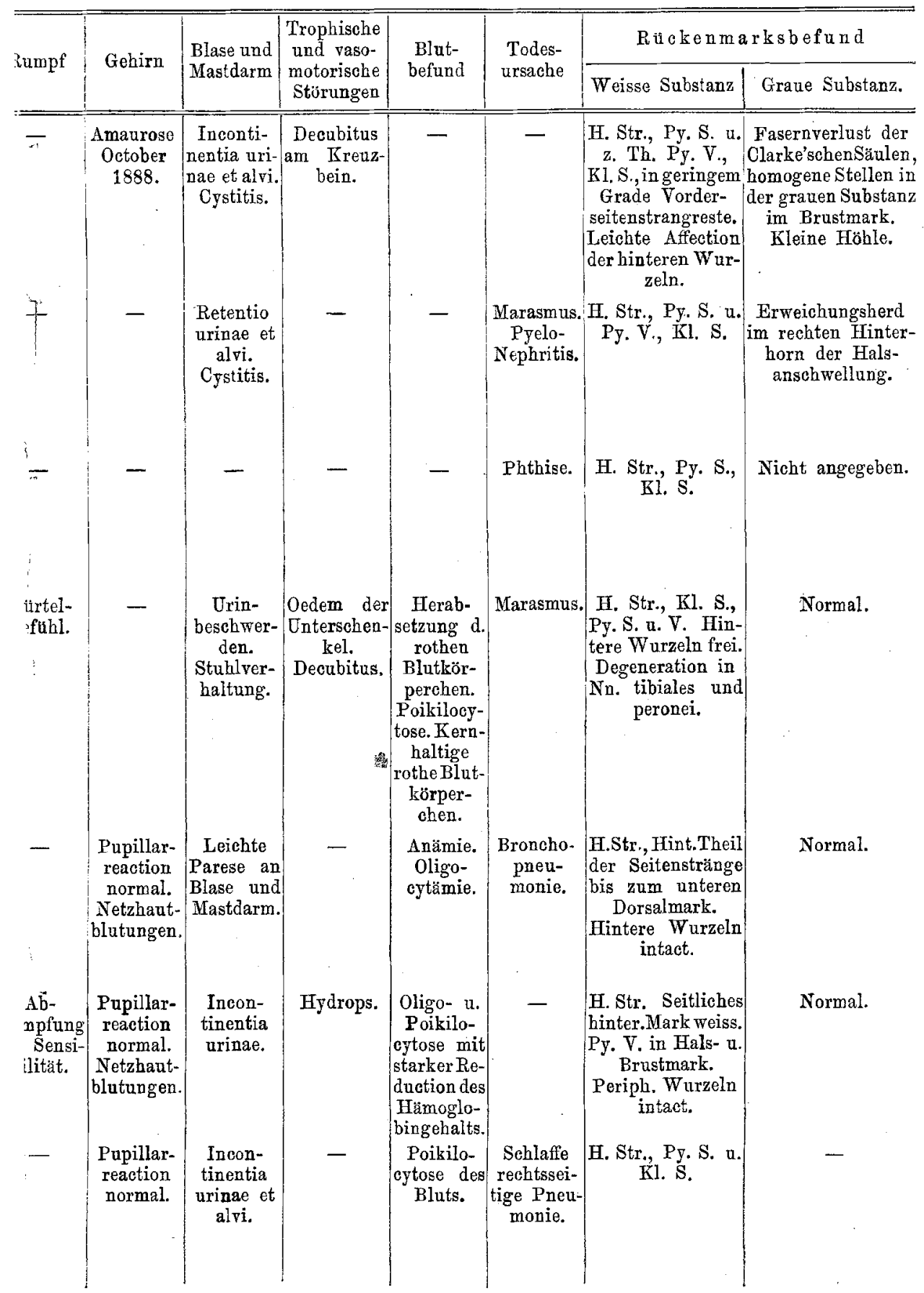




\begin{tabular}{|c|c|c|c|c|c|c|c|c|c|c|c|c|}
\hline \multirow{2}{*}{$0^{\circ}$} & \multirow{2}{*}{ Autor } & \multirow{2}{*}{ 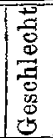 } & \multirow{2}{*}{ 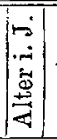 } & \multirow{2}{*}{$\begin{array}{c}\text { Aetio- } \\
\text { logie }\end{array}$} & \multirow{2}{*}{ 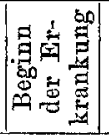 } & \multirow{2}{*}{ Tod } & \multicolumn{3}{|c|}{ Untere Extremitäten } & \multicolumn{3}{|c|}{ Obere Extremitates } \\
\hline & & & & & & & Sensibil. & Motilitat & Reflexe & Sensib. & Motilitat & Reflex \\
\hline 17 & $\begin{array}{c}\text { Leyden, } \\
\text { Ztschr. f. } \\
\text { klin.Med. } \\
\text { XXI. } \\
1892 .\end{array}$ & M. & $?$ & $\begin{array}{c}\text { Eisen- } \\
\text { bahn }- \\
\text { unfall. }\end{array}$ & - & - & Spastise & he Spinalpa & aralyse. & - & - & $i$ \\
\hline 18 & $\begin{array}{c}J . \\
\text { Arnold, } \\
\text { Virchow's } \\
\text { Archiy. } \\
\text { CXXVII. } \\
1892 .\end{array}$ & MI. & 56 & - & $\begin{array}{c}\text { Winter } \\
1889 \mathrm{z} . \\
1890 .\end{array}$ & $\begin{array}{c}\text { 27.Jan. } \\
1891 . \\
\end{array}$ & $\begin{array}{c}\text { Zuerst } \\
\text { Reissen, } \\
\text { dann Her- } \\
\text { absetzung } \\
\text { der Sensi- } \\
\text { bilitiat und } \\
\text { Schmerz- } \\
\text { empfin- } \\
\text { dung. Mus- } \\
\text { kelsinn er- } \\
\text { loschen. }\end{array}$ & $\begin{array}{l}\text { Spastische } \\
\text { Parese. } \\
\end{array}$ & $\begin{array}{c}\text { Sehnen- } \\
\text { reflexe } \\
\text { stark er- } \\
\text { höbt. } \\
\text { Fuss- } \\
\text { clonus. }\end{array}$ & $\begin{array}{c}\text { Par- } \\
\text { ästhe- } \\
\text { sie. }\end{array}$ & $\begin{array}{c}\text { Früh Pa- } \\
\text { rese, dann } \\
\text { Besserung. } \\
\text { Schwäche. } \\
\text { Ataxie. }\end{array}$ & $\begin{array}{l}\text { Sehnr } \\
\text { refie } \\
\text { leicht } \\
\text { höht }\end{array}$ \\
\hline 19 & $\begin{array}{c}\text { Nonne, } \\
\text { Arch. } \\
\text { f. Psych. } \\
\text { XXV. } \\
1893 .\end{array}$ & M. & 48 & 一 & $\begin{array}{l}\text { Decbr. } \\
1890 .\end{array}$ & $\begin{array}{c}18 . \\
\text { März } \\
1892 .\end{array}$ & $\begin{array}{l}\text { Schmer- } \\
\text { zen. }\end{array}$ & $\begin{array}{c}\text { Motorische } \\
\text { Schwäche. } \\
\text { Ataxie. } \\
\text { Klonische } \\
\text { Zuckun- } \\
\text { gen. }\end{array}$ & $\begin{array}{c}\text { Patellar- } \\
\text { reflex ver- } \\
\text { schwindet } \\
\text { Iangsam, } \\
\text { erscheint } \\
\text { kurz vor } \\
\text { dem Tode } \\
\text { wieder. }\end{array}$ & . & - & $\rightarrow$ \\
\hline 20 & $\begin{array}{c}\text { Derselbe, } \\
\text { Ebenda. }\end{array}$ & M. & 57 & - & $\begin{array}{l}\text { Somm. } \\
1891 .\end{array}$ & $\begin{array}{c}22 . \\
\text { Juni } \\
1892 .\end{array}$ & \begin{tabular}{|} 
Parästhe- \\
sie und \\
Schmer- \\
zen, später \\
Sensibili- \\
tät und \\
Sehmerz- \\
gefühl her- \\
abgesetzt.
\end{tabular} & \begin{tabular}{|} 
Ataxie, die \\
sich in den \\
letzten Sta- \\
dien \\
bessert. \\
\end{tabular} & $\begin{array}{c}\text { Patellar- } \\
\text { reflex } \\
\text { zuerst ab- } \\
\text { norm } \\
\text { schwach, } \\
\text { später nor- } \\
\text { mal. }\end{array}$ & $\begin{array}{c}\text { Par- } \\
\text { ästhe- } \\
\text { sie, } \\
\text { dann } \\
\text { Herab- } \\
\text { setzung } \\
\text { der } \\
\text { Sensi- } \\
\text { bilität. }\end{array}$ & 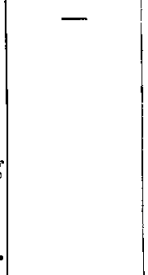 & - \\
\hline 21 & $\begin{array}{c}H . M . \\
\text { Bowman, } \\
\text { Brain } \\
1894 \\
\text { p. } 198 .\end{array}$ & F. & 53 & - & $\begin{array}{c}\text { Herbst } \\
1891 .\end{array}$ & $\begin{array}{c}16 . \\
\text { Septbr. } \\
1893 .\end{array}$ & $\begin{array}{c}\text { Parästhe- } \\
\text { sien, Her- } \\
\text { absetzung } \\
\text { der Sensi- } \\
\text { bilität und } \\
\text { Schmerz- } \\
\text { empfin- } \\
\text { dung. }\end{array}$ & $\begin{array}{l}\text { Motorische } \\
\text { Schwäche. } \\
\text { Später Pa- } \\
\text { reso mit } \\
\text { Spasmen. }\end{array}$ & $\begin{array}{c}\text { Patellar- } \\
\text { reflex leb- } \\
\text { haft; } \\
\text { leichter } \\
\text { Fuss- } \\
\text { clonus. }\end{array}$ & $\begin{array}{c}\text { Hyper- } \\
\text { asthe- } \\
\text { sie an } \\
\text { den } \\
\text { Fin- } \\
\text { ger- } \\
\text { spitzen. }\end{array}$ & $\begin{array}{l}\text { Motorische } \\
\text { Schwäche. }\end{array}$ & $\vdots$ \\
\hline 22 & $\begin{array}{c}\text { Karl } \\
\text { Mayer, } \\
\text { Beiträge } \\
\text { z. klin. } \\
\text { Med. u. } \\
\text { Chi.r. } \\
\text { Heft } 4 . \\
1894 .\end{array}$ & M. & 45 & $\begin{array}{c}1880 \\
\text { ulcus } \\
\text { durum. }\end{array}$ & 1888. & $\begin{array}{c}25 . \\
\text { Juni } \\
1891 .\end{array}$ & $\begin{array}{c}\text { Sohmer- } \\
\text { zen, dann } \\
\text { Sensibili- } \\
\text { täts- } \\
\text { störungen. }\end{array}$ & $\begin{array}{c}\text { Spastische } \\
\text { Parese. } \\
\end{array}$ & $\begin{array}{l}\text { Patellar- } \\
\text { reflex An- } \\
\text { fangs ge- } \\
\text { steigert, } \\
\text { zuletzt fast } \\
\text { erloschen. }\end{array}$ & - & $\begin{array}{c}\text { Parese mit } \\
\text { Contrac- } \\
\text { turen. }\end{array}$ & $\begin{array}{l}\text { Trice] } \\
\text { reflex } \\
\text { fangs } \\
\text { steige } \\
\text { später } \\
\text { ge- } \\
\text { schwär }\end{array}$ \\
\hline
\end{tabular}




\begin{tabular}{|c|c|c|c|c|c|c|c|}
\hline \multirow{2}{*}{ Rumpf } & \multirow{2}{*}{ Gehirn } & \multirow{2}{*}{$\begin{array}{l}\text { Blase und } \\
\text { Mastdarm }\end{array}$} & \multirow{2}{*}{$\begin{array}{l}\text { Trophische } \\
\text { und vaso- } \\
\text { motorische } \\
\text { Störungen }\end{array}$} & \multirow{2}{*}{$\begin{array}{l}\text { Blut- } \\
\text { befund }\end{array}$} & \multirow{2}{*}{$\begin{array}{l}\text { Todes- } \\
\text { ursache }\end{array}$} & \multicolumn{2}{|c|}{ Rückenmarksbefund. } \\
\hline & & & & & & Weisse Substanz & Graue Substanz \\
\hline$=1$ & - & 一 & - & $\begin{array}{c}\text { Perniciöse } \\
\text { Anämie. }\end{array}$ & Marasmus. & $\begin{array}{l}\text { Py. S. u. V., } \\
\text { H. Str., Kl. }\end{array}$ & - \\
\hline $\begin{array}{l}\text { astische } \\
\text { rese der } \\
\text { askeln, } \\
\text { Jenden- } \\
\text { irbel- } \\
\text { le u. d. } \\
\text { auchs, } \\
\text { nsibili- } \\
\text { d. unte- } \\
\text { Rumpf- } \\
\text { egend } \\
\text { ibge- } \\
\text { etzt. }\end{array}$ & $\begin{array}{c}\text { Pupillen } \\
\text { normal. }\end{array}$ & $\begin{array}{c}\text { Sphink- } \\
\text { teren nor- } \\
\text { mal. }\end{array}$ & $\begin{array}{c}\text { Oedem } \\
\text { der Beine. } \\
\text { Decubitus. }\end{array}$ & - & $\begin{array}{c}\text { Herz- } \\
\text { schwäche. }\end{array}$ & $\begin{array}{l}\text { H. Str., Py. S. u. } \\
\text { V., Kl. S. Vorder- } \\
\text { seitenstränge } \\
\text { schwach afficirt. }\end{array}$ & $\begin{array}{l}\text { Perivasculäre Blu- } \\
\text { tungen der grauen } \\
\text { Substanz des Hals- } \\
\text { marks. Veränderung } \\
\text { der Fasern der } \\
\text { Clarke'schenSäulen. }\end{array}$ \\
\hline 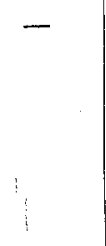 & $\begin{array}{l}\text { Träge } \\
\text { Pupillar- } \\
\text { reaction. }\end{array}$ & $\begin{array}{c}\text { Vortiber- } \\
\text { gehende } \\
\text { Blasenläh- } \\
\text { mung. }\end{array}$ & . & $\begin{array}{l}\text { Pernic. } \\
\text { Anämie. }\end{array}$ & - & $\begin{array}{c}\text { H. Str., Py. S., } \\
\text { Kl. S. }\end{array}$ & $\begin{array}{l}\text { Feine Faserung der } \\
\text { Clarke'schen Säulen } \\
\text { vermindert. }\end{array}$ \\
\hline $\begin{array}{l}\text { Xurtel- } \\
\text { peftul, } \\
\text { strische } \\
\text { rungen. }\end{array}$ & $\begin{array}{c}\text { Pupillen } \\
\text { normal. }\end{array}$ & - & - & $\begin{array}{l}\text { Pernic. } \\
\text { Anämie. }\end{array}$ & Marasmus. & $\begin{array}{l}\text { H. Str., Py. S., } \\
\text { Kl. S. Hintere } \\
\text { Wurzeln frei. }\end{array}$ & Normal. \\
\hline- & $\begin{array}{c}\text { Pupillen } \\
\text { normal. }\end{array}$ & $\begin{array}{l}\text { Blasen- } \\
\text { lähmung. }\end{array}$ & $\begin{array}{l}\text { Oedem der } \\
\text { Fússe. }\end{array}$ & $\begin{array}{l}\text { Pernic. } \\
\text { Anämie. }\end{array}$ & Marasmus. & $\begin{array}{l}\text { H. Str, Py. S. u. } \\
\text { V., Kl.S. Hintere } \\
\text { Wurzeln frei. }\end{array}$ & Normal, \\
\hline $\begin{array}{l}\text { Beginn } \\
\text { issende } \\
\text { rürtel- } \\
\text { efühle. }\end{array}$ & $\begin{array}{l}\text { Pupillen } \\
\text { starre. } \\
\text { Dys- } \\
\text { arthrische } \\
\text { Sprach- } \\
\text { störung. }\end{array}$ & $\begin{array}{l}\text { Blasen- } \\
\text { lähmung. }\end{array}$ & - & - & - & $\begin{array}{l}\text { H. Str., Py. S., } \\
\text { Kl. S. Seiten- } \\
\text { strangreste. } \\
\text { Degeneration der } \\
\text { hinteren Wurzeln. }\end{array}$ & $\begin{array}{l}\text { Schwund der Zellen } \\
\text { der Olarke'schen } \\
\text { Säulen, der Rücken- } \\
\text { marksvorderhörner } \\
\text { des XII., VII., VI. } \\
\text { Hirnnervenkerns. }\end{array}$ \\
\hline
\end{tabular}




\begin{tabular}{|c|c|c|c|c|c|c|c|c|c|c|c|c|}
\hline \multirow{2}{*}{$\dot{0}$} & \multirow{2}{*}{ Autor } & \multirow{2}{*}{ 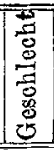 } & \multirow{2}{*}{ 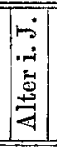 } & \multirow{2}{*}{$\begin{array}{l}\text { Aetio- } \\
\text { logie }\end{array}$} & \multirow{2}{*}{ 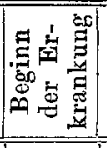 } & \multirow{2}{*}{ Tod } & \multicolumn{3}{|c|}{ Untere Extremitäten } & \multicolumn{3}{|c|}{ Obere Extremitatej } \\
\hline & & & & & & & Sensibil. & Motilität & Refiexe & Sensib. & Motilität & Reflex \\
\hline 23 & $\begin{array}{c}\text { Derselbe } \\
\text { Ebenda. }\end{array}$ & F. & 46 & 一 & $\begin{array}{c}\text { Anfang } \\
1890 .\end{array}$ & $\begin{array}{c}31 . \\
\text { Decbr. } \\
1892 .\end{array}$ & $\mid \begin{array}{c}\text { Lancini- } \\
\text { rende } \\
\text { Schmer- } \\
\text { zen, sonst } \\
\text { Dormal. }\end{array}$ & $\begin{array}{c}\text { Spastische } \\
\text { Paralyse. }\end{array}$ & $\begin{array}{c}\text { Reflexe } \\
\text { gesteigert. }\end{array}$ & - & $\begin{array}{l}\text { Spastische } \\
\text { Parese. }\end{array}$ & $\begin{array}{l}\text { Refles } \\
\text { erhǘr }\end{array}$ \\
\hline 24 & $\begin{array}{c}\text { Hoch- } \\
\text { haus, } \\
\text { Dtsch. } \\
\text { Ztschr. f. } \\
\text { Nerven- } \\
\text { beilk. IV. } \\
1893 .\end{array}$ & $\mathrm{F}$. & 47 & $\begin{array}{c}\text { Blut- } \\
\text { ar- } \\
\text { muth. } \\
(?)\end{array}$ & $\begin{array}{l}\text { Ende } \\
1889 .\end{array}$ & $\begin{array}{l}20 . \\
\text { April } \\
1892 .\end{array}$ & $\begin{array}{c}\text { Zuerst Un- } \\
\text { empfind- } \\
\text { lichkeit, } \\
\text { dann Her- } \\
\text { absetzung } \\
\text { der Sensi- } \\
\text { bilität. }\end{array}$ & $\begin{array}{c}\text { Parese mit } \\
\text { Contrac- } \\
\text { turen. }\end{array}$ & $\begin{array}{l}\text { Erhöhung } \\
\text { des Patel- } \\
\text { larreflexes. }\end{array}$ & $\begin{array}{c}\text { Krie- } \\
\text { beln in } \\
\text { den } \\
\text { Fin- } \\
\text { gern. }\end{array}$ & $\begin{array}{l}\text { Motorische } \\
\text { Schwäche. }\end{array}$ & - \\
\hline 25 & $\begin{array}{l}\text { C. Jakob, } \\
\text { Ebenda, } \\
\text { VI. } 1894 .\end{array}$ & - & - & 一 & - & - & - & - & - & - & - & - \\
\hline 26 & $\begin{array}{c}\text { M. Roth } \\
\text { mann. }\end{array}$ & M. & 36 & \begin{tabular}{|c} 
Pernic. \\
Anä- \\
mie. \\
$(?)$
\end{tabular} & $\begin{array}{c}\text { Anf. } \\
\text { Sept. } \\
1890 .\end{array}$ & $\begin{array}{c}27 . \\
\text { Defbr. } \\
1890 .\end{array}$ & $\begin{array}{c}\text { Anf. Par- } \\
\text { ästhesie, } \\
\text { dann lang- } \\
\text { samaufstei- } \\
\text { gendeHer- } \\
\text { absetzung } \\
\text { an beiden } \\
\text { Beinen. }\end{array}$ & $\begin{array}{c}\text { Spastische } \\
\text { Parese mit } \\
\text { deutlicher } \\
\text { Ataxie und } \\
\text { Contrac- } \\
\text { turen. } \\
\end{array}$ & $\begin{array}{c}\text { Patellar- } \\
\text { refexeAnf. } \\
\text { erhöht, } \\
\text { dann lang- } \\
\text { sam schwä- } \\
\text { cher wer- } \\
\text { dend.Fuss } \\
\text { clonus. } \\
\text { Lbh. Plan- } \\
\text { tarreflex. }\end{array}$ & - & $\begin{array}{l}\text { Herab- } \\
\text { setzung d. } \\
\text { motorisch. } \\
\text { Kraft, i. d. } \\
\text { letzten Zeit } \\
\text { mit Spas- } \\
\text { men im } \\
\text { recht. Arm. }\end{array}$ & $\begin{array}{l}\text { Trice } \\
\text { reflex } \\
\text { fangs } \\
\text { halten } \\
\text { ter nis } \\
\text { gepri: }\end{array}$ \\
\hline 27 & Derselbe. & M. & 38 & 8 Lues. & $\begin{array}{c}\text { Herbst } \\
1892 .\end{array}$ & $\begin{array}{l}30 . \\
\text { März } \\
1893 .\end{array}$ & $\begin{array}{c}\text { ZuerstPar- } \\
\text { ästhesien, } \\
\text { dann Ab- } \\
\text { nabme der } \\
\text { Sensibili- } \\
\text { tät und } \\
\text { Schmerz- } \\
\text { empfind. b. } \\
\text { z. völligen } \\
\text { Verlust } \\
\text { derselben. }\end{array}$ & $\begin{array}{c}\text { Schlaffe } \\
\text { Parese bei- } \\
\text { der Beine } \\
\text { mit zeit- } \\
\text { weise auf- } \\
\text { tretenden } \\
\text { unwillktur- } \\
\text { lichen } \\
\text { Zuckun- } \\
\text { gen. }\end{array}$ & $\begin{array}{l}\text { Patellar- } \\
\text { reflex Anf. } \\
\text { schwach, } \\
\text { dann ganz } \\
\text { erloschen. } \\
\text { Plantar- } \\
\text { reflex zu- } \\
\text { erst erhal- } \\
\text { ten, später } \\
\text { nichtzu er- } \\
\text { zielen. }\end{array}$ & $\begin{array}{c}\text { Pär- } \\
\text { austhe- } \\
\text { sien. } \\
\\
\\
\end{array}$ & $\begin{array}{c}\text { Langsame } \\
\text { Abnahme } \\
\text { der motor. } \\
\text { Kraft, i. d. } \\
\text { letzten Zeit } \\
\text { deutliche } \\
\text { Praese mit } \\
\text { Ataxie. }\end{array}$ & - \\
\hline 28 & Derselbe. & M. & 29 & $\begin{array}{c}\text { Rheu- } \\
\text { matis- } \\
\text { mus. } \\
\text { Durch- } \\
\text { näs- } \\
\text { sung. }\end{array}$ & $\begin{array}{c}\text { Mitte } \\
\text { Decbr. } \\
1892 .\end{array}$ & $\begin{array}{c}10 . \\
\text { Juni } \\
1893 .\end{array}$ & $\begin{array}{l}\text { Parästhe- } \\
\text { sie, dann } \\
\text { leiehte Hy- } \\
\text { perästhe- } \\
\text { sie, zuletzt } \\
\text { totale Auf- } \\
\text { hebung der } \\
\text { Sensibili- } \\
\text { tät und } \\
\text { schmerz- } \\
\text { empindg. }\end{array}$ & $\begin{array}{c}\text { Schlaffe } \\
\text { Parese bei- } \\
\text { der Beine } \\
\text { mit Spitz- } \\
\text { fuss- } \\
\text { stellung. }\end{array}$ & $\begin{array}{l}\text { Patellar- } \\
\text { reflex An- } \\
\text { fangs er- } \\
\text { halten, er- } \\
\text { liseht spä- } \\
\text { ter. Plan- } \\
\text { tarreflex } \\
\text { desgl. }\end{array}$ & $\begin{array}{l}\text { In der } \\
\text { letaten } \\
\text { Zeit } \\
\text { leichte } \\
\text { Hyper- } \\
\text { ästhe- } \\
\text { sien. }\end{array}$ & $\begin{array}{c}\text { Abnahme } \\
\text { der moto- } \\
\text { rischen } \\
\text { Kraft. } \\
\end{array}$ & $\begin{array}{c}\text { Trice] } \\
\text { reflex } \\
\text { fangs } \\
\text { lebha } \\
\text { später } \\
\text { seh } \\
\text { schwa }\end{array}$ \\
\hline
\end{tabular}




\begin{tabular}{|c|c|c|c|c|c|c|c|}
\hline \multirow{2}{*}{ iumpf } & \multirow{2}{*}{ Gehirn } & \multirow{2}{*}{$\begin{array}{l}\text { Blase und } \\
\text { Mastdarm }\end{array}$} & \multirow{2}{*}{\begin{tabular}{|} 
Trophisehe \\
und vaso- \\
motorische \\
Störungen
\end{tabular}} & \multirow{2}{*}{$\begin{array}{l}\text { Blut- } \\
\text { befund }\end{array}$} & \multirow{2}{*}{$\begin{array}{l}\text { Todes- } \\
\text { ursache }\end{array}$} & \multicolumn{2}{|c|}{ Rückenmarks befund } \\
\hline & & & & & & Weisse Substanz & Graue Substanz \\
\hline $\begin{array}{l}\text { ifgkeit } \\
\text { im } \\
\text { cken. }\end{array}$ & $\begin{array}{l}\text { Opticus. } \\
\text { Atrophie. } \\
\text { Spraoh- } \\
\text { störung. } \\
\text { Schluckbe- } \\
\text { schwerden. }\end{array}$ & Blasen- & $\begin{array}{c}\text { Decubitus } \\
\text { am } \\
\text { Kreuzbein. }\end{array}$ & - & $\begin{array}{c}\text { Marasmus. } \\
\text { Cystitis } \\
\text { purulenta. }\end{array}$ & $\begin{array}{l}\text { H. Str,, Py. S. u. } \\
\text { V., Kl. S. Seiten- } \\
\text { strangreste. } \\
\text { Leichte Degene- } \\
\text { ration der hinte- } \\
\text { ren Wurzeln. }\end{array}$ & $\begin{array}{l}\text { Zellenschwund im } \\
\text { Hypoglossuskern u. } \\
\text { Clarke'schenSäulen. }\end{array}$ \\
\hline- & $\begin{array}{l}\text { Pupillar- } \\
\text { reflex } \\
\text { erhaiten. }\end{array}$ & $\begin{array}{l}\text { Blasen- ‥ } \\
\text { Mastdarm- } \\
\text { lähmung. }\end{array}$ & $\begin{array}{c}\text { Oedem der } \\
\text { Füsse und } \\
\text { Decubitus } \\
\text { am } \\
\text { Kreuzbein. }\end{array}$ & - & $\begin{array}{l}\text { Hohes } \\
\text { Fieber. } \\
\text { Kurzath- } \\
\text { migkeit. }\end{array}$ & $\begin{array}{l}\text { H. Str., Py. S., } \\
\text { Kl. S. }\end{array}$ & $\begin{array}{l}\text { Zellenschwund } \\
\text { in den Clarke'schen } \\
\text { Säulen. }\end{array}$ \\
\hline - & - & - & - & - & - & $\begin{array}{l}\text { Py. S. u. V., } \\
\text { Kl. S., H. Str. } \\
\text { Leichte Affection } \\
\text { der hinteren } \\
\text { Wurzeln. }\end{array}$ & $\begin{array}{l}\text { Fasernschwund } \\
\text { in den Clarke'schen } \\
\text { Sänlen, in Hinter- } \\
\text { und Vorderhörnern. } \\
\text { Ganglienzellen an- } \\
\text { scheinend normal. }\end{array}$ \\
\hline $\begin{array}{c}\text { nck- } \\
\text { pfind- } \\
\text { keitam } \\
\text { Brust- } \\
\text { irbel. } \\
\vdots\end{array}$ & $\begin{array}{l}\text { Pupillar- } \\
\text { reaction } \\
\text { erhalten, } \\
\text { sonst nor- } \\
\text { maler Be- } \\
\text { fund. }\end{array}$ & $\begin{array}{c}\text { Incon- } \\
\text { tinentia } \\
\text { urinae et } \\
\text { alvi. }\end{array}$ & $\begin{array}{c}\text { Oedem } \\
\text { des rechten } \\
\text { Beins. } \\
\text { Drüsenan- } \\
\text { schwellung. } \\
\text { Decubitus } \\
\text { am } \\
\text { Kreuzbein. }\end{array}$ & $\begin{array}{c}\text { Poikilo- } \\
\text { cytose. } \\
\text { Kernhal- } \\
\text { tige R. Bl. } \\
\text { K. Hämo- } \\
\text { globin } \\
50 \text { Proc. }\end{array}$ & Kachexie. & $\begin{array}{l}\text { Degeneration der } \\
\text { H. Str., Kl. S., } \\
\text { Py. S. u. V. Hin- } \\
\text { tere WurzeIn fast, } \\
\text { vordere ganz frei }\end{array}$ & $\begin{array}{l}\text { Blutungen. Rare- } \\
\text { fication der Vorder- } \\
\text { hörner des oberen } \\
\text { Bi ustmarks. }\end{array}$ \\
\hline $\begin{array}{l}\text { pfind- } \\
\text { bheit } \\
\text { Brust- } \\
\text { irbel- } \\
\text { le. Her- } \\
\text { intzung } \\
\text { Sensi- } \\
\text { tät an } \\
\text { lch und } \\
\text { l.cken. } \\
\text { }\end{array}$ & $\begin{array}{c}\text { Pupillar- } \\
\text { reaction } \\
\text { erbalten. } \\
\end{array}$ & $\begin{array}{c}\text { Incon- } \\
\text { tinentia } \\
\text { urinae et } \\
\text { alvi. Bla- } \\
\text { sencatarrh. }\end{array}$ & $\begin{array}{c}\text { Oedem der } \\
\text { Beine u. des } \\
\text { Abdomen. } \\
\text { Decubitus } \\
\text { an Fersen u. } \\
\text { Kreuzbein. }\end{array}$ & Normal. & $\begin{array}{l}\text { Zwerch- } \\
\text { fells- } \\
\text { lähmung. }\end{array}$ & $\begin{array}{l}\text { Degeneration der } \\
\text { H. Str., KI. S., } \\
\text { Py. S. u. V. } \\
\text { Hintere Wurzeln } \\
\text { fast, vordere ganz } \\
\text { normal. }\end{array}$ & $\begin{array}{l}\text { Blutungen. Vacuo- } \\
\text { lisirung u. Atrophie } \\
\text { einiger Ganglien- } \\
\text { zellen der Vorder- } \\
\text { hörner. Exsudat im } \\
\text { Sulcus anterior des } \\
\text { Halsmarks. }\end{array}$ \\
\hline $\begin{array}{c}\text { itweise } \\
\text { ruck- } \\
\text { upfind- } \\
\text { keit der } \\
\text { ustwir- } \\
\text { :äule.In } \\
\text { unte- } \\
\text { Bauch- } \\
\text { agend } \\
\text { nsibili- } \\
\text { herab- } \\
\text { ssetzt. }\end{array}$ & $\begin{array}{l}\text { Pupillar- } \\
\text { reaction } \\
\text { erhalten. }\end{array}$ & $\begin{array}{l}\text { Incon- } \\
\text { tinentia } \\
\text { urinae et } \\
\text { alvi. }\end{array}$ & $\begin{array}{l}\text { Deeubitus } \\
\quad \text { am } \\
\text { Kreuzbein. }\end{array}$ & Normal. & $\begin{array}{c}\text { Zwerch- } \\
\text { fells- } \\
\text { lähmung. }\end{array}$ & $\begin{array}{l}\text { Degerreration der } \\
\text { H. Str., Kl. S., } \\
\text { Py. S. u. V. Un- } \\
\text { regelmässige Be- } \\
\text { theiligung d. Rests } \\
\text { der Vorder- und } \\
\text { Seitenstränge. } \\
\text { Leichte Degenera- } \\
\text { tion der vorderen } \\
\text { und binteren } \\
\text { Wurzeln. }\end{array}$ & $\begin{array}{l}\text { Blutungen. Vacuo- } \\
\text { lisirung u. Atrophie } \\
\text { v. Vorderhornzellen. } \\
\text { Rarefication der } \\
\text { Vorderhörner des } \\
\text { oberen Brustmarks. } \\
\text { Exsudat im Sulcus } \\
\text { anterior des Hals- } \\
\text { marks. }\end{array}$ \\
\hline
\end{tabular}


Es bleibt nun immer noch eine Reihe von Fällen übrig, die in keiner dieser Gruppen unterzubringen sind. Hierher gehören der zweite Fall Déjerine's (l. c.), der Fall von Kahler und Pick von $1880^{1}$ ), die Fälle von Ballet und Minor (l. c.), Dreschfeld ${ }^{2}$, Raymond und Tenneson ${ }^{3}$, endlich Fall III und VI von Minnich (l. c.). Es sind dies Fälle, in denen der Process in Hinter- und Seitensträngen einen derartig unregelmässigen Charakter hat, dass es nicht möglich ist, irgend ein bestimmtes Bild herauszuschälen. Zum Theil handelt es sich hier thatsächlich um Sklerosen mit anf- und absteigenden Degenerationen (Dreschfeld) oder Meningomyelitiden (Raymond und Tenneson). Fälle jedoch, wie der von Ballet und Minor beschriebene, lassen sich auch auf diese Weise nicht erklären; ja für dieselben genügt meiner Ansicht nach auch die Mariesche Anschauung von einer primären Erkrankung der Arteria spinalis posterior und ibrer Aeste nicht. Die Fälle von Minnich endlich, nach perniciöser Anämie, zeigen gleichfalls eine so unregelmässige, auf Strecken ganz fehlende Erkrankung der Seitenstränge, dass ich mich nicht entschliessen konnte, sie den beiden anderen zur combinirten Strangerkrankung gerechneten anzureihen. Es ist allerdings zu vermuthen, dass dieselben sich in ihrer weiteren Entwicklung zu Fällen von combinirter Strangerkrankung ausgebildet hätten. Nach den bisherigen Erfabrungen jedoch ist es nicht möglich, diese Frage zu entscheiden.

Zum Schluss fasse ich meine Ausführungen in folgende Sätze zusammen:

1. Die primäre combinirte Strangerkrankung des Rückenmarks ist als ein selbständiges Krankheitsbild aufrecht $\mathrm{zu}$ erhalten.

2. Klinisch ist dieselbe im Allgemeinen durch gleichzeitiges Auftreten von auf Erkrankung der Hinter- und Seitenstränge zu beziehenden Symptomen ausgezeichnet. Der Patellarreflex ist Anfangs erböht, bleibt entweder bis zum Tode erhalten oder verschwindet doch erst in den letzten Stadien. Die Pupillarreaction ist gleichfalls in beinahe sämmtlichen Fällen erhalten. Der Process ergreift fast stets zuerst die unteren Extremitäten und steigt später nach aufwärts.

3. Die Krankheit verläuft ziemlich schnell, erstreckt sich nicht über 3 Jahre hinaus.

4. Im Rückenmark findet sich stets eine Erkrankung der Hinterstränge mit fast gänzlicher Freilassung der hinteren Wurzeln und spätem Befallensein der hinteren Wurzelzone, der Py. S. und gewöhnlich auch Py. V. und der Kl. S. Daneben kann eine unregelmässige schwächere Degeneration der Vorder- und Seitenstrangreste bestehen.

1) Archiv für Psychiatrie. Bd. X. 1880.

2) Brain X. 1887 .

3) Arch. de Physiol. VIII. 1886. p. 84. 
5. In einer grossen Zahl von Fällen ist eine Erkrankung der grauen Substanz des Rückenmarks nachzuweisen.

6. Eine primäre Affection der grauen Substanz ist am besten im Stande, den ganzen Process der combinirten Strangerkrankung zu erklären. Aetiologisch kommt Rückenmarkserschuitterung und perniciöse Anämie besonders in Betracht, während Lues keine wesentliche Rolle spielt.

7. Scharf von der primären combinirten Strangerkrankung zu scheiden sind die Fälle von alter Tabes mit secundärer Seitenstrangserkrankung in den letzten Stadien und von spastischer Spinalparalyse mit Degeneration der Py. S. und secundärer Affection der Goll'schen Stränge und Kl. S.

Zum Schluss erlaube ich mir, Herrn Prof. A. Fränkel für die Ueberlassung des Materials und das freundliche Interesse an dieser Arbeit meinen wärmsten Dank auszusprechen.

\section{NACHTRAG.}

Durch den nach Abschluss dieser Arbeit erschienenen Aufsatz von Nonne, ,Weitere Beiträge zur Kenntniss der im Verlaufe letaler Anämien beobachteten Spinalkerkrankungen" 1 ) werde ich auf zwei im Jahre 1894 erschienene Arbeiten Pierre Marie's ${ }^{2}$ ) aufmerksam gemacht, in denen derselbe die bei Pellagra und bei Paralyse beobachteten Hinter- und Seitenstrangsdegenerationen auf eine primäre Erkrankung von Ganglienzellen der grauen Substanz des Rückenmarks zurückführt. Die im Gebiet der Pyramidenseitenstrangbahnen bestehende Degeneration ist nach ihm die Folge einer Erkrankung der „Cellules du cordon latéral", die in den Hintersträngen auftretende Degeneration der "Bandelettes en virgule" und der medianen Flechsig'schen Zone geht von den erkrankten Zellen der Hinterhörner aus. Ohne hier näher auf diese Arbeiten des berühmten französischen Forschers eingehen zu wollen, möchte ich nur auf die Uebereinstimmung mit den von mir für die primären combinirten Strangerkrankungen entwickelten Anschaungen hinweisen.

Was die Nonne'sche Arbeit selbst betrifft, so hält derselbe auf Grund der Untersuchung des Rückenmarks in 17 Fällen von letaler Anämie an der bereits früher entwickelten Anschaung fest, dass die Veränderungen in der weissen Substanz lediglich von der Vertheilung der erkrankten Gefässe abhängig sind, und dass von systematischen Strangdegenerationen hier gar keine Rede sein kann. Um die Nonneschen Ergebnisse richtig zu beurtheilen, darf man nicht vergessen, dass es sich hier um Anämien mit theils gänzlichem Mangel, theils schwacher Andeutung von auf eine spinale Erkrankung zu beziehenden Symptomen bandelt. Dem entsprechend ist die Degeneration im Rücken-

1) Deutsche Zeitschrift für Nervenheilkunde. VI. 1895. S. 313.

2) La semaine médicale. 1894. p.17. - Gazette des hôpitaux. 1894. p. 55. 
mark in vielen Fällen nur auf die Hinterstränge beschränkt und hier erst fleckenförmig entwickelt; jedoch ist in einigen Fällen auch die Erkrankung der Seitenstränge bereits aufgetreten. . Die Degenerationen machen vielfach schon einen entschieden strangförmigen Eindruck, wie wir es bei den klinisch und pathologisch-anatomisch entwickelteren Fällen combinirter Strangerkrankung zu sehen gewohnt sind. Das wir aber gerade bei der Annahme einer primären Erkrankung der grauen Substanz anfänglich nur fleckenförmige Degenerationen in der weissen Substanz erwarten können, habe ich bereits in der obigen Arbeit hervorgehoben (S. 248).

Wenn aber Nonne in Uebereinstimmung mit Minnich in den typischen Fällen die Gefässe durchweg abnorm findet, hyaline Degeneration der Capillarwände und vor Allem periarterielle Veränderungen, und von hier aus die Degeneration der weissen Substanz ihren Ursprung nehmen lässt, so ist dagegen auf die kürzlich ersehienene Arbeit von Charles W. Burr, "The spinal cord lesions and symptoms of pernicious anemia" 1 ) hinzuweisen. Derselbe konnte in 7 derartigen Fällen mit zum Theil sehr beträchtlichen Hinter- und Seitenstrangsdegenerationen niemals eine bemerkenswerthe Gefässerkrankung nachweisen. Dazu kommt, das es schwierig sein dürfte, die Aneinanderreihung der kleineren Degenerationsherde zu strangförmigen Erkrankungen durch die Annahme einer primären Gefässerkrankung in der weissen Substanz zu erklären.

\section{Erklärung der Abbildungen.}

\section{(Tafel I-IV.)}

Fig. 1. Erster Fall (Plotzki). 1. Oberes Halsmark, 2. Halsanschwellung, 3. Unteres Halsmark, 4. Mittleres Brustmark, 5. Lendenanschwellung, 6. Unteres Lendenmark. Die degenerirten Partien der weissen Substanz sind weiss eingezeichnet.

Fig. 2. Erster Fall (Plotz ki). Leptomeningitische Narbe über den Hinterstrăngen der Lendenanschwellung. Fi. p. = Fissura posterior.

Fig. 3. Erster Fall (Plotzki). Perivasculäre Blutungen im rechten Vorderhorn der Halsanschwellung. Hämatoxylin-Eosinfärbung.

Fig. 4. Zweiter Fall (Algner). 1. Oberes Halsmark, 2. Halsanschwellung, 3. Unteres Halsmark, 4. Oberes Brustmark, 5. Unteres Brustmark, 6. Oberes Lendenmark, $\bar{\tau}$. Unteres Lendenmark.

Fig. 5. Dritter Fall (R e i chert). 1. Unterer Theil der Pyramidenkreuzung, 2. Oberes Halsmark, 3. Halsanschwellung, 4. Unteres Halsmark, 5. Oberes Brustmark, 6. Unteres Brustmark, 7 . Oberes Lendenmark, 8. Unteres Lendenmark.

In diesen beiden Fällen sind die degenerirten Partien der weissen Substanz schwarz eingezeichnet.

Fig. 6. Vacuolisirte Ganglienzellen aus den Vorderhörnern des Lendenmarks, 1. und 2. aus dem zweiten Fall $(A \operatorname{lgner}), 3$. und 4. aus dem dritten Fall (Reichert).

Fig. 7. Uebersichtsbild aus dem oberen Halsmark vom dritten Fall (R eicher t), das die Vertheilung der Blutungen zeigt. Nach einem während der Kupferung mit Săurefuchsin behandelten Weigert-Präparat gezeichnet. Sämmtliche rothe Blutkörperchen rothviolett gefärbt. Bltg., Bltg. $1=$ Blutungen in der grauen Substanz.

Fig. 8. Ein Theil der Blutung Bltg. 1 des vorigen Bildes mit stärkerer Vergrösserung gezeichnet. Die hellen Stellen innerhalb der Blutungen sind Exsudatmassen, Reste älterer Blutungen, die im Weigert-Präparat gelb gefärbt sind.

1) University medical magazine. April 1895. 